\title{
Compilation of tRNA sequences and sequences of tRNA genes
}

\author{
Mathias Sprinzl ${ }^{*}$, Norbert Dank, Steffen Nock and Astrid Schön \\ Laboratorium für Biochemie, Universität Bayreuth, Postfach 1012 51, 8580 Bayreuth, FRG
}

\section{INTRODUCTION}

This compilation contains 1710 sequences of tRNAs and tRNA genes published so far, including 274 sequences that have been published since 1989 (printed in bold letters in table 1) and covering the literature up to December 1990 . Sequences of mutant tRNAs, tRNA genes and suppressors are included only if they are naturally occurring and expressed in vivo. Sequences originating from transformed or differentiated cells are considered as a separate entry only in the case of sequence differences.

A summary of all sequences contained in the compilation is given in Table 1. The sequences in this summary are listed by source, i.e. organism or organelle. Each sequence entry is specified by a four-digit code identifying the source, and the one letter code for the respective amino acid. In the cases where several isoacceptors have been sequenced, each sequence has an individual identification code. Also included in the table is the (abbreviated) name of the organism from which the sequence was derived. The complete identification code for a particular tRNA (or subset) is thus easily obtained by combining the amino acid code with the source identification number(s).

The references for the sequenced tRNAs or tRNA genes included in Table 1 are listed in Table 2 (separately for RNA and DNA) by their identification code. The references are restricted to the first complete publication of the sequence unless additional, crucial information (e.g. base modifications etc.) was obtained in later work.
Different from previous editions, this compilation does not contain a sequence printout. Instead, the sequences have been deposited with the EMBL Database. The present publication should be quoted as reference for data obtained from the electronically accessible compilation. Information on how to access the sequence files can be obtained by electronic mail: contact 'NETSERV at EMBL.BITNET', and inquire for 'HELP', 'HELP TRNA' and 'DIR'. The help file will contain all the information needed to obtain the requested sequence information. Researchers who do not have access to electronic mail and wish to obtain the sequence information on floppy disk or as hardcopy should contact the authors.

\section{ACKNOWLEDGEMENT}

This project was supported by Fonds der Chemischen Industrie and Deutsche Forschungsgemeinschaft (SFB 213).

\section{REFERENCE}

1. Transfer RNA: Structure, Properties and Recognition. P.R. Schimmel, D.Söll, J.N.Abelson (eds). Cold Spring Harbour Laboratory, N.Y., pp. 518-519 (1979).

* To whom correspondence should be addressed 
2128 Nucleic Acids Research, Vol. 19, Supplement

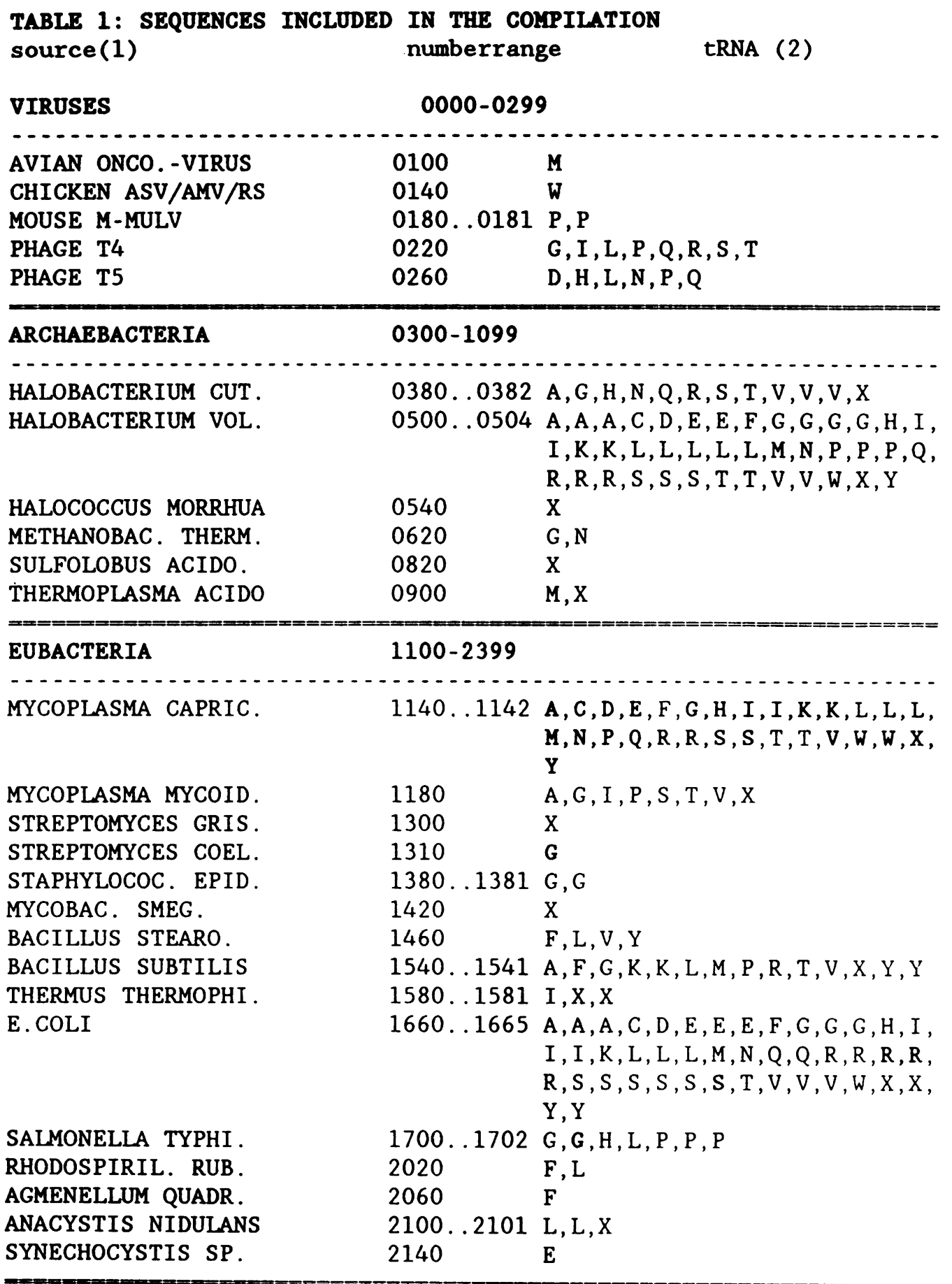

\section{ORGANELLES :}

CHLOROPLASTS

CHLAMYDOMONAS REIN

EUGLENA GRACILIS

CODIUM FRAGILE

SCENEDESMUS OBLIQ.

HORDEUM VULGARE

ZEA MAYS

GLYCINE MAX

PHASEOLUS VULGARIS

SPINACIA OLERACEA
$2400-3599$

$\begin{array}{ll}2440 & \text { E } \\ 2520 & \text { F } \\ 2530 & \text { G, K, M, R } \\ 2560 & \text { M, X, Y } \\ 2640 & \text { E, Q } \\ 2720 & \text { I } \\ 2840 \ldots 2842 & \text { L, L, L } \\ 3160 \ldots 3162 & \text { F, L, L, L, W , X } \\ 3280 \ldots 3281 & \text { F, I, I, L, M, P, T, V, W, X }\end{array}$




\begin{tabular}{|c|c|c|}
\hline \multicolumn{3}{|c|}{$3600-5999$} \\
\hline \multicolumn{3}{|c|}{ SINGLE CELL ORGANISMS AND FUNGI 3600-4199 } \\
\hline TETRAHYMENA PYRIF. & 3800 & $\mathbf{F}, \mathbf{Y}$ \\
\hline NEUROSPORA CRASSA & $3920 \ldots 3921$ & $\mathrm{~A}, \mathrm{~L}, \mathrm{~L}, \mathrm{~T}, \mathrm{~V}, \mathrm{~W}, \mathrm{X}, \mathrm{Y}$ \\
\hline SACCHAROMYCES CER. & $4000 \ldots 4002$ & $\begin{array}{l}F, G, I, K, L, M, M, P, R, R, S, S, S, T, \\
W, Y\end{array}$ \\
\hline YEAST & 4120 & $\mathrm{H}, \mathrm{X}$ \\
\hline
\end{tabular}

PLANTS 4200-4599

\begin{tabular}{|c|c|c|}
\hline $\begin{array}{l}\text { SOLANUM TUBEROSUM } \\
\text { PHASEOLUS VULGARIS }\end{array}$ & $\begin{array}{l}4310 \\
4400 \ldots 4403\end{array}$ & $\begin{array}{l}I, L \\
F, L, L, L, L, M, P, W, X, Y\end{array}$ \\
\hline \multicolumn{3}{|l|}{ ANIMALS 4600-5999 } \\
\hline $\begin{array}{l}\text { AEDES ALBOPICTUS } \\
\text { HAMSTER } \\
\text { RAT LIVER } \\
\text { BOVINE LIVER } \\
\text { HUMAN }\end{array}$ & $\begin{array}{l}4800 \\
5240 \\
5280 \ldots 5282 \\
5360 \ldots 5361 \\
5880\end{array}$ & $\begin{array}{l}D, E, G, I, K, Q, R, S, V, X \\
D, K, R, S \\
D, D, F, K, L, L, L, R, V, V, W \\
E, G, I, K, L, L, R, S, S, T, V, W, X \\
S\end{array}$ \\
\hline EUKARYOTIC CYTOPLASM & $6000-9999$ & \\
\hline SINGLE CELL ORGANISMS AND & FUNGI $6000-6$ & 6699 \\
\hline EUGLENA GRACILIS & 6040 & $\mathrm{D}, \mathrm{F}$ \\
\hline TETRAHYMENA THERM. & $6080 \ldots 6082$ & $Q, Q, Q, X$ \\
\hline SCENEDESMUS OBLIQ. & 6120 & $F, X, Y$ \\
\hline NEUROSPORA CRASSA & 6200 & $\mathrm{~F}, \mathrm{X}$ \\
\hline SACCHAROMYCES CER. & $6280 \ldots 6281$ & $G, G, H, H, I, K, L, L, M, P, P, S, W, X$ \\
\hline SCHIZOSACCHA. POM. & 6320 & $E, F, Y$ \\
\hline TORULOPSIS UTILIS & 6360 & $A, I, L, P, V, X, Y$ \\
\hline YEAST & $6400 \ldots 6402$ & $\begin{array}{l}A, C, D, E, F, F, K, N, R, R, R, S, S, T, \\
T, V, V, V, Y\end{array}$ \\
\hline
\end{tabular}

PLANTS 6700-7499

HORDEUM VULGARE

WHEAT GERM

BRASSICA NAPUS

LUPINUS LUTEUS

PHASEOLUS VULGARIS

PISUM SATIVUM

SPINACIA OLERACEA

NICOTIANA RUSTICA

SOLANUM TUBEROSUM

$6780 \ldots 6781 \mathrm{E}, \mathrm{E}, \mathrm{F}$

$6820 \ldots 6821$ F, G, K, M, R, W, X, Y, Y

$6860 \quad F$

$6940 E$ E, F, G, H , I , M , N , P , S , V , X, Y

$6980 \ldots 6983$ L, L, L, L, X

$7020 \quad$ F

$7040 \quad$ S

$7060 \ldots 7061 \mathrm{Y}, \mathrm{Y}$

$7070 \quad$ L

ANIMALS 7500-9999

CAENORHABDI . ELEG.

ASTERINA AMURENSIS

BOMBYX MORI

DROSOPHILA MELANO.

EUPHAUSIA SPERBA

XENOPUS LAEVIS

SALMON LIVER

CHICKEN

$\begin{array}{ll}7560 & \text { L } \\ 7620 & X \\ 7680 \ldots 7681 & \text { A, A, F, F, G, G } \\ 7740 \ldots 7742 & \text { E, F, H, K, K, S , S , S , V, V , V , X,Y } \\ 7860 & \text { X } \\ 7920 & \text { D, F,X } \\ 7980 & \text { X } \\ 8040 & \text { W }\end{array}$


2130 Nucleic Acids Research, Vol. 19, Supplement

MOUSE

RAT ASCIT. HEPATOM

RABBIT LIVER
BOVINE LIVER
CALF LIVER
COW MAMMARY GLAND
SHEEP LIVER
HUMAN

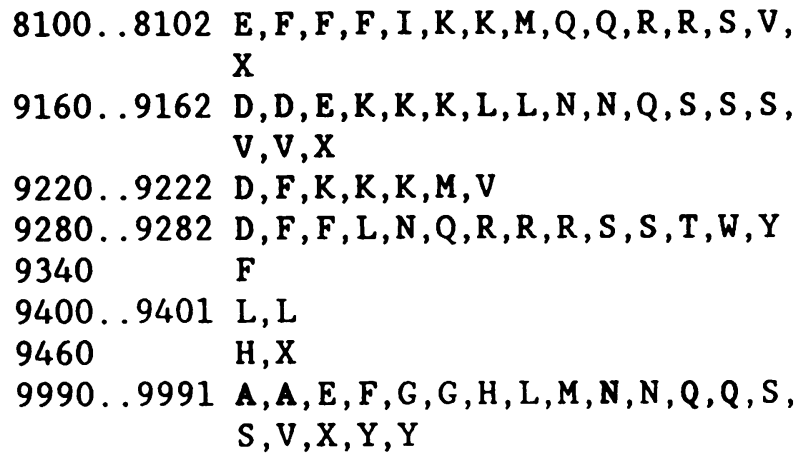

source(1)

numberrange

tRNA genes

(2)

\begin{tabular}{|c|c|c|}
\hline VIRUS & $0000-0299$ & \\
\hline $\begin{array}{l}\text { PHAGE T4 } \\
\text { PHAGE T5 }\end{array}$ & 0220 & $\begin{array}{l}G, I, L, P, Q, R, S, T \\
A, A, D, G, H, I, K, L, M, P, Q, S, S, T, \\
V, X\end{array}$ \\
\hline ARCHAEBACTERIA & $0300-1099$ & \\
\hline ARCHAEGLOBUS FULG. & 0340 & A \\
\hline HALOBACTERIUM CUT. & 0380 & A, C \\
\hline HALOBACTERIUM HAL. & 0420 & A \\
\hline HALOBACTERIUM MED. & 0460 & $\mathrm{~W}$ \\
\hline HALOBACTERIUM VOL. & 0500 & $\mathrm{C}, \mathrm{W}$ \\
\hline METHANOBAC . FORMI . & 0580 & A \\
\hline METHANOBAC. THERM. & 0620 & A \\
\hline METHANOCOC . VANI . & $0660 \ldots 0661$ & $\begin{array}{l}A, D, E, F, H, I, K, L, N, P, Q, R, T, T, \\
V, Y\end{array}$ \\
\hline METHANOTHRIX SOEH. & 0670 & A \\
\hline METHANOTHERM. FER. & 0680 & $A, D, E, H, I, K, L, N, P, S, T$ \\
\hline RUMINOBACTER AMYLO & 0700 & E \\
\hline METHANOCOC.VOLTAE & 0740 & $D, K, P, T, Y$ \\
\hline METHANOSPIR. HUNG. & 0780 & A \\
\hline SULFOLOBUS SOLFA. & 0860 & $F, G, L, S, V, X$ \\
\hline THERMOCOCCUS CELER & 0940 & A \\
\hline THERMOFIL. PENDENS & 0960 & $G, M$ \\
\hline THERMOPROT. TENAX & $0980 \ldots 0981$ & $A, A, L, L, X$ \\
\hline EUBACTERIA & $1100-2399$ & \\
\hline MYCOPLASMA CAPRIC. & $1140 \ldots 1141$ & 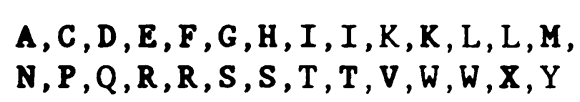 \\
\hline MYCOPLASMA MYCOID. & $1180 \ldots 1181$ & $\begin{array}{l}A, D, E, F, G, I, M, N, P, R, R, S, T, V \text {, } \\
X\end{array}$ \\
\hline MYCOPLASMA PNEUMO. & 1200 & $\mathbf{G}, \mathbf{K}, \mathbf{L}, \mathrm{Q}, \mathbf{Y}$ \\
\hline MYCOPLASMA PG50 & 1220 & $\mathrm{~K}, \mathrm{~L}$ \\
\hline ACHOLEPLASMA LAID. & 1230 & $\mathbf{w}$ \\
\hline SPIROPLASMA MELIF. & 1260 & $A, C, D, F, I, M, P, R, S, X$ \\
\hline STREPTOMYCES COEL. & 1310 & L \\
\hline STREPTOMYCES RIM. & $1340 \ldots 1341$ & $\mathrm{x}, \mathrm{X}$ \\
\hline STREPTOMYCES LIV. & $1350 \ldots 1351$ & $C, G, R, N, N, V, V$ \\
\hline
\end{tabular}




\section{LACTOBAC. BULG. LACTOBAC. DELBRUEC. BACILLUS SUBTILIS \\ THERMUS THERMOPHI. THIOBACILLUS FERRO E. COLI}

SALMONELLA TYPHI. PHOTOBACT. PHOSPH. PHOTOBAC. LEIOGNA. AEROMONAS HYDROPH. PSEUDOMONAS AER. CAMPYLOBAC.JEJUNI CAULOBACTER CRES. RHIZOBIUM MELILOTI BORDETELLA PERTUS . HAEMOPHILUS INFLU. ANACYSTIS NIDULANS CYANOPHORA PARAD. PYLAIELLA LITTORA.
1500

1520

1540..1543 A, A, A, A, C, D, E, F, F, G, G, H, H, I, $I, I, K, L, L, L, L, M, M, N, N, P, Q, R$, $S, S, S, T, T, T, V, W, X, Y$

$1580 \ldots 1581$ G, G,T, T,Y

$1620 \quad A, I$

1660. 1665 A, A, C, D, E, F, G, G, G, H, I, I , K, L, $L, L, L, L, M, N, P, P, P, Q, Q, R, R, R$, $R, R, S, S, S, S, S, S, T, T, T, T, V, V$, , W, X, X,Y, Y

$1700 \quad H, L, P, R$

$1740 \quad$ H,P

1750 L, M

$1780 \quad \mathrm{H}, \mathrm{L}, \mathrm{P}, \mathrm{R}$

1820..1821 A, G, I, T, T, Y

$1860 \quad$ A, I

$1900 \quad$ A, I

1940 L

1980 L

$2000 \quad$ G, $K, L$

$2100 \quad A, I$

2180 A, E, G, I, L , S

2220 A, I

\section{ORGANELLES :}

\section{CHLOROPLASTS}

CHLAMYDOMONAS REIN CHLAMYDOMO. MOEWU. CHLORELLA ELLIPSO. EUGLENA GRACILIS

CRYPTOMONAS SPEC. SPIROGYRA MAXIMA MARCHANTIA POLYM.

COLEOCHAETE ORBIC. HORDEUM VULGARE TRITICUM AESTIVUM ZEA MAYS

ARABIDOPSIS THAL. BRASSICA OLERACEA GLYCINE MAX MEDICAGO SATIVA NICOTIANA TABACUM

NICOTIANA DEBNEYI OENOTHERA SP. GOSSYPIUM HIRSUTUM PELARGONIUM ZONALE PENNISETUM AMERICA PETUNIA HYBRIDA PISUM SATIVUM
$2400-3599$

$$
\begin{aligned}
& 2440 \\
& 2460 \\
& \text { T } \\
& 2480 \quad A, I, R, S \\
& \text { 2520. .2522 A, A, C, D , E, F, G, G, H, I , K, L, L, L, } \\
& M, N, P, Q, R, S, S, T, V, W, X, Y \\
& 2540 \quad \text { R } \\
& 2550 \quad \text { I } \\
& \text { 2600. .2602 A, C, D, E, F, G, G, H, I, I, K, L, L, L, } \\
& M, N, P, P, Q, R, R, R, S, S, S, T, T, V \text {, } \\
& \mathrm{V}, \mathrm{W}, \mathrm{X}, \mathrm{Y} \\
& 2620 \quad A, I \\
& \text { 2640.2641 G, G,M, S, T, V, X } \\
& \text { 2680.2681 C, D, E, G, G, M, P, R, S, T, W, X, Y } \\
& \text { 2720..2722 A, C, F, H, I, L, L, M, N, P, R, S , S , S, } \\
& T, V, V, W \\
& 2760 \quad M \\
& 2800 \quad \mathrm{~L} \\
& 2840 \quad \text { A, I , M, V } \\
& 2880 \quad \mathrm{H} \\
& \text { 2920. .2922 A, C, D, E, F, G, G, H, I, I , I , K, L, L, } \\
& L, M, N, P, Q, R, R, S, S, S, T, T, V, V \text {, } \\
& \mathrm{W}, \mathrm{X}, \mathrm{Y} \\
& 2960 \quad H \\
& 3000 \quad \text { P,W } \\
& 3020 \text { H } \\
& 3040 \quad \text { R } \\
& 3080 \quad \text { I } \\
& 3120 \quad \text { H } \\
& 3200 \ldots 3201 \text { D, E, G, H, K, L, N, P, R, R, S , T , V , W, } \\
& \mathrm{X}, \mathrm{Y}
\end{aligned}
$$


2132 Nucleic Acids Research, Vol. 19, Supplement

\begin{tabular}{|c|c|c|}
\hline $\begin{array}{l}\text { SINAPIS ALBA } \\
\text { SPINACIA OLERACEA }\end{array}$ & $\begin{array}{l}3240 \\
3280 \ldots 3281\end{array}$ & $\begin{array}{l}H, K, Q, S, V \\
A, C, D, E, H, I, I, L, M, R, S, S, T, T, \\
V, Y\end{array}$ \\
\hline $\begin{array}{l}\text { SPIRODELA OLIGORH. } \\
\text { VICIA FABA } \\
\text { SORGHIM BTCOIOR }\end{array}$ & $\begin{array}{l}3320 \ldots 3321 \\
3360 \ldots 3361\end{array}$ & $\begin{array}{l}N, R, R \\
E, F, H, L, L, T, Y\end{array}$ \\
\hline
\end{tabular}

KITOCHOIDRTA 3600-5999

SINGLE CELL ORGANISMS AND FUNGI 3600-4199

\begin{tabular}{|c|c|c|}
\hline CHLAMYDOMO. REINH. & 3640 & $M, Q, W$ \\
\hline TRYPANOSOMA BRUCEI & $3680 \ldots 3681$ & $\mathbf{A}, \mathbf{A}$ \\
\hline PARAMECIUM PRIM. & 3720 & $X, Y$ \\
\hline PARAMECIUM TETRA. & 3760 & w, Y \\
\hline PARAMECIUM AURELIA & 3770 & $\mathbf{F}, \boldsymbol{W}, \mathbf{Y}$ \\
\hline TETRAHYMENA PYRIF. & 3800 & $\mathbf{E}, \mathbf{F}, \mathrm{H}, \mathrm{L}, \mathrm{W}, \mathrm{X}$ \\
\hline TETRAHYMENA THERM. & 3840 & $\mathrm{~L}, \mathrm{X}, \mathrm{Y}$ \\
\hline ASPERGILLUS NIDUL. & $3880 \ldots 3881$ & $\begin{array}{l}A, C, C, D, E, F, G, G, H, I, K, L, L, M, \\
M, N, P, Q, R, S, S, T, V, W, X, Y\end{array}$ \\
\hline NEUROSPORA CRASSA & 3920 & $A, C, M, R$ \\
\hline PODOSPORA ANSERINA & 3960 & $D, M, N, S, V, W$ \\
\hline SACCHAROMYCES CER. & $4000 \ldots 4001$ & $\begin{array}{l}\text { A, A, C, D, E, F, G, H, I , K, M, N , P, Q, } \\
R, R, S, S, T, T, V, V, Y, Y\end{array}$ \\
\hline SCHIZOSACCHA.POM. & 4040 & G, H, L, P, Q \\
\hline KLUYVEROMYCES LAC. & 4050 & $C, K, L, Q$ \\
\hline CANDIDA PARAPSILO. & 4060 & $\mathrm{P}$ \\
\hline TORULOPSIS GLAB. & $4080 \ldots 4081$ & $\begin{array}{l}A, C, D, E, F, G, H, I, K, L, M, N, P, Q, \\
R, S, S, T, T, V, W, X, Y\end{array}$ \\
\hline YEAST & 4120 & $\mathrm{~L}, \mathrm{~W}, \mathrm{X}$ \\
\hline
\end{tabular}

PLANTS $4200-4599$

\begin{tabular}{|c|c|c|}
\hline ARABIDOPSIS THAL. & 4240 & $E, M, S, Y$ \\
\hline GLYCINE MAX & 4280 & $E, M, X$ \\
\hline SOLANUM LYCOPERS. & 4300 & C \\
\hline LUPINUS LUTEUS & 4320 & $G, I, N, X$ \\
\hline OENOTHERA SP. & 4360 & $\mathrm{~S}, \mathrm{~W}, \mathrm{X}$ \\
\hline PHASEOLUS VULGARIS & 4400 & $\mathrm{~N}, \mathrm{~S}, \mathrm{Y}$ \\
\hline TRITICUM AESTIVUM & $4440 \ldots 4442$ & $\begin{array}{l}\text { C, D , E , F , K, N , P, Q, Q, S , S , S , W, X, } \\
\mathrm{Y}\end{array}$ \\
\hline ZEA MAYS & $4480 \ldots 4481$ & $\mathrm{C}, \mathrm{D}, \mathbf{E}, \mathrm{H}, \mathrm{K}, \mathrm{M}, \mathbf{M}, \mathrm{P}, \mathrm{S}, \mathrm{S}, \mathrm{W}, \mathrm{X}, \mathrm{Y}$ \\
\hline \multicolumn{3}{|l|}{ ANIMALS $4600-5999$} \\
\hline ASCARIS SUUM & $4640 \ldots 4641$ & $\begin{array}{l}A, C, D, E, F, G, H, I, K, L, L, N, P, Q \text {, } \\
R, S, S, T, V, W, X, Y\end{array}$ \\
\hline CAENORHABDI . ELEG. & $4680 \ldots 4681$ & $C, D, G, H, K, L, L, N, R, S, S, T, W, X$ \\
\hline ARTEMIA SP. & 4720 & $\mathbf{E}, \mathbf{F}$ \\
\hline LOCUSTA MIGRATORIA & $4760 \ldots 4761$ & $D, G, K, L, L, S$ \\
\hline AEDES ALBOPICTUS & 4800 & $A, E, F, G, L, N, R, S, V$ \\
\hline DROSOPHILA MELANO. & 4840 & $C, D, G, K, L, W, Y$ \\
\hline DROSOPHILA YAKUBA & 4880 & $\begin{array}{l}A, C, D, E, F, G, H, I, K, L, N, P, Q, R \text {, } \\
S, T, V, W, X, Y\end{array}$ \\
\hline DROSOPHILA YAKUBA & 4921 & $\mathrm{~L}, \mathrm{~S}$ \\
\hline DROSOPHILA VIRILIS & 4960 & $I, Q, X$ \\
\hline PISASTER OCHRACEUS & $4980 \ldots 4981$ & $\underset{\mathbf{Y}}{A, C, D, E, G, L, L, N, P, Q, T, V, W, X,}$ \\
\hline
\end{tabular}




\section{ASTERINA PECTINI.}

ASTERIAS FORBESII PARACENTROTUS LIV.

STRONGYLOCEN . PURP .

ACIPENSER TRANSM. GADUS MORHUA

XENOPUS LAEVIS

RANA CATESBEIANA

CEPHALORHYN . COM.

CHICKEN

RAT

MOUSE

BOVINE

GREEN MONKEY

MACACA FUSCATA

MACACA MULATTA

MACACA FASCICULA.

MACACA SYLVANUS

SAIMIRI SCIUREUS

TARSIUS SYRICHTA

LEMUR CATTA

CHIMPANZEE

GIBBON

GORILLA

ORANG UTAN

HUMAN
$5000 \ldots 5001$ A, C, D, G, H, L, L, M, N, P, Q, S , S , V,

$$
\text { W, Y }
$$

$5020 \ldots 5021$ A, C, D, G, L, L, N, V, W, X, Y

5040. .5041 A, C, D, E, F, F, G, H, I, K, L, L, N , P, $Q, R, S, S, T, V, W, X, Y$

5080 . 5081 A, C, D, E, F, G, H, I, K, L, L, N , P, Q, $R, S, S, T, V, W, X, Y$

$5090 \quad$ P, T

$5100 \quad A, C, F, G, H, K, L, N, R, S, W, Y$

5120.5121 A, C, D, E, F, F, G, H, I, K, L, L, N , P, $Q, R, S, S, T, V, W, X, Y$

$5160 \quad$ A, C, F, I , L, N, P, Q, T, W, X, Y

$5200 \quad$ F, P, T

$5220 \quad D, K, S$

$5280 \ldots 5282$ A , C , C , D , D , E , F, G , H , I , K, K, L, L, $N, N, N, P, P, Q, Q, R, S, S, S, T, T, V$, $W, W, X, X, Y$

$5320 \ldots 5321$ A, C, D, E, F, G, H, I , K, L, L, N, P, Q, $R, S, S, T, V, W, X, Y$

5360.5361 A, C, D, E, F, G, H, I , K, L, L, N , P, Q,

$5400 \quad \mathrm{~F}$

$5440 \quad$ H, L, S

$5480 \quad \mathrm{H}, \mathrm{L}, \mathrm{S}$

$5520 \quad H, L, S$

$5560 \quad \mathrm{H}, \mathrm{L}, \mathrm{S}$

$5600 \quad \mathrm{H}, \mathrm{L}, \mathrm{S}$

$5640 \quad$ H, L, S

$5680 \quad$ H, L, S

$5720 \quad$ H, L, S

$5760 \quad H, L, S$

$5800 \quad H, L, S$

$5840 \quad H, L, S$

$5880 \ldots 5881$ A , C , D , E , F , G, H, I , K, L, L, N , P, Q, $R, S, S, T, V, W, X, Y$

EUKARYOTIC CYTOPLASM

$6000-9999$

SINGLE CELL ORGANISMS AND FUNGI 6000-6699

\begin{tabular}{|c|c|c|}
\hline TRYPANOSOMA BRUCEI & 6050 & $\mathbf{K}, \mathbf{Q}, \mathbf{V}$ \\
\hline TETRAHYMENA PYRIF. & 6060 & $N, Q, S$ \\
\hline DICTYOSTELIUM DIS. & $6160 \ldots 6161$ & $E, V, V, W$ \\
\hline NEUROSPORA CRASSA & 6200 & $F, L$ \\
\hline PODOSPORA ANSERINA & $6240 \ldots 6241$ & $\mathrm{~S}, \mathrm{~s}$ \\
\hline SACCHAROMYCES CER. & $6280 \ldots 6282$ & $\begin{array}{l}A, A, C, D, E, E, G, H, I, K, K, L, M, P, \\
Q, Q, R, R, R, S, S, V, V, W, X, X, Y\end{array}$ \\
\hline $\begin{array}{l}\text { SCHIZOSACCHA. POM. } \\
\text { YEAST }\end{array}$ & $\begin{array}{l}6320 \ldots 6322 \\
6400 \ldots 6402\end{array}$ & $\begin{array}{l}D, E, F, H, K, R, R, S, S, S, X, X \\
F, F, I, S, S, S\end{array}$ \\
\hline
\end{tabular}

PLANTS 6700-7499

ARABIDOPSIS THAL.

GLYCINE MAX

PHASEOLUS VULGARIS

NICOTIANA RUSTICA

PETUNIA SP. SORGHUM BICOLOR

$\begin{array}{ll}6740 & \text { A, F, V,X,Y } \\ 6900 & \text { D, M,X } \\ 6980 \ldots 6981 & \text { L, P,P } \\ 7060 & \text { Y } \\ 7100 & \text { N } \\ 7140 & \text { G }\end{array}$


2134 Nucleic Acids Research, Vol. 19, Supplement

\begin{tabular}{|c|c|c|}
\hline $\begin{array}{l}\text { ORYZA SATIVA } \\
\text { TRITICUM AESTIVUM } \\
\text { TRITICUM VULGARE }\end{array}$ & $\begin{array}{l}7180 \\
7200 \\
7240\end{array}$ & $\begin{array}{l}\mathbf{G} \\
\mathbf{Y} \\
\mathbf{S}\end{array}$ \\
\hline \multicolumn{3}{|l|}{ ANIMALS 7500-9999 } \\
\hline $\begin{array}{l}\text { CAENORHABDI. ELEG. } \\
\text { BOMBYX MORI } \\
\text { DROSOPHILA MELANO. }\end{array}$ & $\begin{array}{l}7560 \\
7680 . .7681 \\
7740 . .7742\end{array}$ & $\begin{array}{l}D, K, L, P, S, W, X \\
A, A, E, G, K \\
A, D, E, E, E, F, G, G, H, I, K, K, L, L, \\
M, N, P, R, R, S, S, S, T, V, V, X, Y\end{array}$ \\
\hline $\begin{array}{l}\text { DROSOPHILA SIMUL. } \\
\text { XENOPUS LAEVIS }\end{array}$ & $\begin{array}{l}7800 \\
7920.7922\end{array}$ & S $A, F, K, L, N, S, V, X, X, Y, Y, Y$ \\
\hline CHICKEN & $8040 \ldots 8041$ & $\mathrm{~K}, \mathrm{P}, \mathrm{P}, \mathrm{S}, \mathrm{W}$ \\
\hline MOUSE & $8100 \ldots 8101$ & $A, D, E, G, H, I, K, K, L, P, P, X$ \\
\hline RAT & $9160 \ldots 9162$ & $D, D, E, E, E, F, G, G, K, L, L, L, P, P$ \\
\hline BOVINE & $9280 \ldots 9281$ & s,s \\
\hline HUMAN & $9990 \ldots 9995$ & $\begin{array}{l}E, E, G, G, K, K, L, L, N, N, P, P, Q, Q, \\
S, S, S, T, T, V, V, V, V, V, V, X, X, Y, \\
Y\end{array}$ \\
\hline
\end{tabular}


TABLE 2: REFERENCES :

DLA SEQUENCES

DA0260 V.N.KSENZENKO ET AL. (1987) NUCL. ACIDS RES. 15, 5480-5481

DA0261 V.N.KSENZENKO ET AL. (1987) NUCL. ACIDS RES. 15, 5480-5481

DA0340 L.ACHENBACH-RICHTER, C.R.WOESE (1988) SYSTEM. APPL. MICROBIOL. 10, $211-214$

DA0380 I.HUI, P.P.DENNIS (1985) J. BIOL. CHEM. 260, 899-906

DA0420 A.S.MANKIN, V.K.KAGRAMANOVA (1986) MOL. GEN. GENET. 202, $152-161$

DA0580 K.LECHNER, G.WICH, A.BOECK (1985) SYSTEM. APPL. MICROBIOL. 6, 157-163

DA0620 L.OSTERGAARD ET AL. (1987) SYSTEM. APPL. MICROBIOL. 9, 199-209

DA0660 M.JARSCH, A.BOECK (1983) NUCL. ACIDS RES. 11, 7537-7544

DA0670 R. EGGEN, H.HARMSEN, W.M.DE VOS (1990) NUCL. ACIDS RES. 18, 1306-1306

DA0680 E.S.HAAS, J.W.BROWN, C.J.DANIELS, J.N.REEVE (1990) GENE 90, 51-59

DA0780 L.ACHENBACH-RICHTER, C.R.WOESE (1988) SYSTEM. APPL. MICROBIOL. 10, $211-214$

DA0940 L.ACHENBACH-RICHTER, C.R.WOESE (1988) SYSTEM. APPL. MICROBIOL. 10, $211-214$

DA0980 G.WICH, W.LEINFELDER, A.BOECK (1987) EMBO J. 6, 523-528

DA0981 G.WICH, W.LEINFELDER, A.BOECK (1987) EMBO J . 6, 523-528

DA1140 A.MUTO, Y.ANDACHI, H.YUZAWA, F.YAMAO, S.OSAWA (1990) NUCL. ACIDS RES. 18, 50375043

DA1180 T.SAMUELSSON, P.ELIAS, F.LUSTIG, Y.S.GUINDY (1985) BIOCHEM. J. 232, $223-228$

DA1260 M.J.ROGERS, A.A.STEINMETZ, R.T.WALKER (1986) NUCL. ACIDS RES. 14,3145

DA1540 E.F.WAWROUSEK, N.NARASIMHAN, J.N.HANSEN (1984) J. BIOL. CHEM 259, 3694-3702

DA1541 K.LOUGHNEY, E.LUND, J.E.DAHLBERG (1982) NUCL. ACIDS RES. 10, 1607-1624

E.F.WAWROUSEK, J.N.HANSEN (1983) J . BIOL. CHEM. 258, 291-298

DA1542 C.J.GREEN, G.C.STEWART, M.A.HOLLIS, B.S.VOLD, K.F.BOTT (1985) GENE $37,261-266$

DA1543 N.OGASAWARA, S.MORIYA, H.YOSHIKAWA (1983) NUCL. ACIDS RES. 11, 6301-6318

DA1620 A.VENEGAS, E.HEVIA, H.SANCHEZ (1988) NUCL. ACIDS RES. 16, 8179-8179

DA1660 R.A.YOUNG, R.MACKLIS, J.A.STEITZ (1979) J. BIOL. CHEM. 254, 3264-3271

DA1661 Y.KOMINE, T.ADACHI, H.INOKUCHI, H.OZEKI (1990) J. MOL. BIOL. 212, $579-598$

DA1820 P.J.HOUSIAUX, D.F.HILL, G.B.PETERSEN (1988) NUCL. ACIDS RES. 16, $2721-2721$

DA1860 A.RASHTCHIAN, M.SCHAFFER (1986) NUCL. ACIDS RES . 14, 5560-5560

DA1900 J.FEINGOLD, V.BELLOFATTO, L.SHAPIRO, K.AMEMIYA (1985) J . BACT. 163, $155-166$

DA2100 S.E.WILLIAMSON, W.F.DOOLITTLE (1983) NUCL. ACIDS RES. 11, 225-235 N.TOMIOKA, M.SUGIURA (1984) MOL. GEN. GENET. 193, 427-430

DA2180 I.JANSSEN, H.MUCKE, W.LOEFFELHARDT, H.J.BOHNERT (1987) PLANT MOL. BIOL. 9, 479484

DA2220 Y.MARKOWICZ, R.MACHE, S.LOISEAUX-DE GOER (1988) PLANT MOL. BIOL. $10,465-469$

DA2440 M.SCHNEIDER, J.D.ROCHAIX (1986) PLANT MOL. BIOL. 6, 265-270

DA2480 T.YAMADA, M.SHIMAJI (1987) MOL. GEN. GENET. 208, 377-383

DA2520 L.GRAF, H.KOESSEL, E.STUTZ (1980) NATURE 286, $908-910$; R.B.HALLICK ET AL. (1984) PLANT. MOL. BIOL. 3, 169-175

DA2521 M.R.EL-GEWELY, R.B.HELLING, J.G.TH.DIBBITS (1984) MOL. GEN. GENET. 194, $432-443$

DA2600 K.OHYAMA ET AL. (1988), J. MOL. BIOL. 203, 281-298

DA2620 J.R.MANHART, J.D.PALMER (1990) NATURE 345, 268-270

DA2720 W.KOCH, K.EDWARDS, H.KOESSEL (1981) CELL 25, 203-213

DA2840 G.DE LANVERSIN, D.T.N.PILLAY, B.JACQ (1987) PLANT MOL. BIOL. 10, 65-82

DA2920 M.SUGIURA, K.SHINOZAKI, M.OHME IN:NATO ASI SER; SER. A 83 (1985) (MOL. FORM FUNCT. PLANT GENOME) 325-334

DA3280 O.MASSENET, P.MARTINEZ, P.SEYER, J.-F.BRIAT (1987) PLANT MOL. BIOL. $10,53-63$

DA3680 B.F.DE VRIES ET AL. (1988) MOL. BIOCHEM. PARASITOL. $27,71-82$

DA3681 B.F.DE VRIES ET AL. (1988) MOL. BIOCHEM. PARASITOL. 27, $71-82$

DA3880 H.G.KOECHEL, C.M. LAZARUS, N.BASAK, H.KUENTZEL (1981) CELL 23, 625-633

DA3920 M.R.GREEN, M.F.GRIMM, R.R.GOEWERT, R.A.COLLINS (1981) J. BIOL. CHEM. $256,2027-$ 2034

DA4000 R.BORDONNE, G.DIRHEIMER, R.P.MARTIN (1987) NUCL. ACIDS RES. 15, $7381-7394$

DA4001 S.G.BONITZ, A.TZAGOLOFF (1980) J. BIOL. CHEM. 255, 9075-9081

DA4080 G.D.CLARK-WALKER, C.R.MCARTHUR, K.S.SRIPRAKASH (1985) EMBO J. 4, 465-473

DA4640 D.R. WOLSTENHOLME ET AL. (1987) PROC. NATL. ACAD. SCI. USA 84, 1324-1328 
DA4800 D.T.DUBIN, C-C.HSUCHEN, L.E.TILLOTSON (1986) CURR. GENET. 10, 701-707

DA4880 D.0.CLARY, D.R. WOLSTENHOLME (1985) J. KOL. EVOL. 22, 252-271

DA4980 H.T.JACOBS, S.ASAKAWA, T.ARAKI, K.MIURA, M.J.SMITH, K.WATANABE (1989) CURR. GENET. 15, 193-206

DA5000 H.T.JACOBS, S.ASAKAWA, T.ARAKI, K.MIURA, M.J.SMITH, K. WATANABE (1989) CURR. GENET. 15, 193-206

DA5020 H.T.JACOBS, S.ASAKAWA, T.ARAKI, K.MIURA, M.J.SMITH, K. WATANABE (1989) CURR. GENET. 15, 193-206

DA5040 P.GANTATORE ET AL. (1988) CURR. GENET. 13, 91-96

DA5080 H.T.JACOBS, D.J.ELLIOTT, V.B.MATH, A.FARQUHARSON (1988) J. MOL. BIOL. 202, 185217

DA5100 S.JOHANSEN, P.H.GUDDAL, T.JOHANSEN (1990) NUCL. ACIDS RES. 18, 411-419

DA5120 B.A.ROE, D.P.MA, R.K.WILSON, J.F.H.WONG (1985) J. BIOL. CHEM. 260, 9759-9774

DA5160 H.FUJII, T.SHIMADA, Y.GOTO, T.OKAZAKI (1988) J. BIOCHEM. 103, 474-481

DA5280 P.CANTATORE ET AL. (1982) NUCL. ACIDS RES. 10, 3279-3289;

R.GROSSKOPF, H.FELDMANN (1981) CURR. GENET . 4, 191-196

G.PEPE ET AL. (1983) BIOCHEM. INT. 6, 553-563

M. TAIRA ET AL. (1983) NUCL. ACIDS RES. 2, 1635-1643

DA5320 M.J.BIBB, R.A.VAN ETTEN, C.T.WRIGHT, M.W.WALBERG, D.A.CLAYTON (1981) CELL 26, $167-180$

DA5360 S.ANDERSON ET AL. (1982) J. MOL. BIOL. 156, 683-717

DA5880 S.ANDERSON ET AL. (1981) NATURE 290, 457-465

DA6280 H.J.DRABKIN, U.L.RAJBHANDARY (1985) J. BIOL. CHEM. 260, 5596-5602

DA6281 F.CREUSOT, M.GAISNE, J.VERDIERE, P.P.SLONIMSKI (1989) NUCL. ACIDS RES. 17, 18651866

DA6740 K.AKAMA, S.TANIFUJ (1990) PLANT MOL. BIOL. 15, 337-346

DA7680 0.HAGENBUECHLE, D.LARSON, G.I.HALL, K.U.SPRAGUE (1979) CELL 18, 1217-1229

R.L.GARBER, L.P.GAGE (1979) CELL 18, 817-828

D.G.MORTON, K.U.SPRAGUE (1982) MOL. CELL. BIOL. 1524-1531

DA7681 D.C.UNDERWOOD ET AL. (1988) MOL. CELL. BIOL. 8, 5504-5512

DA7740 R.DELOTTO, P.SCHEDL (1984) J. MOL. BIOL. 179, 587-605

DA7920 F.MUELLER, S.G.CLARKSON, D.J.GALAS (1987) NUCL. ACIDS RES. 15, 7191-7191

DA8100 T.RUSSO ET AL. (1986) EUR. J. BIOCHEM. 158, 437-442

DC0380 I.HUI, P.P.DENNIS (1985) J. BIOL. CHEM. 260, 899-906

DC0500 C.J.DANIELS ET. AL. (1985) MOL. GEN. GENET. 198, 270-274

DC1140 A.MUTO, Y.ANDACHI, H.YUZAWA, F.YAMAO, S.OSAWA (1990) NUCL. ACIDS RES. 18, $5037-$ 5043

DC1260 M.J.ROGERS, A.A.STEINMETZ, R.T.WALKER (1986) NUCL. ACIDS RES. 14, 3145

DC1350 R.SEDLMEIER, H.SCHMIEGER (1990) NUCL. ACIDS RES. 18, 4027-4027

DC1540 E.F.WAWROUSEK, N.NARASIMHAN, J.N.HANSEN (1984) J. BIOL. CHEM. 259, 3694-3702

DC1660 Y.KOMINE, T.ADACHI, H.INOKUCHI, H.OZEKI (1990) J. MOL. BIOL. 212, 579-598

DC2440 G.P.ONEILL, A.SCHOEN, H.CHOW, M.CHEN, Y.KIM, D.SOELL (1990) NUCL. ACIDS RES. 18, $5893-5893$

DC2520 R.B.HALLICK ET AL. (1984) PLANT. MOL. BIOL 3, 169-175

DC2600 K. OHYAMA ET AL. (1988) J. MOL. BIOL. 203, 281-298

DC2680 F.QUIGLEY, J.M.GRIENENBERGER, J.H.WEIL (1985) PLANT MOL. BIOL. 4, 305-310

DC2720 A.MEINKE, G.L.IGLOI, H.KOESSEL (1988) NUCL. ACIDS RES. 16, 5696-5696

DC2920 T.WAKASUGI, M.OHME, K.SHINOZAKI, M.SUGIURA (1986) PLANT MOL. BIOL. 7, 385-392

DC3280 G.S.HUDSON, T.A.HOLTON, P.R.WHITFELD, W.BOTTOMLEY (1988) J. MOL. BIOL. 200, 639 654

DC3880 T.A.BROWN, R.B.WARING, C.SCAZZOCCHIO, R.W.DAVIES (1985) CURR. GENET. 9, 113-117

DC3881 T.A.BROWN, R.B.WARING, C.SCAZZOCCHIO, R.W.DAVIES (1985) CURR. GENET. 9, $113-117$

DC3920 H.DE VRIES, P.HAIMA, M.BRINKER, J.C.DE JONGE (1985) FEBS LETTERS 179, $337-342$

DC4000 J.L.BOS, K.A.OSINGA, G.VAN DER HORST, P.BORST (1979) NUCL. ACIDS RES. 6, 32553266

DC4050 C.M.HARDY, G.D.CLARK-WALKER (1989) NUCL. ACIDS RES. 17, 1762-1762

R.E. BERLANI, C.PENTELLA, G.MACINO, A.TZAGOLOFF (1980) J. BACT. 41, 1086-1097

DC4300 S.IZUCHI, M.SUGITA (1989) NUCL. ACIDS RES. 17, 1248-1248 
DC4440 P.B.M.JOYCE, M.W.GRAY (1989) NUCL. ACIDS RES. 17, 5461-5476

DC4480 H.WINTZ, J.-M.GRIENENBERGER, J .-H.WEIL, D.M.LONSDALE (1988) 247-254

DC4640 D.R.WOLSTENHOLYE ET AL. (1987) PROC. NATL. ACAD. SCI. USA 84, 1324-1328

DC4680 D.R. WOLSTENHOLME ET AL. (1987) PROC. NATL. ACAD. SCI. USA 84, 1324-1328

DC4840 M.H.L.DE BRUIJN (1983) NATURE 304, 234-241

DC4880 D.0.CLARY, D.R. WOLSTENHOLME (1985) J. MOL. EVOL. 22, 252-271

DC4980 H.T.JACOBS, S.ASAKAWA, T.ARAKI, K.MIURA, M.J.SMITH, K.WATANABE (1989) CURR. GENET. 15, 193-206

DC5000 H.T.JACOBS, S.ASAKAWA, T.ARAKI, K.MIURA, M.J.SMITH, K.WATANABE (1989) CURR. GENET. 15, 193-206

DC5020 H.T.JACOBS, S.ASAKAWA, T.ARAKI, K.MIURA, M.J.SMITH, K.WATANABE (1989) CURR. GENET. 15, 193-206

DC5040 P.CANTATORE ET AL. (1988) CURR. GENET. 13, 91-96

DC5080 H.T.JACOBS, D.J.ELLIOTT, V.B.MATH, A.FARQUHARSON (1988) J. MOL. BIOL. 202, 185217

DC5100 S.JOHANSEN, P.H.GUDDAL, T.JOHANSEN (1990) NUCL. ACIDS RES. 18, 411-419

DC5120 B.A.ROE, D.P.MA, R.K.WILSON, J.F.H.WONG (1985) J. BIOL. CHEM. 260, 9759-9774

DC5160 Y.YONEYAMA (1987) J. NIPPON MED. SCH. 54, 429-440

DC5280 P.CANTATORE ET AL. (1982) NUCL. ACIDS RES. 10, 3279-3289 G.PEPE ET AL. (1983) BIOCHEM. INT. 6, 553-563

DC5281 M.TAIRA, E.YOSHIDA, M.KOBAYASHI, K.YAGINUMA, K.KOIKE (1983) NUCL. ACIDS RES. 11, 1635-1643 R.GROSSKOPF, H.FELDMANN (1981) CURR. GENET. 4, 191-196

DC5320 M.J.BIBB, R.A.VAN ETTEN, C.T.WRIGHT, M.W.WALBERG, D.A.CLAYTON (1981) CELL 26, $167-180$

DC5360 S.ANDERSON ET AL. (1982) J. MOL. BIOL. 156, 683-717

DC5880 S.ANDERSON ET AL. (1981) NATURE 290, 457-465

DC6280 F.S.GENBAUFFE, G.E.CHISHOLM, T.G.COOPER (1984) J. BIOL. CHEM. 259, 10518-10525

DD0260 M.G.SHLYAPNIKOV, V.N.KSENZENKO, N.M.KRYUKOV, A.A.BAYEV (1986) EUR. J. BIOCHEM. $156,285-289$

DD0660 G.WICH, M.JARSCH, A.BOECK (1984) MOL. GEN. GENET. 196, 146-151

DD0680 E.S.HAAS, C.J.DANIELS, J.N.REEVE (1989) GENE 77, 253-263

DD0740 G.WICH, L.SIBOLD, A.BOECK (1987) Z. NATURFORSCH. 42c, 373-380

DD1140 A.MUTO, Y.ANDACHI, H.YUZAWA, F.YAMAO, S.OSAWA (1990) NUCL. ACIDS RES. 18, $5037-$ 5043

DD1180 T.SAMUELSSON, P.ELIAS, F.LUSTIG, Y.S.GUINDY (1985) BIOCHEM. J. 232, 223-228

DD1260 M.J.ROGERS, A.A.STEINMETZ, R.T.WALKER (1986) NUCL. ACIDS RES. 14, 3145-3145

DD1500 A.C.PITTET, H.HOTTINGER (1989) NUCL. ACIDS RES. 17, 4873-4873

DD1540 Y.YAMADA, M.OHKI, H.ISHIKURA (1983) NUCL. ACIDS RES. 11, 3037-3045 C.J.GREEN, G.C.STEWART, M.A.HOLLIS, B.S.VOLD, K.F.BOTT (1985) GENE 37, 261-266

DD1660 R.A.YOUNG (1979) J. BIOL. CHEM. 254, 12725-12731 T.SEKIYA, M.MORI, N. TAKAHASHI, S.NISHIMURA (1980) NUCL. ACIDS RES. 8, 3809-3827 W.R.FOLK, H.HOFSTETTER, M.L.BIRNSTIEL (1982) NUCL. ACIDS RES. 10, 7153-7162

DD2520 T.MANZARA, J.X. HU, C.A.PRICE, R.B.HALLICK (1987) PLANT MOL. BIOL. 8, $327-336$

DD2600 K. OHYAMA ET AL. (1988) J. MOL. BIOL. 203, 281-298

DD2680 F.QUIGLEY, J.M.GRIENENBERGER, J.H.WEIL (1985) PLANT MOL. BIOL. 4, 305-310

DD2920 M.OHME, T.KAMOGASHIRA, K.SHINOZAKI, M.SUGIURA (1985) NUCL. ACIDS RES. 13,10451056

DD3200 O.F.RASMUSSEN, B.M.STUMMANN, W.HENNINGSEN (1984) NUCL. ACIDS RES. 12, $9143-9153$

DD3280 K.HOLSCHUH, W.BOTTOMLEY, P.R.WHITFELD (1983) NUCL. ACIDS RES. 11, 8547-8554

DD3880 H.G.KOECHEL, C.M.LAZARUS, N.BASAK, H.KUENTZEL (1981) CELL 23, 625-633

DD3960 D.J.CUMMINGS, I.A.MACNEIL, J.DOMENICO, , E.T.MATSUURA (1985) J. MOL. BIOL. 185, $659-680$

DD4000 S.G.BONITZ, A.TZAGOLOFF (1980) J. BIOL. CHEM. 255,9075-9081 D.L.MILLER, D.R.NAJARIAM, J.R.FOLSE, N.C.MARTIN (1981) J. BIOL. CHEM. 256, 9774-9777

D.L.MILLER, N.C.MARTIN (1981) CURR. GENET. 4, 135-143

DD4080 G.D.CLARK-WALKER, C.R.MCARTHUR, K.S.SRIPRAKASH (1985) EMBO J. 4, 465-473

DD4440 P.B.M.JOYCE, D.F.SPENCER, L.BONEN, M.W.GRAY (1988) PLANT MOL. BIOL. 10, 251-262 
2138 Nucleic Acids Research, Vol. 19, Supplement

DD4480 T.D.PARKS, W.G.DOUGHERTY, C.S.LEVINGS III, D.H.TIMOTHY (1985) CURR. GENET. 9, 517-519

DD4640 D.R. WOLSTENHOLYE ET AL. (1987) PROC. NATL. ACAD. SCI. USA 84,1324-1328

DD4680 D.R. WOLSTENHOUME ET AL. (1987) PROC. NATL. ACAD. SCI. USA 84, 1324-1328

DD4760 H.-R.HAUCKE, G.GELLISSEN (1988) CURR. GENET. 14, 471-476

DD4840 M.H.L.DE BRUIJN (1983) NATURE 304, 234-241

DD4880 D.0.CLARY, D.R.WOLSTENHOLME (1985) J. KOL. EVOL. 22, 252-271

DD4980 H.T.JACOBS, S.ASAKAWA, T.ARAKI, K.MIURA, M.J.SMITH, K.WATANABE (1989) CURR. GENET. 15, 193-206

DD5000 H.T.JACOBS, S.ASAKAWA, T.ARAKI, K.MIURA, M.J.SMITH, K.WATANABE (1989) CURR. GENET. $15,193-206$

DD5020 H.T.JACOBS, S.ASAKAWA, T.ARAKI, K.MIURA, M.J.SMITH, K.WATANABE (1989) CURR. GENET. $15,193-206$

DD5040 P.CANTATORE ET AL. (1988) CURR. GENET. 13, 91-96

DD5080 H.T.JACOBS, D.J.ELLIOTT, V.B.MATH, A.FARQUHARSON (1988) J. MOL. BIOL. 202, 185217

DD5120 B.A.ROE, D.P.MA, R.K.WILSON, J.F.H.WONG (1985) J. BIOL. CHEM. 260, 9759-9774

DD5220 Y.H.W.LEE, L.L.LIAW, T.T.YUNG, S.J.LO (1989) NUCL. ACIDS RES. 17, 9477-9477

DD5280 R.GROSSKOPF, H.FELDMANN (1981) CURR. GENET. 4,151-158

DD5281 P.CANTATORE ET AL. (1982) NUCL. ACIDS RES. 10, 3279-3289 G.PEPE ET AL. (1983) BIOCHEM. INT. 6, 553-563

DD5320 M.J.BIBB, R.A.VAN ETTEN, C.T.WRIGHT, M.W.WALBERG, D.A.CLAYTON (1981) CELL 26, $167-180$

DD5360 S.ANDERSON ET AL. (1982) J. MOL. BIOL. 156, 683-717

DD5880 S.ANDERSON ET AL. (1981) NATURE 290, 457-465

DD6280 H.J.DRABKIN, U.L.RAJBHANDARY (1985) J. BIOL. CHEM. 260, 5596-5602

DD6320 J.MAO ET AL. (1982) NUCL. ACIDS RES. 10, 487-500

DD6900 C.WALDRON, N.WILLS, R.F.GESTELAND (1985) J. MOL. APPL. GENET . 3, 7-17

DD7560 T.A.TRANQUILLA, R.CORTESE, D.MELTON, J.D.SMITH (1982) NUCL. ACIDS RES. 10, 7919 7934

DD7740 G.DAS, D.HENNING, R.REDDY (1986) NUCL. ACIDS RES. 14, 7816-7816

DD8100 J.E.LOONEY, J.D.HARDING (1983) NUCL. ACIDS RES. 11, 8761-8775

DD9160 K.SHIBUYA, S.NOGUCHI, M.YAMAKI, S.NISHIMURA, T.SEKIYA (1985) J. BIOCHEM. 97 , $1719-1725$

DD9161 A.ROSEN, S.SARID, V.DANIEL (1984) NUCL. ACIDS RES. 12, 4893-4906

DE0660 G.WICH, L.SIBOLD, A.BOECK. (1986) SYSTEM. APPL. MICROBIOL. 7, 18-25

DE0680 E.S.HAAS, C.J.DANIELS, J.N.REEVE (1989) GENE 77, 253-263

DE0700 B.MARTENS, H.SPIEGL, E.STACKEBRANDT (1987) SYSTEM.APPL.MICROBIOL. 9, $224-230$

DE1140 A.MUTO, Y.ANDACHI, H.YUZAWA, F.YAMAO, S.OSAWA (1990) NUCL. ACIDS RES. 18, 5037 5043

DE1180 T.SAMUELSSON ET AL. (1987) PROC. NATL. ACAD. SCI. USA 84, 3166-3170

DE1500 A.C.PITTET, H.HOTTINGER (1989) NUCL. ACIDS RES. 17, 4873-4873

DE1540 Y.YAMADA, M.OHKI, H.ISHIKURA (1983) NUCL. ACIDS RES. 11, 3037-3045 C.J.GREEN, G.C.STEWART, M.A.HOLLIS, B.S.VOLD, K.F.BOTT (1985) GENE 37, 261-266

DE1660 J.BROSIUS, T.J.DULL, D.D.SLEETER, H.F.NOLLER (1981) J. MOL. BIOL. 148, 107-127

E.A.MORGAN, T.IKEMURA, L.E.POST, M.NOMURA (1980) IN:TRANSFER RNA, D. SOELL,

J.ABELSON, P.SCHIMMEL (ED), COLD SPRING HARB. 259-266

DE2180 J.-L.EVRARD, M.KUNTZ, N.A.STRAUS, J.-H.WEIL (1988) GENE 71, 115-122

DE2440 G.P.ONEILL, A.SCHOEN, H.CHOW, M.CHEN, Y.KIM, D.SOELL (1990) NUCL. ACIDS RES. 18, $5893-5893$

DE2520 R.B.HALLICK ET AL. (1984) PLANT. MOL. BIOL. 3, 169-175

DE2600 K. OHYAMA ET AL. (1988) J. MOL. BIOL. 203, 281-298

DE2680 F.QUIGLEY, J.H.WEIL (1985) CURR. GENET. 9, 495-503

DE2920 M.OHME, T.KAMOGASHIRA, K.SHINOZAKI, M.SUGIURA (1985) NUCL. ACIDS RES. 13, 1045 1056

DE3200 D.R.SHAPIRO, K.K.TEWARI (1986) PLANT MOL BIOL. 6, 1-12

DE3280 K.HOLSCHUH, W.BOTTOMLEY, P.R.WITHFELD (1984) PLANT MOL. BIOL. 3, 313-317

DE3360 J.H.WEIL, G.BONNARD, M.KUNTZ, A.STEINMETZ IN:NATO ASI SER; SER. A 83 (1985) (MOL. FORM FUNCT. PLANT GENOME) 313-324 
DE3800 Y.SUYAMA, F.JENNEY (1989) NUCL. ACIDS RES. 17, 803-803

DE3880 H.G.KOECHEL, C.M.LAZARUS, N.BASAK, H.KUENTZEL (1981) CELL 23, 625-633

DE4000 F.G.NOBREGA, A.TZAGOLOFF (1980) FEBS LETTERS 113, 52-54

DE4080 G.D.CLARK-WALKER, C.R.MCARTHUR, K.S.SRIPRAKASH (1985) EMBO J. 4, 465-473

DE4240 H.C.CHEN, H.WINTZ, J.H.WEIL, D.T.N.PILLAY (1989) NUCL. ACIDS RES. 17, $2613-2621$

DE4280 H.WINTZ, H. -C.CHEN, D.T.N.PILLAY (1987) NUCL. ACIDS RES. 15, 10588-105

DE4440 J.M.GUALBERTO, C.DOMON, J.H.WEIL, J.M.GRIENENBERGER (1989) NUCL. ACIDS RES. 17, $3586-3586$

DE4480 A.SANGARE, J.H.WEIL, J.M.GRIENENBERGER (1989) NUCL. ACIDS RES . 17 5837-5837

DE4640 D.R.WOLSTENHOLME ET AL. (1987) PROC. NATL. ACAD. SCI. USA 84, 1324-1328

DE4720 B.BATUECAS ET AL. (1988) NUCL. ACIDS RES. 16, 6515-6529

DE4800 D.T.DUBIN, C.-C.HSUCHEN, L.E.TILLOTSON (1986) CURR. GENET. 10, 701-707

DE4880 D.0.CLARY, D.R. WOLSTENHOLME (1985) J. MOL. EVOL. 22, 252-271

DE4980 H.T.JACOBS, S.ASAKAWA, T.ARAKI, K.MIURA, M.J.SMITH, K.WATANABE (1989) CURR. GENET. 15, 193-206

DE5040 P.CANTATORE ET AL. (1988) CURR. GENET. 13, 91-96

DE5080 H.T.JACOBS, D.J.ELLIOTT, V.B.MATH, A.FARQUHARSON (1988) J. MOL. BIOL. 202, 185217

DE5120 B.A.ROE, D.P.MA, R.K.WILSON, J.F.H.WONG (1985) J. BIOL. CHEM. 260, 9759-9774 D.DUNON-BLUTEAU, M.VOLOVITCH, G.BRUN (1985) GENE 36, 65-78

DE5280 G.GOERTZ, H.FELDMANN (1982) CURR. GENET. 5, 221-225 K.KOIKE ET AL. (1982) GENE $20,177-185$

DE5320 M.J.BIBB, R.A.VAN ETTEN, C.T.WRIGHT, M.W.WALBERG, D.A.CLAYTON (1981) CELL 26, $167-180$

DE5360 S.ANDERSON ET AL. (1982) J. MOL. BIOL. 156, 683-717

DE5880 S.ANDERSON ET AL. (1981) NATURE 290, 457-465

DE6160 T.DINGERMANN ET.AL. (1986) NUCL. ACIDS RES. 14, 1127-1127

DE6280 A.EIGEL, H.FELDMANN (1982) EMBO J. 1, 1245-1250 F.S.GENBAUFFE, G.E.CHISHOLM, T.G.COOPER (1984) J. BIOL. CHEM. 259 10518-10525 S.D.TUCKER, E.J.MURGOLA (1985) BIOCHIMIE 67, 1053-1057

DE6281 R.STUCKA, J.HAUBER, H.FELDMANN (1987) CURR. GENET. 12, 323-328

DE6320 V.GAMULIN ET AL. (1983) NUCL. ACIDS RES. 11, 8537-8546

DE7680 J.CORLET, S.G.CLARKSON, A.FOURNIER, M.A.GUERIN, (1986) NUCL. ACIDS RES. 14, $1916-1916$

DE7740 H.A.HOSBACH, M.SILBERKLANG, B.J.MC CARTHY (1980) CELL 21, 169-178

DE7741 H.A.HOSBACH, M.SILBERKLANG, B.J.MC CARTHY (1980) CELL 21, 169-178

DE7742 Z.K. INDIK, K.D.TARTOF (1982) NUCL. ACIDS RES. 10, 4159-4172

DE8100 J.E.LOONEY, J.D.HARDING (1983) NUCL. ACIDS RES . 11, 8761-8775

DE9160 T.SEKIYA, Y.KUCHINO, S.NISHIMURA (1981) NUCL. ACIDS RES. 9, 2239-2250

DE9161 A.ROSEN, S.SARID, V.DANIEL (1984) NUCL. ACIDS RES. 12, 4893-4906

DE9162 A.ROSEN, S.SARID, V.DANIEL (1984) NUCL. ACIDS RES. 12, 4893-4906

DE9990 J.P.GODDARD, M.SQUIRE, M.BIENZ, J.D.SMITH (1983) NUCL. ACIDS RES. 11, 2551-2562

DE9991 E.S.GONOS, J.P.GODDARD (1990) NUCL. ACIDS RES. 18, 6705-6705

DF0660 G.WICH, L.SIBOLD, A.BOECK (1986) SYSTEM. APPL. MICROBIOL. 7, 18-25

DF0860 B.P.KAINE (1987) J. MOL. EVOL. 25, 248-254

DF1140 A.MUTO, Y.ANDACHI, H.YUZAWA, F.YAMAO, S.OSAWA (1990) NUCL. ACIDS RES. 18, 5037 5043

DF1180 T.SAMUELSSON, P.ELIAS, F.LUSTIG, Y.S.GUINDY (1985) BIOCHEM. J. 232, 223-228

DF1260 M.J.ROGERS, A.A.STEINMETZ, R.T.WALKER (1986) NUCL. ACIDS RES. 14, 3145-3145

DF1540 Y.YAMADA, M.OHKI, H.ISHIKURA (1983) NUCL. ACIDS RES. 11, 3037-3045 C.J.GREEN, G.C.STEWART, M.A.HOLLIS, B.S.VOLD, K.F.BOTT (1985) GENE 37, 261-266

DF1541 Y.YAMADA, M.OHKI, H.ISHIKURA (1983) NUCL. ACIDS RES. 11, 3037-3045

DF1660 R.K.WILSON, T.BROWN, B.A.ROE (1986) NUCL. ACIDS RES. 14, 5937

DF2520 R.B.HALLICK ET AL. (1984) PLANT. MOL. BIOL. 3, 169-175

DF2600 K. OHYAMA ET AL. (1988) J. MOL. BIOL. 203, 281-298

DF2720 A.A.STEINMETZ, E.T.KREBBERS, Z.SCHWARZ, E.J.GUBBINS, L. BOGORAD (1983) J. BIOL. CHEM. 258, 5503-5511

DF2920 K. YAMADA, K.SHINOZAKI, M.SUGIURA (1986) PLANT MOL. BIOL. 6, 193-199 
2140 Nucleic Acids Research, Vol. 19, Supplement

DF3360 J.H.WEIL, G.BONNARD, M.KUNTZ, A.STEINMETZ IN:NATO ASI SER; SER. A 83 (1985) (MOL. FORM FUNCT. PLANT GENOME) 313-324

DF3770 A.E.PRITCHARD, J.J.SEILHAMER, R.MAHALINGAM, C.L.SABLE, S.E.VENUTI, D.J.CUMMINGS (1990) NUCL. ACIDS RES. 18, 173-180

DF3800 Y.SUYAMA (1985) NUCL. ACIDS RES. 13, 3273-3284

DF3880 H.G.KOECHEL, C.M.LAZARUS, N.BASAK, H.KUENTZEL (1981) CELL 23, 625-633

DF4000 D.L.MILLER, N.C.MARTIN, H.D.PHAM, J.E.DONELSON (1980) J. BIOL. CHEM. 254, 11735 11740

DF4080 G.D.CLARK-WALKER, C.R.MCARTHUR, K.S.SRIPRAKASH (1985) EMBO J. 4, 465-473

DF4440 P.B.M.JOYCE, M.W.GRAY (1989) NUCL. ACIDS RES. 17, 5461-5476

DF4640 D.R. WOLSTENHOLME ET AL. (1987) PROC. NATL. ACAD. SCI. USA 84, 1324-1328

DF4720 B.BATUECAS ET AL. (1988) NUCL. ACIDS RES. 16, 6515-6529

DF4800 D.T.DUBIN, C.C.HSUCHEN, L.E.TILLOTSON (1986) CURR. GENET. 10, 701-707

DF4880 D.0.CLARY, D.R.WOLSTENHOLME (1985) J. MOL. EVOL. 22, 252-271

DF5040 P.CANTATORE ET AL. (1987) GENE 53, 41-54

DF5041 P.CANTATORE ET AL. (1988) CURR. GENET. 13, 91-96

DF5080 H.T.JACOBS, D.J.ELLIOTT, V.B.MATH, A.FARQUHARSON (1988) J. MOL. BIOL. 202, 185 217

DF5100 S.JOHANSEN, P.H.GUDDAL, T.JOHANSEN (1990) NUCL. ACIDS RES. 18, 411-419

DF5120 S.S.CAIRNS, D.F. BOGENHAGEN (1986) J. BIOL. CHEM. 261, 8481-8487

DF5121 B.A.ROE, D.P.MA, R.K.WILSON, J.F.H.WONG (1985) J. BIOL. CHEM. 260, 9759-9774

D.DUNON-BLUTEAU, M.VOLOVITCH, G.BRUN (1985) GENE 36, 65-78

DF5160 Y.YONEYAMA (1987) J. NIPPON MED. SCH. 54, 429-440

DF5200 S.O.SOUTHERN, P.J.SOUTHERN, A.E.DIZON (1988) J. MOL. EVOL. 28, $32-42$

DF5280 M.KOBAYASHI, T.SEKI, K.YAGINUMA, K.KOIKE (1981) GENE 16, 297-307 R.G.GROSSKOPF, H. FELDMANN (1981) CURR. GENET. 4, 191-196

DF5320 M.J.BIBB, R.A.VAN ETTEN, C.T.WRIGHT, M.W.WALBERG, D.A.CLAYTON (1981) CELL 26, $167-180$

DF5360 S.ANDERSON ET AL. (1982) J. MOL. BIOL. 156, 683-717

DF5400 E.M.KARAWYA, R.G.MARTIN (1987) BIOCHIM. BIOPHYS. ACTA 909, 30-34

DF5880 S.ANDERSON ET AL. (1981) NATURE 290, 457-465 S.CREWS, G.ATTARDI (1980) CELL 19, 775-784 D.0.CHANG, D.A.CLAYTON (1984) CELL 36, 635-643

DF6200 E.SELKER, C.YANOFSKY (1980) NUCL. ACIDS RES. 8, 1033-1042

DF6320 V.GAMULIN ET AL. (1983) NUCL. ACIDS RES. 11, 8537-8546

DF6400 P.VALENZUELA, A.VENEGAS, F.WEINBERG, R.BISHOP, W.J.RUTTER (1978) PROC. NATL.

ACAD. SCI. USA 75, 190-194 P.BULL ET AL. (1987) DNA 6, 353-362

DF6401 P.BULL ET AL. (1987) DNA 6, 353-362

DF6740 K.AKAMA, S.TANIFUJ I (1990) PLANT MOL. BIOL. 14, 337-346

DF7740 W.R.ADDISON ET AL. (1982) J. BIOL. CHEM. 257, 670-673

DF7920 F.MUELLER, S.G.CLARKSON (1980) CELL 19, 345-353

DF9160 A.ROSEN, V.DANIEL (1988) GENE 69, 275-283

DG0220 J.BROIDA, J.ABELSON (1985) J. MOL. BIOL. 185, 545-563

DG0260 V.N.KSENZENKO ET AL. (1987) NUCL. ACIDS RES. 15, 5480-5481

DG0860 B.P.KAINE (1987) J. MOL. EVOL. 25, 248-254

DG0960 J.KJEMS, H.LEFFERS, T.OLESEN, R.A.GARRETT (1989) J. BIOL. CHEM. 264, 17834-17837

DG1140 A.MUTO, Y.ANDACHI, H.YUZAWA, F.YAMAO, S.OSAWA (1990) NUCL. ACIDS RES. 18, $5037-$ 5043

DG1180 T.SAMUELSSON, T.BOREN, T.-I.JOHANSEN, F.LUSTIG (1988) J. BIOL. CHEM. 263, 13692 13699

DG1200 P.SIMONEAU, R.WENZEL, R.HERRMANN, P.C.HU (1990) NUCL. ACIDS RES . 18, 2814-2814

DG1350 R.SEDLMEIER, H.SCHMIEGER (1990) NUCL. ACIDS RES. 18, 4027-4027

DG1500 A.C.PITTET, H.HOTTINGER (1989) NUCL. ACIDS RES . 17, 4873-4873

DG1540 C.J.GREEN, G.C.STEWART, M.A.HOLLIS, B.S.VOLD, K.F.BOTT (1985) GENE 37, $261-266$

DG1541 E.F.WAWROUSEK, J.N.HANSEN (1983) J. BIOL. CHEM. 258, 291-298 C.J.GREEN,

DG1580 D.VOGEL ET AL. (1987) BIOCHEM. INT. 14, 167-175

DG1581 M.WEISSHAAR, R.AHMADIAN, M.SPRINZL, M.SATOH, A.KUSHIRO, K.TOMITA (1990) NUCL. ACIDS RES. 18, 1902-1902 
DG1660 G.AN, J.D.FRIESEN (1980) GENE 12, 33-39 L.HUDSON, J.ROSSI, A.LANDY (1981) NATURE 294, 422-427 A.MIYAJIMA, T.YOKOTA, Y.TAKEBE, N.NAKAMURA, Y.KAZIRO (1983) J . BIOCHEY. 93, 1101-1108

DG1661 S.D.TUCKER, E.J.MURGOLA (1985) BIOCHIMIE 67, 1053-1057

DG1662 Y.KOMINE, T.ADACHI, H.INOKUCHI, H.OZEKI (1990) J. MOL. BIOL. 212, 579-598

DG1820 M.A.HUGHES, D.S.JONES (1988) NUCL. ACIDS RES. 16, 7193-7193

DG2000 M.A.HAUSER, J.J.SCOCCA (1990) NUCL. ACIDS RES. 18, 5305-5305

DG2180 M.KUNTZ, J.-L.EVRARD, J.-H.WEIL (1988) NUCL. ACIDS RES. 16, 8733-8733

DG2440 D.ZHANG, R.J.SPREITZER (1989) NUCL. ACIDS RES. 17, 8873-8873

DG2520 R.B.HALLICK ET AL. (1984) PLANT. MOL. BIOL. 3, 169-175

DG2521 R.B.HALLICK ET AL. (1984) PLANT. MOL. BIOL. 3, 169-175

DG2600 K.UMESONO, H.INOKUCHI, K.OHYAMA, H.OZEKI (1984) NUCL. ACIDS RES. 12, 9551-9565

DG2601 K.OHYAMA ET AL. (1988) J. MOL. BIOL. 203, 281-298

DG2640 R.P.OLIVER, C.POULSEN (1984) CARLSBERG RES. COMMUN. 49, 647-673

DG2641 R.P.OLIVER, C.POULSEN (1984) CARLSBERG RES. COMMUN. 49, 647-673

DG2680 F.QUIGLEY, J.H.WEIL (1985) CURR. GENET. 9, 495-503 F.QUIGLEY, J.M.GRIENENBERGER, J.H.WEIL (1985) PLANT MOL. BIOL. 4, 305-310

DG2681 F.QUIGLEY, J.H.WEIL (1985) CURR. GENET. 9, 495-503

DG2920 M.SUGIURA, K.SHINOZAKI, M.OHME IN:NATO ASI SER; SER. A 83 (1985) (MOL. FORM FUNCT. PLANT GENOME) 325-334

DG2921 M.SUGIURA, K.SHINOZAKI, M.OHME IN:NATO ASI SER; SER. A 83 (1985) (MOL. FORM FUNCT. PLANT GENOME) 325-334

DG3200 J.LEHMBECK, B.M.STUMMANN, K.W.HENNINGSEN (1987) NUCL. ACIDS RES. 15, 3630-3630

DG3880 H.G.KOECHEL, C.M.LAZARUS, N.BASAK, H.KUENTZEL (1981) CELL 23, 625-633

DG3881 H.G.KOECHEL, C.M.LAZARUS, N.BASAK, H.KUENTZEL (1981) CELL 23, 625-633

DG4000 S.G.BONITZ, A.TZAGOLOFF (1980) J. BIOL. CHEM. 255, 9075-9081 D.L.MILLER, N.C.MARTIN (1981) CURR. GENET. 4, 135-143

DG4040 B.F.LANG ET AL. (1983) IN: MITOCHONDRIA 1983, R.J.SCHWEYEN, K.WOLF, F. KAUDEWITZ (ED) WALTER DE GRUYTER BERLIN PP.313-329

DG4080 G.D.CLARK-WALKER, C.R.MCARTHUR, K.S.SRIPRAKASH (1985) EMBO J. 4, 465-473

DG4320 E.BARTNIK, P.BORSUK (1986) NUCL. ACIDS RES. 14, 2407-2407

DG4640 D.R.WOLSTENHOLME ET AL. (1987) PROC. NATL. ACAD. SCI. USA 84, 1324-1328

DG4680 D.R.WOLSTENHOLME ET AL. (1987) PROC. NATL. ACAD. SCI. USA 84, 1324-1328

DG4760 H.-R.HAUCKE, G.GELLISSEN (1988) CURR. GENET. 14, 471-476

DG4800 D.T.DUBIN, C.C.HSUCHEN, L.E.TILLOTSON (1986) CURR. GENET. 10, 701-707

DG4840 D.R.WOLSTENHOLME, D.0.CLARY (1985) GENETICS 109, $725-744$

DG4880 D.0.CLARY, D.R.WOLSTENHOLME (1985) J. MOL. EVOL. 22, 252-271

DG4980 H.T.JACOBS, S.ASAKAWA, T.ARAKI, K.MIURA, M.J.SMITH, K.WATANABE (1989) CURR. GENET. 15, 193-206

DG5000 H.T.JACOBS, S.ASAKAWA, T.ARAKI, K.I.MIURA, M.J.SMITH, K.WATANABE (1989) CURR. GENET. 15, 193-206

DG5020 H.T.JACOBS, S.ASAKAWA, T.ARAKI, K.MIURA, M.J.SMITH, K.WATANABE (1989) CURR. GENET. 15, 193-206

DG5040 P.CANTATORE ET AL. (1988) CURR. GENET. 13, 91-96

DG5080 H.T.JACOBS, D.J.ELLIOTT, V.B.MATH, A.FARQUHARSON (1988) J. MOL. BIOL. 202, 185 217

DG5100 S.JOHANSEN, P.H.GUDDAL, T.JOHANSEN (1990) NUCL. ACIDS RES. 18, 411-419

DG5120 B.A.ROE, D.P.MA, R.K.WILSON, J.F.H.WONG (1985) J. BIOL. CHEM. 260, 9759-9774

DG5280 P.CANTATORE ET AL. (1982) NUCL. ACIDS RES. 10, 3279-3289 R.GROSSKOPF, H. FELDMANN (1981) CURR. GENET. 4, 151-158 G.PEPE ET AL. (1983) BIOCHEM. INT. 6, 553-563

DG5320 M.J.BIBB, R.A.VAN ETTEN, C.T.WRIGHT, M.W.WALBERG, D.A.CLAYTON (1981) CELL 26, $167-180$

DG5360 S.ANDERSON ET AL. (1982) J. MOL. BIOL. 156, 683-717

DG5880 S.ANDERSON ET AL. (1981) NATURE 290, 457-465

DG6280 H.J.DRABKIN, U.L.RAJBHANDARY (1985) J. BIOL. CHEM. 260, 5596-5602

DG7140 D. - P.MA, Y. -W. YANG (1988) NUCL. ACIDS RES. 16, 3588-3588

DG7180 P.S.REDDY, J.D.PADAYATTY (1988) PLANT MOL. BIOL. 11, 575-583

DG7680 A.FOURNIER ET AL. (1984) EMBO-J. 3, 1547-1552

DG7740 N.D.HERSHEY, N.DAVIDSON (1980) NUCL. ACIDS RES. 8, 4899-4910 
DG7741 Y.B.MENG ET AL. (1988) NUCL. ACIDS RES. 16, 7189-7189

DG8100 J.C.HU, B.D.COTE, E.LUND, J.E.DAHLBERG (1983) NUCL. ACIDS RES. 11, 4809-4821 J.E.LOONEY, J.D.HARDING (1983) NUCL. ACIDS RES. 11, 8761-8775 M.J.MORRY, J.D.HARDING (1986) MOL. CELL. BIOL. 6, 105-115

DG9160 T.SEKIYA, Y.KUCHINO, S.NISHIMURA (1981) NUCL. ACIDS RES. 9, 2239-2250 A.ROSEN, S.SARID, V.DANIEL (1984) NUCL. ACIDS RES. 12, 4893-4906

DG9161 A.ROSEN, S.SARID, V.DANIEL (1984) NUCL. ACIDS RES . 12, 4893-4906

DG9990 I.L.PIRTLE, R.D.SHORTRIDGE, R.M.PIRTLE (1986) GENE 43, 155-167

DG9991 R.D.SHORTRIDGE, I.L.PIRTLE, R.M.PIRTLE (1985) GENE 33, 269-277

DH0260 V.N.KSENZENKO ET AL. (1987) NUCL. ACIDS RES. 15, 5480-5481

DH0660 G.WICH, L.SIBOLD, A.BOECK (1986) SYSTEM. APPL. MICROBIOL. 7, 18-25

DH0680 E.S.HAAS, C.J.DANIELS, J.N.REEVE (1989) GENE 77, 253-263

DH1140 A.MUTO, Y.ANDACHI, H.YUZAWA, F.YAMAO, S.OSAWA (1990) NUCL. ACIDS RES. 18, 5037 5043

DH1540 E.F.WAWROUSEK, N.NARASIMHAN, J.N.HANSEN (1984) J. BIOL. CHEM. 259, 3694-3702

DH1541 C.J.GREEN, G.C.STEWART, M.A.HOLLIS, B.S.VOLD, K.F.BOTT (1985) GENE 37,261-266

DH1660 0.ORELLANA, L.COOLEY, D.SOELL (1986) MOL. CELL. BIOL. 6, 525-529

DH1700 L.BOSSI (1983) MOL. GEN. GENET. 192, 163-170

DH1740 S.GIROUX, R.CEDERGREN (1988) PROC. NATL. ACAD. SCI. USA 85, 9101-9105

DH1780 X.-R.GU, S.GIROUX, R.CEDERGREN (1988) NUCL. ACIDS RES. 16, 10936-10936

DH2520 R.B.HALLICK ET AL. (1984) PLANT. MOL. BIOL. 3, 169-175

DH2600 K. OHYAMA ET AL. (1988) J. MOL. BIOL. 203, 281-298

DH2720 Z.SCHWARZ, S.0.JOLLY, A.A.STEINMETZ, L.BOGORAD (1981) PROC. NATL. ACAD. SCI. USA $78,3423-3427$

DH2880 J.ALDRICH, B.W.CHERNEY, E.MERLIN, L.CHRISTOPHERSON (1988) CURR. GENET. 14, 137 146

DH2920 M.SUGIURA, K.SHINOZAKI, M.OHME IN:NATO ASI SER; SER. A 83 (1985) (MOL. FORM FUNCT. PLANT GENOME) 325-334

DH2960 G.ZURAWSKI, W.BOTTOMLEY, P.R.WITHFELD (1984) NUCL. ACIDS RES. 12, 6547-6558

DH3020 T.N.ULMASOV, M.K.GULOV, K.A.ALIEV, V.M.ANDRIANOV, E.S.PIRUZIAN (1990) NUCL. ACIDS RES. 18, 186-186

DH3120 J.ALDRICH, B.W.CHERNEY, E.MERLIN, L.CHRISTOPHERSON (1988) CURR. GENET. 14, 137 146

DH3200 D.R.SHAPIRO, K.K.TEWARI (1986) PLANT MOL. BIOL. $6,1-12$

DH3240 J.NICKELSEN, G.LINK (1990) NUCL. ACIDS RES. 18, 1051-1051

DH3280 G.ZURAWSKI, W.BOTTOMLEY, P.R.WHITFELD (1984) NUCL. ACIDS RES. 12, 6547-6558

DH3360 F.HERDENBERGER, D.T.N.PILLAY, A.STEINMETZ (1990) NUCL. ACIDS RES. 18, 1297-1297

DH3800 Y.SUYAMA (1985) NUCL. ACIDS RES. 13, 3273-3284

DH3880 R.NETZKER, H.G.KOECHEL, N.BAZAK, H.KUENTZEL (1982) NUCL. ACIDS RES. 10, 47834794

DH4000 J.L.BOS, K.A.OSINGA, G.VAN DER HORST, P.BORST (1979) NUCL. ACIDS RES. 6, $3255-$ 3266; R.E.BERLANI, C.PENTELLA, G.MACINO, A.TZAGOLOFF (1980) J. BACT. 141, 1086 1097

DH4040 B.F.LANG ET AL. (1983) IN: MITOCHONDRIA 1983, R.J.SCHWEYEN, K.WOLF, F.KAUDEWITZ (ED) WALTER DE GRUYTER BERLIN PP.313-329 D.R.MASSARDO (1990) NUCL. ACIDS RES. $18,6429-6429$

DH4080 G.D.CLARK-WALKER, C.R.MCARTHUR, K.S.SRIPRAKASH (1985) EMBO J. 4, 465-473

DH4480 K.P.IAMS, J.E.HECKMAN, J.H.SINCLAIR (1985) PLANT MOL. BIOL. 4, 225-232

DH4640 D.R. WOLSTENHOLME ET AL. (1987) PROC. NATL. ACAD. SCI. USA 84, 1324-1328

DH4680 D.R. WOLSTENHOLME ET AL. (1987) PROC. NATL. ACAD. SCI. USA 84, 1324-1328

DH4880 D.O.CLARY, D.R.WOLSTENHOLME (1985) J. MOL. EVOL. 22, 252-271

DH5000 H.HIMENO ET AL. (1987) GENE 56, 219-230

DH5040 P.CANTATORE ET AL. (1988) CURR. GENET. 13, 91-96

DH5080 H.T.JACOBS, D.J.ELLIOTT, V.B.MATH, A.FARQUHARSON (1988) J. MOL. BIOL. 202, 185 217

DH5100 S.JOHANSEN, P.H.GUDDAL, T.JOHANSEN (1990) NUCL. ACIDS RES. 18, 411-419

DH5120 B.A.ROE, D.P.MA, R.K.WILSON, J.F.H.WONG (1985) J. BIOL. CHEM. 260, 9759-9774

DH5280 R.GROSSKOPF, H.FELDMANN (1981) CURR. GENET. 4, 191-196 
DH5320 M.J.BIBB, R.A.VAN ETTEN, C.T.WRIGHT, M.W.WALBERG, D.A.CLAYTON (1981) CELL 26, $167-180$

DH5360 S.ANDERSON ET AL. (1982) J. MOL. BIOL. 156, 683-717

DH5440 K.HAYASAKA, T.GOJOBORI, S.HORAI (1988) MOL. BIOL. EVOL. 5(6), 626-644

DH5480 K.HAYASAKA, T.GOJOBORI, S.HORAI (1988) MOL. BIOL. EVOL. 5(6), 626-644

DH5520 K.HAYASAKA, T.GOJOBORI, S.HORAI (1988) MOL. BIOL. EVOL. 5(6), 626-644

DH5560 K.HAYASAKA, T.GOJOBORI, S.HORAI (1988) MOL. BIOL. EVOL. 5(6), 626-644

DH5600 K.HAYASAKA, T.GOJOBORI, S.HORAI (1988) MOL. BIOL. EVOL. 5(6), 626-644

DH5640 K.HAYASAKA, T.GOJOBORI, S.HORAI (1988) MOL. BIOL. EVOL. 5(6), 626-644

DH5680 K.HAYASAKA, T.GOJOBORI, S.HORAI (1988) MOL. BIOL. EVOL. 5(6), 626-644

DH5720 W.M.BROWN, E.M.PRAGER, A.WANG, A.C.WILSON (1982) J.MOL.EVOL. 18, 225-239

DH5760 W.M.BROWN, E.M.PRAGER, A.WANG, A.C.WILSON (1982) J. MOL. EVOL. 18, 225-239

DH5800 W.M.BROWN, E.M.PRAGER, A.WANG, A.C.WILSON (1982) J. MOL. EVOL. 18, 225-239

DH5840 W.M.BROWN, E.M.PRAGER, A.WANG, A.C.WILSON (1982) J. MOL. EVOL. 18, 225-239

DH5880 S.ANDERSON ET AL. (1981) NATURE 290, 457-465

W.M.BROWN, E.M.PRAGER, A.WANG, A.C.WILSON (1982) J. MOL. EVOL. 18, 225-239

DH6280

DH6320

F.DEL REY, T.F.DONAHUE, G.R.FINK (1983) J. BIOL. CHEM. 258, 8175-8182

DH7740 L.COOLEY, B.APPEL, D. SOELL (1982) PROC. NATL. ACAD. SCI. USA 79, 6475-6479

DH8100 M.J.MORRY, J.D.HARDING (1986) MOL. CELL. BIOL. 6, 105-115

DI0220 J.BROIDA, J.ABELSON (1985) J. MOL. BIOL. 185, 545-563

DI0260 V.N.KSENZENKO ET AL. (1987) NUCL. ACIDS RES. 15, 5480-5481

DI0660 G.WICH, L.SIBOLD, A.BOECK (1986) SYSTEM. APPL. MICROBIOL. 7, 18-25

DI0680 E.S.HAAS, C.J.DANIELS, J.N.REEVE (1989) GENE 77, 253-263

DI1140 A.MUTO, Y.ANDACHI, H.YUZAWA, F.YAMAO, S.OSAWA (1990) NUCL. ACIDS RES. 18, 5037. 5043

DI1141 A.MUTO, Y.ANDACHI, H.YUZAWA, F. YAMAO, S.OSAWA (1990) NUCL. ACIDS RES. 18, 5037 5043

DI1180 T.SAMUELSSON, P.ELIAS, F.LUSTIG, Y.S.GUINDY (1985) BIOCHEM. J. 232, 223-228

DI1260 M.J.ROGERS, A.A.STEINMETZ, R.T.WALKER (1986) NUCL. ACIDS RES. 14, 3145-3145

DI1540 C.J.GREEN, G.C.STEWART, M.A.HOLLIS, B.S.VOLD, K.F.BOTT (1985) GENE 37, 261-266

DI1541 C.J.GREEN, G.C.STEWART, M.A.HOLLIS, B.S.VOLD, K.F.BOTT (1985) GENE 37, 261-266

DI1542 C.J.GREEN, G.C.STEWART, M.A.HOLLIS, B.S.VOLD, K.F.BOTT (1985) GENE 37, $261-266$

DI1620 A.VENEGAS, E.HEVIA, H.SANCHEZ (1988) NUCL. ACIDS RES. 16, 8179-8179

DI1660 R.A.YOUNG, R.MACKLIS, J.A.STEITZ (1979) J. BIOL. CHEM. 254, 3264-3271

DI1661 T.MURAMATSU ET AL. (1988) NATURE 336, 179-181

DI1820 P.J.HOSIAUX, D.F.HILL, G.B.PETERSEN (1988) NUCL. ACIDS RES. 16, 2721-2721

DI1860 A.RASHTCHIAN, M.SCHAFFER (1986) NUCL. ACIDS RES. 14, 5560-5560

DI1900 J.FEINGOLD, V.BELLOFATTO, L.SHAPIRO, K.AMEMIYA (1985) J. BACT. 163, 155-166

DI2100 S.E.WILLIAMSON, W.F.DOOLITTLE (1983) NUCL. ACIDS RES. 11, 225-235 N.TOMIOKA, M. SUGIURA, (1984) MOL. GEN. GENET. 193, 427-430

DI2180 I.JANSSEN, H.MUCKE, W.LOEFFELHARDT, H.J.BOHNERT (1987) PLANT MOL. BIOL. 9,479 484

DI2220 Y.MARKOWICZ, R.MACHE, S.LOISEAUX-DE GOER (1988) PLANT MOL. BIOL. 10, 465-469

DI2440 M.SCHNEIDER, J.D.ROCHAIX (1986) PLANT MOL. BIOL. 6, 265-270

DI2480 T. YAMADA, M.SHIMAJI (1986) NUCL. ACIDS RES. 14, 3827-3839

DI2520 L.GRAF, H.KOESSEL, E.STUTZ (1980) NATURE 286, 908-910; T.MIYATA, R.KIKUNO, Y.OSHIMA (1982) NUCL. ACIDS RES. 10, 1771-1780 R.B.HALLICK ET AL. (1984) PLANT. MOL. BIOL. 3, 169-175 M.R.EL-GEWELY, R.B.HELLING, J.G.TH.DIBBITS (1984) MOL.

GEN. GENET. 194, 432-443

DI2550 J.R.MANHART, J.D.PALMER (1990) NATURE 345, 268-270

DI2600 K. OHYAMA ET AL. (1988) J. MOL. BIOL. 203, 281-298

DI2601 K. OHYAMA ET AL. (1988) J. MOL. BIOL. 203, 281-298

DI2620 J.R.MANHART, J.D.PALMER (1990) NATURE 345, 268-270

DI2720 W.KOCH, K.EDWARDS, H.KOESSEL (1981) CELL 25, 203-213; P.GUILLEMAUT, J.H.WEIL (1982) NUCL. ACIDS RES. 10, 1653-1659

DI2840 G.DE LANVERSIN, D.T.N.PILLAY, B.JACQ (1987) PLANT MOL. BIOL. 10, 65-82

DI2920 M.SUGIURA, K.SHINOZAKI, M.OHME IN:NATO ASI SER; SER. A 83 (1985) (MOL. FORM FUNCT. PLANT GENOME) 325-334 
2144 Nucleic Acids Research, Vol. 19, Supplement

DI2921 M.TANAKA ET AL. (1986) PROC. NATL. ACAD. SCI. USA 83, 6030-6034

DI2922 T.WAKASUGI, M.OHME, K.SHINOZAKI, M.SUGIURA (1986) PLANT MOL. BIOL. 7, 385-392

DI3080 G.H.LEARN, M.L.DURBIN, M.T.CLEGG (1988) NUCL. ACIDS RES. 16, 4734-4734

DI3280 M.A.KASHDAN, B.S.DUDOCK (1982) J. BIOL. CHEM. 257, 11191-11194 W.G.GRUISSEM, B.M.GREENBERG, G.ZURAWSKI, D.M.PRESCOTT, R.B.HALLICK (1983) CELL 35, 815-828

DI3281

DI3880

DI4000

DI4080

O.MASSENET, P.MARTINEZ, P.SEYER, J. - F.BRIAT (1987) PLANT MOL. BIOL. 10, 53-63

H.G.KOECHEL, C.M.LAZARUS, N.BASAK, H.KUENTZEL (1981) CELL 23, 625-633

DI4320

R.BORDONNE, G.DIRHEIMER, R.P.MARTIN (1987) NUCL. ACIDS RES. 15, $7381-7394$

G.D.CLARK-WALKER, C.R.MCARTHUR, K.S.SRIPRAKASH (1985) EMBBO J. 4, 465-473

F.WEBER, A.DIETRICH, J.WEIL, L.MARECHAL-DROUARD (1990) NUCL. ACIDS RES . 18, 5027-5030

DI4640 D.R. WOLSTENHOLME ET AL. (1987) PROC. NATL. ACAD. SCI. USA 84, 1324-1328

DI4880 D.0.CLARY, D.R.WOLSTENHOLME (1985) J. MOL. EVOL. 22, 252-271

DI4960 D.0.CLARY, D.R.WOLSTENHOLME (1987) J. MOL. EVOL. 25, 116-125

DI5040 P.CANTATORE ET AL. (1988) CURR. GENET. 13, 91-96

DI5080 H.T.JACOBS, D.J.ELLIOTT, V.B.MATH, A.FARQUHARSON (1988) J. MOL. BIOL. 202, 185 217

DI5120 B.A.ROE, D.P.MA, R.K.WILSON, J.F.H.WONG (1985) J. BIOL. CHEM. 260, 9759-9774

DI5160 H.FUJII, T.SHIMADA, Y.GOTO, T.OKAZAKI (1988) J. BIOCHEM. 103, 474-481

DI5280 P.CANTATORE ET AL. (1982) NUCL. ACIDS RES. 10, 3279-3289 D.R.WOLSTENHOLME, C.M. R.FAURON, J.M.GODDARD (1982) GENE 20, 63-69

DI5320 M.J.BIBB, R.A.VAN ETTEN, C.T.WRIGHT, M.W.WALBERG, D.A.CLAYTON (1981) CELL 26, $167-180$

DI5360 S.ANDERSON ET AL. (1982) J. MOL. BIOL. 156, 683-717

DI5880 S.ANDERSON ET AL. (1981) NATURE 290, 457-465

DI6280 F.FELICI, G.CESARENI (1987) NUCL. ACIDS RES. 15, 364-364

DI6400 C.L.PEEBLES, P.GEGENHEIMER, J.ABELSON (1983) CELL 32, 525-536

DI7740 B.HOVEMANN, S.SHARP, H.YAMADA, D.SOELL (1980) CELL 19, 889-895 R.R.ROBINSON,

N.DAVIDSON (1981) CELL 23, 251-259

DI8100 T.RUSSO ET AL. (1987) NUCL. ACIDS RES. 15, 8562-8562

DK0260 S.M.DESAI, J.VAUGHAN, S.B.WEISS (1986) NUCL. ACIDS RES . 14, 4197-4205

DK0660 G.WICH, M.JARSCH, A.BOECK (1984) MOL. GEN. GENET. 196, 146-151

DK0680 E.S.HAAS, C.J.DANIELS, J.N.REEVE (1989) GENE 77, 253-263

DK0740 G.WICH, L.SIBOLD, A.BOECK (1987) Z. NATURFORSCH. 42c, 373-380

DK1140 Y.ANDACHI ET AL. (1987) PROC. NATL. ACAD. SCI. USA 84, 7398-7402

DK1141 A.MUTO, Y.ANDACHI, H.YUZAWA, F.YAMAO, S.OSAWA (1990) NUCL. ACIDS RES. 18, 5037 5043

DK1200 P.SIMONEAU, R.WENZEL, R.HERRMANN, P.C.HU (1990) NUCL. ACIDS RES. 18, $2814-2814$

DK1220 O.F.RASMUSSEN, J.FRYDENBERG, C.CHRISTIANSEN (1987) MOL. GEN. GENET. 208, 23-29

DK1350 R.SEDLMEIER, H.SCHMIEGER (1990) NUCL. ACIDS RES. 18, 4027-4027

DK1540 Y.YAMADA, M.OHKI, H.ISHIKURA (1983) NUCL. ACIDS RES. 11, 3037-3045 C.J.GREEN, G.C.STEWART, M.A.HOLLIS, B.S.VOLD, K.F.BOTT (1985) GENE 37, 261-266

DK1660 M.YOSHIMURA, M.KIMURA, M.OHNO, H.INOKUCHI, H.OZEKI (1984) J. MOL. BIOL. 177 , $609-625$

DK2000 M.A.HAUSER, J.J.SCOCCA (1990) NUCL. ACIDS RES. 18, 5305-5305

DK2520 T.MANZARA, J.X.HU, C.A.PRICE, R.B.HALLICK (1987) PLANT MOL. BIOL 8, 327-336

DK2600 K. OHYAMA ET AL. (1988) J. MOL. BIOL. 203, 281-298

DK2920 M.SUGITA, K.SHINOZAKI, M.SUGIURA (1985) PROC. NATL. ACAD. SCI. USA 82, 3557-3561

DK3200 S.K.BOYER, J.E.MULLET (1988) PHOTOSYNTHESIS RES . 17, 7-22

DK3240 H.NEUHAUS, G.LINK (1987) CURR.GEN. 11, 251-257

DK3880 H.G.KOECHEL, C.M.LAZARUS, N.BASAK, H.KUENTZEL (1981) CELL 23, 625-633

DK4000 S.G.BONITZ, A.TZAGOLOFF (1980) J. BIOL. CHEM. 255, 9075-9081 D.L.MILLER, N.C.MARTIN (1981) CURR. GENET. 4, 135-143

DK4050 C.M.HARDY, G.D.CLARK-WALKER (1989) NUCL. ACIDS RES. 17, 1762-1762

DK4080 G.D.CLARK-WALKER, C.R.MCARTHUR, K.S.SRIPRAKASH (1985) EMBO J. 4, 465-473

DK4440 P.B.M.JOYCE, M.W.GRAY (1989) BIOCHIM. BIOPHYS. ACTA 1008, $355-356$

DK4480 A.SANGARE, D.LONSDALE, J.H.WEIL, J.M.GRIENENBERGER (1989) CURR. GENET. 16, 195201

DK4640 D.R. WOLSTENHOLME ET AL. (1987) PROC. NATL. ACAD. SCI. USA 84, 1324-1328 
DK4680 R.OKIMOTO, D.R.WOLSTENHOLME (1990) EMBO J. 9, 3405-3411

DK4760 H. -R.HAUCKE, G.GELLISSEN (1988) CURR. GENET. 14, 471-476

DK4840 M.H.L.DE BRUIN (1983) NATURE 304, 234-241

DK4880

D.O.CLARY, D.R.WOLSTENHOLME (1985) J. MOL. EVOL. 22, 252-271

DK5040

P.CANTATORE ET AL. (1989) J. BIOL. CHEM. 264, 10965-10975

DK5080

H.T.JACOBS, D.J.ELLIOTT, V.B.MATH, A.FARQUHARSON (1988) J. MOL. BIOL. 202,185217

DK5100 S.JOHANSEN, P.H.GUDDAL, T.JOHANSEN (1990) NUCL. ACIDS RES. 18, 411-419

DK5120

B.A.ROE, D.P.MA, R.K.WILSON, J.F.H.WONG (1985) J. BIOL. CHEM. 260, 9759-9774

DK5220

Y.H.W.LEE, L.L.LIAW, T.T.YUNG, S.J.LO (1989) NUCL. ACIDS RES. 17, 9477-9477

DK5280 R.GROSSKOPF, H.FELDMANN (1981) CURR. GENET. 4, 151-158

DK5281 P.CANTATORE ET AL. (1982) NUCL. ACIDS RES. 10, 3279-3289 G.PEPE ET AL (1983) BIOCHEM. INT. 6, 553-563

DK5320 M.J.BIBB, R.A.VAN ETTEN, C.T.WRIGHT, M.W.WALBERG, D.A.CLAYTON (1981) CELL 26, $167-180$

DK5360 S.ANDERSON ET AL. (1982) J. MOL. BIOL. 156, 683-717

DK5880 S.ANDERSON ET AL. (1981) NATURE 290, 457-465

DK6050 D.A.CAMPBELL (1989) NUCL. ACIDS RES. 17, $9479-9479$

DK6280 F.J.DEL REY, T.F.DONAHUE, G.R.FINK (1982) PROC. NATL. ACAD. SCI. USA 79, 4138 4142

DK6281 P.NELBOECK, R.STUCKA, H.FELDMANN (1985) BIOL. CHEM. HOP. -SEY. 336, 1041-1051

DK6320 V.GAMULIN ET AL. (1983) NUCL. ACIDS RES. 11, 8537-8546

DK7560 T.A.TRANQUILLA, R.CORTESE, D.MELTON, J.D.SMITH (1982) NUCL. ACIDS RES. 10, 7919 7934

DK7680 A.FOURNIER, M.A.GUERIN, S.G.CLARKSON (1986) NUCL. ACIDS RES. 14, 1915-1915

DK7740 D.DEFRANCO, O.SCHMIDT, D.SOELL (1980) PROC. NATL. ACAD. SCI. USA 77, 3365-3368 B.HOVEMANN, S.SHARP, H.YAMADA, D.SOELL (1980) CELL 19, 889-895 P.H.YEN,

N.DAVIDSON (1980) CELL 22, 137-148

DK7741 D.DEFRANCO ET AL. (1982) NUCL. ACIDS RES. 10, 5799-5808

DK7920 F.MUELLER, S.G.CLARKSON, D.J.GALAS (1987) NUCL. ACIDS RES. 15, 7191-7191

A.MAZABRAUD ET AL. (1987) J. MOL. BIOL. 195, 835-845

DK8040 S.WITTIG, B.WITTIG (1982) NATURE 297, 31-38

DK8100 J.H.HAN, J.D.HARDING (1983) NUCL. ACIDS RES. 11, 2053-2064

DK8101 T.RUSSO ET AL. (1987) NUCL. ACIDS RES. 15, 8562-8562

DK9160 T.SEKIYA, R.NISHIZAWA, K.MATSUDA, Y.TAYA, S.NISHIMURA (1982) NUCL. ACIDS RES. $10,6411-6419$

DK9990 K.L.ROY, H.COOKE, R.BUCKLAND (1982) NUCL. ACIDS RES. 10, 7313-7322

DK9991 L.C.CRAIG ET AL. (1989) DNA 8, 457-471

DL0220 J.BROIDA, J.ABELSON (1985) J. MOL. BIOL. 185, 545-563

DL0260 V.N.KSENZENKO ET AL. (1987) NUCL. ACIDS RES. 15, $5480-5481$

DL0660 G.WICH, L.SIBOLD, A.BOECK (1986) SYSTEM. APPL. MICROBIOL. 7, 18-25

DL0680 E.S.HAAS, C.J.DANIELS, J.N.REEVE (1989) GENE 77, 253-263

DL0860 B.P.KAINE, R.GUPTA, C.R.WOESE (1983) PROC. NATL. ACAD SCI. USA 80, 3309-3312

DL0980 G.WICH, W.LEINFELDER, A.BOECK (1987) EMBO J. 6, 523-528

DL0981 G.WICH, W.LEINFELDER, A.BOECK (1987) EMBO J. 6, 523-528

DL1140 Y.ANDACHI ET AL. (1987) PROC. NATL. ACAD. SCI. USA 84, 7398-7402

DL1141 L.GAFNY, H.C. HYMAN, S.RAZIN, G.GLASER (1988) NUCL. ACIDS RES . 16, 61-7

DL1200 P.SIMONEAU, R.WENZEL, R.HERRMANN, P.C.HU (1990) NUCL. ACIDS RES. 18, 2814-2814

DL1220 O.F.RASMUSSEN, J.FRYDENBERG, C.CHRISTIANSEN (1987) MOL. GEN. GENET. 208, 23-29

DL1310 E.J.LAWLOR, H.A.BAYLIS, K.F.CHATER 1987 GEN. DEVELOP. 1, 1305-1310

DL1540 C.J.GREEN, G.C.STEWART, M.A.HOLLIS, B.S.VOLD, K.F.BOTT (1985) GENE 37, 261-266

DL1541 C.J.GREEN, G.C.STEWART, M.A.HOLLIS, B.S.VOLD, K.F.BOTT (1985) GENE 37, 261-266

DL1542 C.J.GREEN, G.C.STEWART, M.A.HOLLIS, B.S.VOLD, K.F.BOTT (1985) GENE 37, $261-266$

DL1543 C.J.GREEN, G.C.STEWART, M.A.HOLLIS, B.S.VOLD, K.F.BOTT (1985) GENE 37, 261-266

DL1660 G.DUESTER, R.K.CAMPEN, W.M.HOLMES (1981) NUCL. ACIDS RES. 9, 2121-2139 L.M.HSU, H.J.KLEE, J.ZAGORSKI, M.J.FOURNIER (1984) J. BACT. 158, 934-942

DL1661 N.NAKAJIMA, H.OZEKI, Y.SHIMURA (1981) CELL 23, 239-249

DL1662 M.YOSHIMURA, H.INOKUCHI, H.OZEKI (1984) J. MOL. BIOL. 177, 627-644

DL1663 Y.KOMINE, T.ADACHI, H.INOKUCHI, H.OZEKI (1990) J. MOL. BIOL. 212, 579-598 
DL1664 Y.KOMINE, T.ADACHI, H.INOKUCHI, H.OZEKI (1990) J. MOL. BIOL. 212, 579-598

DL1700 L.BOSSI (1983) MOL. GEN. GENET. 192, 163-170

DL1750 N.FTOUHI, R.CEDERGREN (1990) NUCL. ACIDS RES. 18, 3662-3662

DL1780 X.-R.GU, S.GIROUX, R.CEDERGREN (1988) NUCL. ACIDS RES. 16, 10936-10936

DL1940 B.BOESTEN, G.LENZEN, A.DANCHIN, F.0'GARA (1987) GENE 55, 153-156

DL1980 I.CREMON, G.LENZEN, A.ULIMANN, A.DANCHIN (1987) FEMS MICROBIOL. LETTERS 44, 1922

DL2000 M.A.HAUSER, J.J.SCOCCA (1990) NUCL. ACIDS RES. 18, 5305-5305

DL2180 J. -L.EVRARD, M.KUNTZ, N.A.STRAUS, J. -H.WEIL (1988) GENE 71, 115-122

DL2520 R.B.HALLICK ET AL. (1984) PLANT. MOL. BIOL. 3, 169-175

DL2521 R.B.HALLICK ET AL. (1984) PLANT. MOL. BIOL 3, 169-175

DL2522 A.MONFORT, B.RUTTI E.STUTZ (1986) NUCL. ACIDS RES. 14, 3971-3971

DL2600 K. OHYAMA ET AL. (1988) J. MOL. BIOL. 203, 281-298

DL2601 K. OHYAMA ET AL. (1988) J. MOL. BIOL. 203, 281-298

DL2602 K. OHYAMA ET AL. (1988) J. MOL. BIOL. 203, 281-298

DL2720 A.STEIMMETZ, E.J.GUBBINS, L.BOGORAD (1982) NUCL. ACIDS RES. 10, 3027-3037

DL2721 A.A.STEIMETZ, E.T.KREBBERS, Z.SCHWARZ, E.J.GUBBINS, L. BOGORAD (1983) J. BIOL. CHEM. 258, 5503-5511

DL2800 M.DRON, C.HARTMANN, A.RODE, M.SEVIGNAC (1985) NUCL. ACIDS RES. 13, 8603-8610

DL2920 A.KATO, F.TAKAIWA, K.SHINOZAKI, M.SUGIURA (1985) CURR. GENET . 9, 405-409

DL2921 K. YAMADA, K.SHINOZAKI, M.SUGIURA (1986) PLANT MOL. BIOL. 6, 193-199

DL2922 T.WAKASUGI, M.OHME, K.SHINOZAKI, M.SUGIURA (1986) PLANT MOL. BIOL. 7, 385-392

DL3200 D.R.SHAPIRO, K.K.TEWARI (1986) PLANT MOL. BIOL. 6, 1-12

DL3280 D. -X.ZHOU, F.QUIGLEY, R.MACHE (1987) NUCL. ACIDS RES. 15, 3621-3621

DL3360 G.BONNARD, J.H.WEIL, A.STEINMETZ (1985) CURR. GENET. 9, 417-422

DL3361 G.BONNARD, J.H.WEIL, A.STEINMETZ (1985) CURR. GENET . 9, 417-422

DL3400 D.P.MA, J.DOEBLEY (1986) GENE 43, 169-174

DL3800 T.Y.K.HEINONEN, M.N.SCHNARE, P.G.YOUNG, M.W.GRAY (1987) J. BIOL. CHEM. 262, 2879-2887 Y. SUYAMA, F.JENNEY, N.OKAWA (1987) CURR. GENET. 11, 327-330

DL3840 G.B.MORIN, T.R.CECH (1988) NUCL. ACIDS RES. 16, 327-346

DL3880 H.G.KOECHEL, C.M.LAZARUS, N.BASAK, H.KUENTZEL (1981) CELL 23, 625-633

DL3881 H.G.KOECHEL, C.M.LAZARUS, N.BASAK, H.KUENTZEL (1981) CELL 23, 625-633

DL4040 B.F.LANG ET AL. (1983) IN: MITOCHONDRIA 1983, R.J.SCHWEYEN, K. WOLF, F. KAUDEWITZ (ED) WALTER DE GRUYTER BERLIN PP.313-329

DL4050 C.M.HARDY, G.D.CLARK-WALKER (1989) NUCL. ACIDS RES. 17, 1762-1762

DL4080 G.D.CLARK-WALKER, C.R.MCARTHUR, K.S.SRIPRAKASH (1985) EMBO J. 4, 465-473

DL4120 B.BERLANI, S.G.BONITZ, G.CORUZZI, M.NOBREGA, A.TZAGOLOFF (1980) NUCL. ACIDS RES. $8,5017-5030$

DL4640 D.R.WOLSTENHOLME ET AL. (1987) PROC. NATL. ACAD. SCI. USA 84, 1324-1328

DL4641 D.R.WOLSTENHOLME ET AL. (1987) PROC. NATL. ACAD. SCI. USA 84, 1324-1328

DL4680 R.OKIMOTO, D.R.WOLSTENHOLME (1990) EMBO J. 9, 3405-3411

DL4681 R.OKIMOTO, D.R.WOLSTENHOLME (1990) EMBO J. 9, 3405-3411

DL4760 I.UHLENBUSCH, R.M.RIPPE, G.GELLISSEN (1987) NATURWISSENSCHAFTEN 74, $142-143$

DL4761 H.R.HAUCKE, G.GELLISSEN (1988) CURR. GENET. 14, 471-476

DL4800 C-C.HSUCHEN, R.M.KOTIN, D.T.DUBIN (1984) NUCL. ACIDS RES. 12, 7771-7785

DL4840 M.H.L.DE BRUIJN (1983) NATURE 304, 234-241

DL4880 D. O.CLARY, D.R. WOLSTENHOLME (1985) J. MOL. EVOL. 22, 252-271

DL4921 D.0.CLARY, D.R.WOLSTENHOLME (1985) J. MOL. EVOL. 22, 252-271

DL4980 H.T.JACOBS, S.ASAKAWA, T.ARAKI, K.MIURA, M.J.SMITH, K. WATANABE (1989) CURR. GENET. 15, 193-206

DL4981 H.T.JACOBS, S.ASAKAWA, T.ARAKI, K.MIURA, M.J.SMITH, K.WATANABE (1989) CURR. GENET. 15, 193-206

DL5000 H.T.JACOBS, S.ASAKAWA, T.ARAKI, K.MIURA, M.J.SMITH, K.WATANABE (1989) CURR.

DL5001 H.T.JACOBS, S.ASAKAWA, T.ARAKI, K.MIURA, M.J.SMITH, K.WATANABE (1989) CURR.

DL5020 H.T.JACOBS, S.ASAKAWA, T.ARAKI, K.MIURA, M.J.SMTTH, K.WATANABE (1989) CURR. GENET. 15, 193-206 
Nucleic Acids Research, Vol. 19, Supplement 2147

DL5021 H.T.JACOBS, S.ASAKAWA, T.ARAKI, K.MIURA, M.J.SMITH, K.WATANABE (1989) CURR. GENET. 15, 193-206

DL5040 P.CANTATORE ET AL. (1988) CURR. GENET. 13, 91-96

DL5041 P.CANTATORE ET AL. (1988) CURR. GENET. 13, 91-96

DL5080 H.T.JACOBS, D.J.ELLIOTT, V.B.MATH, A.FARQUHARSON (1988) J. MOL. BIOL. 202, 185217

DL5081 H.T.JACOBS, D.J.ELLIOTT, V.B.MATH, A.FARQUHARSON (1988) J. MOL. BIOL. 202, 185217

DL5100 S.JOHANSEN, P.H.GUDDAL, T.JOHANSEN (1990) NUCL. ACIDS RES. 18, 411-419

DL5120 B.A.ROE, D.P.MA, R.K.WILSON, J.F.H.WONG (1985) J. BIOL. CHEM. 260, $9759-9774$

DL5121 B.A.ROE, D.P.MA, R.K.WILSON, J.F.H.WONG (1985) J. BIOL. CHEM. 260, $9759-9774$

DL5160 Y.YONEYAMA (1987) J. NIPPON MED. SCH. 54, 429-440

DL5280 R.GROSSKOPF, H.FELDMANN (1981) CURR. GENET. 4, 191-196

DL5281 G.SACCONE ET AL. (1981) NUCL. ACIDS RES. 9, 4139-4148

DL5320 M.J.BIBB, R.A.VAN ETTEN, C.T.WRIGHT, M.W.WALBERG, D.A.CLAYTON (1981) CELL 26, $167-180$

DL5321 M.J.BIBB, R.A.VAN ETTEN, C.T.WRIGHT, M.W.WALBERG, D.A.CLAYTON (1981) CELL 26, $167-180$

DL5360 S.ANDERSON ET AL. (1982) J. MOL. BIOL. 156, 683-717

DL5361 S.ANDERSON ET AL. (1982) J. MOL. BIOL. 156, 683-717

DL5440 K.HAYASAKA, T.GOJOBORI, S.HORAI (1988) MOL. BIOL. EVOL. 5(6), 626-644

DL5480 K.HAYASAKA, T.GOJOBORI, S.HORAI (1988) MOL. BIOL. EVOL. 5(6), 626-644

DL5520 K.HAYASAKA, T.GOJOBORI, S.HORAI (1988) MOL. BIOL. EVOL. 5(6), 626-644

DL5560 K.HAYASAKA, T.GOJOBORI, S.HORAI (1988) MOL. BIOL. EVOL. 5(6), 626-644

DL5600 K.HAYASAKA, T.GOJOBORI, S.HORAI (1988) MOL. BIOL. EVOL. 5(6), 626-644

DL5640 K.HAYASAKA, T.GOJOBORI, S.HORAI (1988) MOL. BIOL. EVOL. 5(6), 626-644

DL5680 K. HAYASAKA, T.GOJOBORI, S.HORAI (1988) MOL. BIOL. EVOL. 5(6), 626-644

DL5720 W.M.BROWN, E.M.PRAGER, A.WANG, A.C.WILSON (1982) J. MOL. EVOL. 18, 225-239

DL5760 W.M.BROWN, E.M.PRAGER, A.WANG, A.C.WILSON (1982) J. MOL. EVOL. 18, 225-239

DL5800 W.M.BROWN, E.M.PRAGER, A.WANG, A.C.WILSON (1982) J. MOL. EVOL. 18, 225-239

DL5840 W.M.BROWN, E.M.PRAGER, A.WANG, A.C.WILSON (1982) J. MOL. EVOL. 18, 225-239

DL5880 S.ANDERSON ET AL. (1981) NATURE 290, 457-465 W.M.BROWN, E.M.PRAGER, A.WANG,

A.C.WILSON (1982) J. MOL. EVOL. 18, 225-239

DL5881 S.ANDERSON ET AL. (1981) NATURE 290, 457-465

DL6200 L.HUIET, B.M.TYLER, N.H.GILES (1984) NUCL. ACIDS RES. 12, 5757-5765

DL6280 D.N.STANDRING, A.VENEGAS, W.J.RUTTER (1981) PROC. NATL. ACAD. SCI. USA 78, 59635967 A.ANDREADIS, Y-P.HSU, G.B.KOHLHAW, P.SCHIMMEL (1982) CELL 31, 319-325

DL6980 G.A.GREEN, L.MARECHAL, J.-H.WEIL, P.GUILLEMAUT (1987) PLANT MOL. BIOL. 10, 13-19

DL7560 T.A.TRANQUILLA, R.CORTESE, D.MELTON, J.D.SMITH (1982) NUCL. ACIDS RES. 10, 79197934

DL7740 R.R.ROBINSON, N.DAVIDSON (1981) CELL 23, 251-259

DL7741 L.GLEW ET AL. (1986) GENE 44, 307-314

DL7920 G.GALLI, H.HOFSTETTER, M.L.BIRNSTIEL (1981) NATURE 294, 626-631

DL8100 B.M.ROSS, J.E.LOONEY, J.D.HARDING (1986) NUCL. ACIDS RES . 14, 5567-5567

DL9160 D.R.MAKOWSKI, R.A.HAAS, K.P.DOLAN, D.GRUNBERGER (1983) NUCL. ACIDS RES. 11, 86098624

DL9161 A.ROSEN, S.SARID, V.DANIEL (1984) NUCL. ACIDS RES. 12, 4893-4897

DL9162 K.SHIBUYA, S.NOGUCHI, M.YAMAKI, S.NISHIMURA, T.SEKIYA (1985) J. BIOCHEM. 97 , $1719-1725$

DL9990 K.L.ROY, H.COCK, R.BUCKLAND (1982) NUCL. ACIDS RES . 10, 7313-7322

DL9991 Y.-N.CHANG, I.L.PIRTLE, R.M.PIRTLE (1986) GENE 48, 165-174

DM0260 V.N.KSENZENKO ET AL. (1987) NUCL. ACIDS RES. 15, 5480-5481

DM0960 J.KJEMS, H.LEFFERS, T.OLESEN, I.HOLZ, R.A.GARRETT (1990) SYSTEM. APPL. MICROBIOL. 13, 117-127

DM1140 A.MUTO, Y.ANDACHI, H.YUZAWA, F.YAMAO, S.OSAWA (1990) NUCL. ACIDS RES. 18, $5037-$ 5043

DM1180 T.SAMUELSSON, P.ELIAS, F.LUSTIG, Y.S.GUINDY (1985) BIOCHEM. J. 232, 223-228

DM1260 M.J.ROGERS, A.A.STEINMETZ, R.T.WALKER (1986) NUCL. ACIDS RES. 14, 3145-3145

DM1540 E.F.WAWROUSEK, N.NARASIMHAN, J.N.HANSEN (1984) J. BIOL. CHEM. 259, 3694-3702 
2148 Nucleic Acids Research, Vol. 19, Supplement

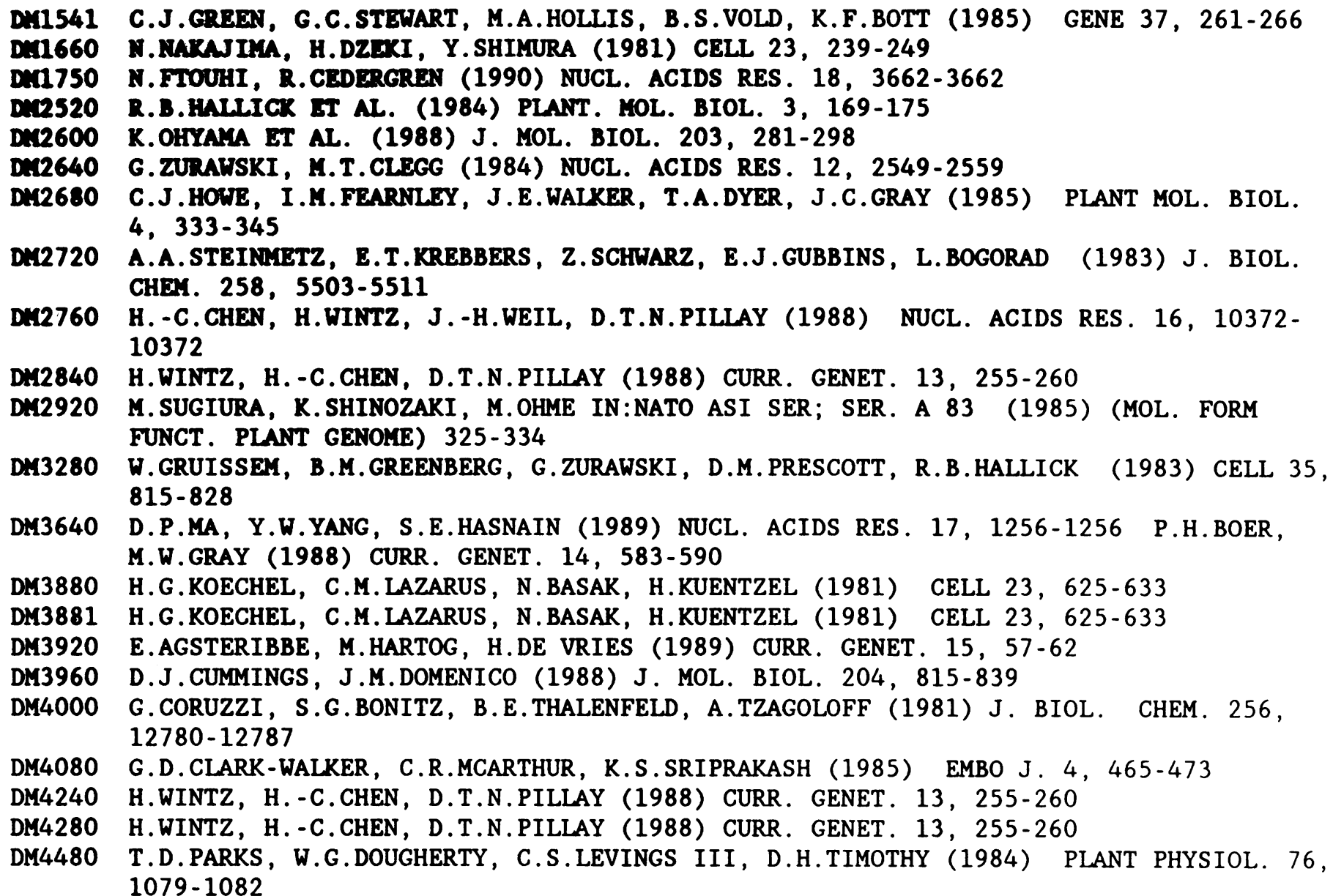

DM4481 A.SANGARE, D.LONSDALE, J.H.WEIL, J.M.GRIENENBERGER (1989) CURR. GENET. 16, 195 201

DM5000 H.T.JACOBS, S.ASAKAWA, T.ARAKI, K.MIURA, M.J.SMITH, K.WATANABE (1989) CURR. GENET. 15, 193-206

DM6280 J.OLAH, H. FELDMANN (1980) NUCL. ACIDS RES. 8, 1975-1986

DM6900 C.WALDRON, N.WILLS, R.F.GESTELAND (1985) J. MOL. APPL. GENET. 3, 7-17

DM7740 S.SHARP ET AL. (1981) NUCL. ACIDS RES . 9, 5867-5882

DN0660 G.WICH, L.SIBOLD, A.BOECK (1986) SYSTEM. APPL. MICROBIOL. 7, 18-25

DN0680 E.S.HAAS, C.J.DANIELS, J.N.REEVE (1989) GENE 77, 253-263

DN1140 A.MUTO, Y.ANDACHI, H.YUZAWA, F.YAMAO, S.OSAWA (1990) NUCL. ACIDS RES. 18, $5037-$ 5043

DN1180 T.SAMUELSSON ET AL. (1987) PROC. NATL. ACAD. SCI. USA 84, 3166-3170

DN1350 R.SEDLMEIER, H.SCHMIEGER (1990) NUCL. ACIDS RES. 18, 4027-4027

DN1351 R.SEDLMEIER, H.SCHMIEGER (1990) NUCL. ACIDS RES. 18, 4027-4027

DN1500 A.C.PITTET, H.HOTTINGER (1989) NUCL. ACIDS RES. 17, 4873-4873

DN1540 C.J.GREEN, G.C.STEWART, M.A.HOLLIS, B.S.VOLD, K.F.BOTT (1985) GENE 37, $261-266$

DN1541 E.F.WAWROUSEK, J.N.HANSEN (1983) J. BIOL. CHEM. 258, 291-298 E.F.WAWROUSEK, N.NARASIMHAN, J.N.HANSEN (1984) J. BIOL. CHEM. 259, 3694-3702

DN1660 Y.KOMINE, T.ADACHI, H.INOKUCHI, H.OZEKI (1990) J. MOL. BIOL. 212, 579-598

DN2520 R.B.HALLICK ET AL. (1984) PLANT. MOL. BIOL. 3, 169-175

DN2600 K.OHYAMA ET AL. (1988) J. MOL. BIOL. 203, 281-298

DN2720 D.DORMANN-PRZYBYL, G.STRITTMATTER, H.KOESSEL (1986) PLANT MOL. BIOL. 7, 419-431

DN2920 M.SUGIURA, K.SHINOZAKI, M.OHME IN:NATO ASI SER; SER. A 83 (1985) (MOL. FORM FUNCT. PLANT GENOME) $325-334$

DN3200 D.R.SHAPIRO, K.K.TEWARI (1986) PLANT MOL. BIOL. 6, 1-12

DN3320 R.J.A.KEUS ET AL. (1984) NUCL. ACIDS RES. 12, 5639-5646

DN3880 R.NETZKER, H.G.KOECHEL, N.BASAK, H.KUENTZEL (1982) NUCL. ACIDS RES. 10, 4783 4794 E.GRISI, T.A.BROWN, R.B.WARING, C.SCAZZOCCHIO, R.W.DAVIES (1982) NUCL. ACIDS RES. 10, 3531-3539 
DN3960

DN4000

DN4080

DN4320

DN4400

DN4440

DN4640

DN4680

DN4800

DN4880

DN4980

DN5000

DN5020

DN5040

DN5080

DN5100

DN5120

DN5160

DN5280

DN5281

DN5282

DN5320

DN5360

DN5880

DN6060

DN7100

DN7740

DN7920

DN9990

DN9991

DP0220

DP0260

DP0660

DP0680

DP0740

DP1140

DP1180

DP1260

DP1500

DP1540

DP1660

DP1661

DP1662

DP1700

DP1740

DP1780

DP2520

DP2600

DP2601

DP2680

D.J.CUMAINGS, J.M.DOMENICO (1988) J. MOL. BIOL. 204, 815-839

G.CORUZZI, S.G.BONITZ, B.E.THALENFELD, A.TZAGOLOFF (1981) J. BIOL. CHEM. 256, $12780-12787$

G.D.CLARK-WALKER, C.R.MGARTHUR, K.S.SRIPRAKASH (1985) EMBO J. 4, 465-473

B.KARPINSKA, H.AUGUSTYNIAK (1988) NUCL.ACIDS.RES 16, 6239-6239

S.BIRD, B.DUNCKER, P.GARBER, L.BONEN (1989) NUCL. ACIDS RES. 17, 4379-4379

P.B.M.JOYCE, M.W.GRAY (1989) NUCL. ACIDS RES. 17, 7865-7878

D.R.WOLSTENHOLME ET AL. (1987) PROC. NATL. ACAD. SCI. USA 84, 1324-1328

R.OKIMOTO, D.R.WOLSTENHOLME (1990) EMBO J. 9, 3405-3411

D.T.DUBIN, C-C.HSUCHEN, L.E.TILLOTSON (1986) CURR. GENET. 10, 701-707

D.O.CLARY, D.R. WOLSTENHOLME (1985) J. MOL. EVOL. 22, 252-271

H.T.JACOBS, S.ASAKAWA, T.ARAKI, K.MIURA, M.J.SMITH, K.WATANABE (1989) CURR. GENET. 15, 193-206

H.T.JACOBS, S.ASAKAWA, T.ARAKI, K.MIURA, M.J.SMITH, K.WATANABE (1989) CURR. GENET. 15, 193-206

H.T.JACOBS, S.ASAKAWA, T.ARAKI, K.MIURA, M.J.SMITH, K.WATANABE (1989) CURR. GENET. 15, 193-206

P.CANTATORE ET AL. (1988) CURR. GENET. 13, $91-96$

H.T.JACOBS, D.J.ELLIOTT, V.B.MATH, A.FARQUHARSON (1988) J. MOL. BIOL. 202, 185 217

S.JOHANSEN, P.H.GUDDAL, T.JOHANSEN (1990) NUCL. ACIDS RES. 18, 411-419

B.A.ROE, D.P.MA, R.K.WILSON, J.F.H.WONG (1985) J. BIOL. CHEM. 260, 9759-9774

Y. YONEYAMA (1987) J. NIPPON MED. SCH. 54, 429-440

P.CANTATORE ET AL. (1982) NUCL. ACIDS RES. 10, 3279-3289 G.PEPE ET AL. (1983)

BIOCHEM. INT . 6, 553-563

R.GROSSKOPF, H.FELDMANN (1981) CURR. GENET . 4, 191-196

M. TAIRA ET AL. (1983) NUCL. ACIDS RES. 11, 1635-1643

M.J.BIBB, R.A.VAN ETTEN, C.T.WRIGHT, M.W.WALBERG, D.A.CLAYTON (1981) CELL 26, $167-180$

S.ANDERSON ET AL. (1982) J. MOL. BIOL. 156, 683-717

S.ANDERSON ET AL. (1981) NATURE 290, 457-465

H.ENDOH, S.NAGAHASHI, N.OKADA (1989) NUCL. ACIDS RES. 17, 10122-10122

N.BAWNIK, J.S.BECKMANN, S.SARID, V.DANIEL (1983) NUCL. ACIDS RES. 11, 1117-1122

A.LOFQUIST, S.SHARP (1986) J. BIOL. CHEM. 261, 14600-14606

F.MUELLER, S.G.CLARKSON, D.J.GALAS (1987) NUCL. ACIDS RES. 15, 7191-7191

D.P.MA, E.LUND, J.E.DAHLBERG, B.A.ROE (1984) GENE 28, 257-262

D.P.MA, E.LUND, J.E.DAHLBERG, B.A.ROE (1984) GENE 28, 257-262

J.BROIDA, J.ABELSON (1985) J. MOL. BIOL. 185, 545-563

S.M.DESAI, J.VAUGHAN, S.B.WEISS (1986) NUCL. ACIDS RES. 14, 4197-4205

G.WICH, M.JARSCH, A.BOECK (1984) MOL. GEN. GENET. 196, 146-151

E.S.HAAS, C.J.DANIELS, J.N.REEVE (1989) GENE 77, 253-263

G.WICH, L.SIBOLD, A.BOECK (1987) Z. NATURFORSCH. 42c, 373-380

A.MUTO, Y.ANDACHI, H.YUZAWA, F.YAMAO, S.OSAWA (1990) NUCL. ACIDS RES. 18, 5037 5043

T.SAMUELSSON, P.ELIAS, F.LUSTIG, Y.S.GUINDY (1985) BIOCHEM. J. 232, 223-228

M.J.ROGERS, A.A.STEINMETZ, R.T.WALKER (1986) NUCL. ACIDS RES. 14, 3145-3145

A.C.PITTET, H.HOTTINGER (1989) NUCL. ACIDS RES. 17, 4873-4873

E.F.WAWROUSEK, J.N.HANSEN (1983) J. BIOL. CHEM. 258, 291-298 C.J.GREEN,

G.C.STEWART, M.A.HOLLIS, B.S.VOLD, K.F.BOTT (1985) GENE 37,261-266

L.M.HSU, H.J.KLEE, J.ZAGORSKI, M.J.FOURNIER (1984) J. BACT. 158, 934-942

Y.KUCHINO, F.MORI, S.NISHIMURA (1985) NUCL. ACIDS RES. 13, 3213-3220

Y.KOMINE, T.ADACHI, H.INOKUCHI, H.OZEKI (1990) J. MOL. BIOL. 212, 579-598

L.BOSSI (1983) MOL. GEN. GENET. 192, 163-170

S.GIROUX, R.CEDERGREN (1988) PROC. NATL. ACAD. SCI. USA 85, 9101-9105

X. -R.GU, S. GIROUX, R.CEDERGREN (1988) NUCL. ACIDS RES. 16, 10936-10936

T.MANZARA, R.B.HALLICK (1988) NUCL. ACIDS RES. 16, 9866-9866

K. OHYAMA ET AL. (1988) J. MOL. BIOL. 203, 281-298

K.OHYAMA ET AL. (1988) J. MOL. BIOL. 203, 281-298

L.MARECHAL ET AL. (1987) CURR. GENET. 12, 91-98 
2150 Nucleic Acids Research, Vol. 19, Supplement

DP2720 J.H.LUKEES, L.BOGORAD (1988) RUCL. ACIDS RES. 16, 5192-5192

D22920 M.SUGIUSA, K.SHINOZAKI, M.OAAR IN:MATO ASI SER; SER. A 83 (1985) (MOL. FORM FUICT. PLATS GDNOAE) 325-334

DP3000 W.SCHUSTIR, J.M.GRIEIEABERER, J.-H.WEIL, A.BRENNICKE (1988) NUCL. ACIDS RES. $16,7737-7737$

DP3200 J.LEHEECK, B.M.STUEMAN, K.H.HENAINGSEN (1987) NUCL. ACIDS RES. 15, 3630-3630

DP3880 H.G.KOEGHEL, C.M.LAZARUS, A.BASAK, H.KUENTZEL (1981) CELL 23, 625-633

DP4000 D.NETHAN, H.D. PHAY, K. UNDERBRINK-LYON, N.C.MARTIN (1980) NUCL. ACIDS RES. 8, 5007-5016;

DP4040 D.R.MASSARDO (1990) NUCL. ACIDS RES. 18, 6429-6429

DP4060 E.GUELIN, J.VELOURS, M.GUERIN (1990) NUCL. ACIDS RES. 18, 4267-4267

DP4080 G.D.CLARK-WALKER, C.R.MCARTHUR, K.S.SRIPRAKASH (1985) EMBO J. 4, 465-473

DP4440 P.RUNEBERG-ROOS ET AL. (1987) PLANT MOL. BIOL. 9, 237-246

DP4480 L. MARECHAL ET AL. (1987) CURR. GENET. 12, 91-98 P.LEON, V.WALBOT, P.BEDINGER (1989) NUCL. ACIDS RES. 17, 4089-4099

DP4640 D.R.WOLSTENHOLME ET AL. (1987) PROC. NATL. ACAD. SCI. USA 84, 1324-1328

DP4880 D.0.CLARY, D.R. WOLSTENHOUYE (1985) J. MOL. EVOL. 22, 252-271

DP4980 H.T.JACOBS, S.ASKAWA, T.ARAKI, K.MIURA, M.J.SMITH, K.WATANABE (1989) CURR. GENET. 15, 193-206

DP5000 H.T.JACOBS, S.ASAKAWA, T.ARAKI, K.MIURA, M.J.SMITH, K.WATANABE (1989) CURR. GENET. 15, 193-206

DP5040 P.CANTATORE ET AL. (1988) CURR. GENET. 13, 91-96

DP5080 H.T.JACOBS, D.J.ELLIOTT, V.B.MATH, A.FARQUHARSON (1988) J. MOL. BIOL. 202, 185 217

DP5090 T.L.GILBERT, J.R.BROWN, P.J.OHARA, N.E.BUROKER, A.T.BECKENBACH, M.J.SMITH (1988) NUCL. ACIDS RES. 16, 11825-11825

DP5120 B.A.ROE, D.P.MA, R.K.WILSON, J.F.H.WONG (1985) J. BIOL. CHEM. 260, 9759-9774 D.DUNON-BLUTEAU, M.VOLOVITCH, G.BRUN (1985) GENE 36, 65-78

DP5160 Y. YONEYAMA (1987) J. NIPPON MED. SCH. 54, 429-440

DP5200 S.0.SOUTHERN, P.J.SOUTHERN, A.E.DIZON (1988) J. MOL. EVOL. $28,32-42$

DP5280 G.GOERTZ, H.FELDMANN (1982) CURR. GENET. 5, 221-225

DP5281 K.KOIKE ET AL. (1982) GENE 20, 177-185 G.GOERTZ, H.FELDMANN (1982) CURR. GENET. $5,221-225$

DP5320 M.J.BIBB, R.A.VAN ETTEN, C.T.WRIGHT, M.W.WALBERG, D.A.CLAYTON (1981) CELL 26, $167-180$

DP5360 S.ANDERSON ET AL. (1982) J.MOL. BIOL. 156, 683-717

DP5880 S.ANDERSON ET AL. (1981) NATURE 290, 457-465

DP6280 M.WINEY, M.D.MENDENHALL, C.M.CUMMINS, M.R.CULBERTSON, G.KNAPP (1986) J. MOL. BIOL. 192, 49-63

DP6980 G.A.GREEN, J.H.WEIL, A.STEINMETZ (1986) PLANT MOL. BIOL. 7, 207-212

DP6981 G.A.GREEN, J.H.WEIL, A.STEINMETZ (1986) PLANT MOL. BIOL. 7, 207-212

DP7560 T.A.TRANQUILLA, R.CORTESE, D.MELTON, J.D.SMITH (1982) NUCL. ACIDS RES. 10, 7919. 7934

DP7740 R.DELOTTO, P.SCHEDL (1984) J. MOL. BIOL. 179, 587-605 J.LEUNG ET AL. (1984) GENE $34,207-217$

DP8040 D.WEILL, T.HEYMAN (1990) NUCL. ACIDS RES. 18, 6134-6134

DP8041 D.WEILL, T.HEYMAN (1990) NUCL. ACIDS RES. 18, 6134-6134

DP8100 J.C.HU, B.D.COTE, E.LUND, J.E.DAHLBERG (1983) NUCL. ACIDS RES. 11, 4809-4821

DP8101 T.RUSSO ET AL. (1986) EUR. J. BIOCHEM.158, 437-442

DP9160 T.SEKIYA, R.NISHIZAWA, K.MATSUDA, Y.TAYA, S.NISHIMURA (1982) NUCL. ACIDS RES $10,6411-6419$

DP9161 T.SEKIYA, R.NISHIZAWA, K.MATSUDA, Y.TAYA, S.NISHIMURA (1982) NUCL. ACIDS RES $10,6411-6419$

DP9990 Y.-N.CHANG, I.L.PIRTLE, R.M.PIRTLE (1986) GENE 48, $165-174$

DP9991 R.D.SHORTRIDGE ET AL. (1989) GENE 79, 309-324

DQ0220 J.BROIDA, J.ABELSON (1985) J. MOL. BIOL. 185, 545-563

DQ0260 M.G.SHLYAPNIKOV ET AL. (1984) BIOCHIM. BIOPHYS. ACTA 782, 313-319

DQ0660 G.WICH, L.SIBOLD, A.BOECK (1986) SYSTEM. APPL. MICROBIOL. 7, 18-25

DQ1140 Y.ANDACHI ET AL. (1987) PROC. NATL. ACAD. SCI. USA 84, 7398-7402 
DQ1200

DQ1540

DQ1660

DQ1661

DQ2520

DQ2600

DQ2920

DQ3240

DQ3640

DQ3880

DQ4000

DQ4040

DQ4050

DQ4080

DQ4440

DQ4441

DQ4640

DQ4880

DQ4960

DQ4980

DQ5000

DQ5040

DQ5080

DQ5120

DQ5160

DQ5280

DQ5281

DQ5320

DQ5360

DQ5880

DQ6050

DQ6060

DQ6280

DQ6281

DQ9990

DQ9991

DR0220

DR0660

DR1140

DR1141

DR1180

DR1181

DR1260

DR1500

DR1540

DR1660

P.SIMONEAU, R.WENZEL, R.HERRMANN, P.C.HU (1990) NUCL.ACIDS RES. 18, 2814-2814

E.F.WAWROUSEK, N.NARASIMHAN, J.N.HANSEN (1984) J. BIOL. CHEM. 259, 3694-3702

N.NAKAJIMA, H.OZEKI, Y.SHIMURA (1981) CELL 23, 239-249

N. NAKA IMA, H.OZEKI, Y.SHIMURA (1981) CELL 23, 239-249

R.B.HALLICK ET AL. (1984) PLANT. MOL. BIOL. 3, 169-175

K. OHYAMA ET AL. (1988) J. MOL. BIOL. 203, 281-298

M.SUGIURA, K.SHINOZAKI, M.OHME IN:NATO ASI SER; SER. A 83 (1985) (MOL. FORM

FUNCT. PLANT GENOME) 325-334

H.NEUHAUS (1989) NUCL. ACIDS RES. 17, 444-444

D.P.MA, Y.W.YANG, S.E.HASNAIN (1989) NUCL. ACIDS RES. 17, 1256-1256 P.H.BOER, M.W.GRAY (1988) CURR. GENET. 14, 583-590

H.G.KOECHEL, C.M. LAZARUS, N.BASAK, H.KUENTZEL (1981) CELL 23, 625-633

R.E.BERLANI, S.G.BONITZ, G.CORUZZI, M.NOBREGA, A.TZAGOLOFF (1980) NUCL. ACIDS RES. 8, 5017-5030

D.R.MASSARDO (1990) NUCL. ACIDS RES. 18, 6429-6429

C.M.HARDY, C.D.CLARK-WALKER (1989) NUCL. ACIDS RES. 17, 1762-1762

G.D.CLARK-WALKER, C.R.MCARTHUR, K.S.SRIPRAKASH (1985) EMBO J. 4,465-473

P.B.M.JOYCE, M.W.GRAY (1988) NUCL. ACIDS RES. 16, 1210-1210

P.B.M.JOYCE, M.W.GRAY (1989) NUCL. ACIDS RES. 17, 4885-4885

D.R.WOLSTENHOLME ET AL. (1987) PROC. NATL. ACAD. SCI. USA 84, 1324-1328

D. O.CLARY, D.R. WOLSTENHOLME (1985) J. MOL. EVOL. 22, 252-271

D. O. CLARY, D.R. WOLSTENHOLME (1987) J. MOL. EVOL. 25, 116-125

H.T.JACOBS, S.ASAKAWA, T.ARAKI, K.MIURA, M.J.SMITH, K.WATANABE (1989) CURR. GENET. 15, 193-206

H.T.JACOBS, S.ASAKAWA, T.ARAKI, K.MIURA, M.J.SMITH, K.WATANABE (1989) CURR. GENET. 15, 193-206

P.CANTATORE ET AL. (1988) CURR. GENET. 13, 91-96

H.T.JACOBS, D.J.ELLIOTT, V.B.MATH, A.FARQUHARSON (1988) J. MOL. BIOL. 202, 185 217

B.A.ROE, D.P.MA, R.K.WILSON, J.F.H.WONG (1985) J. BIOL. CHEM. 260, 9759-9774

H.FUJII, T.SHIMADA, Y.GOTO, T.OKAZAKI (1988) J. BIOCHEM. 103, 474-481

D.R.WOLSTENHOLME, C.M.-R.FAURON, J.R.GODDARD (1982) GENE 20,63-69

P.CANTATORE ET AL. (1982) NUCL. ACIDS RES. 10, 3279-3289

M.J.BIBB, R.A.VAN ETTEN, C.T.WRIGHT, M.W.WALBERG, D.A.CLAYTON (1981) CELL 26, $167-180$

S.ANDERSON ET AL. (1982) J. MOL. BIOL. 156, 683-717

S.ANDERSON ET AL. (1981) NATURE 290, 457-46

D.A.CAMPBELL (1989) NUCL. ACIDS RES. 17, 9479-9479

Y.KUCHINO, N.HANYU, F.TASHIRO, S.NISHIMURA (1985) PROC. NATL. ACAD. SCI. USA $82,4758-4762$

G.TSCHUMPER, J.CARBON (1982) J. MOL. BIOL. 156, 293-307 S.D.TUCKER, E.J.MURGOLA (1985) BIOCHIMIE 67, 1053-1057

W.A.WEISS, E.C.FRIEDBERG (1986) J. MOL. BIOL. 192, 725-735 J.P.LIN, M.AKER,

K.C.SITNEY, R.K.MORTIMER (1986) GENE 49, 383-388

K.L.ROY, H.COOKE, R.BUCKLAND (1982) NUCL. ACIDS RES. 10, 7313-7322

D.P.MA, E.LUND, J.E.DAHLBERG, B.A.ROE (1984) GENE 28, 257-262

J.BROIDA, J .ABELSON (1985) J. MOL. BIOL. 185, 545-563

G.WICH, L.SIBOLD, A.BOECK (1986) SYSTEM. APPL. MICROBIOL. 7, 18-25

A.MUTO, Y.ANDACHI, H.YUZAWA, F.YAMAO, S.OSAWA (1990) NUCL. ACIDS RES. 18, 5037 5043

A.MUTO, Y.ANDACHI, H.YUZAWA, F.YAMAO, S.OSAWA (1990) NUCL. ACIDS RES. 18, $5037-$ 5043

T.SAMUELSSON, P.ELIAS, F.LUSTIG, Y.S.GUINDY (1985) BIOCHEM. J. 232, 223-228

T.SAMUELSSON, P.ELIAS, F.LUSTIG, Y.S.GUINDY (1985) BIOCHEM. J. 232, 223-228

M.J.ROGERS, A.A.STEIMMETZ, R.T.WALKER (1986) NUCL. ACIDS RES. 14, 3145

A.C.PITTET, H.HOTTINGER (1989) NUCL. ACIDS RES. 17, 4873-4873

E.F. WAWROUSEK, J.N. HANSEN (1983) J. BIOL. CHEM. 258, 291-298 C.J.GREEN,

G.C.STEWART, M.A.HOLLIS, B.S.VOLD, K.F.BOTT (1985) GENE 37, 261-266

G.M.GARCIA, P.K.MAR, D.A.MULLIN, J.R.WALKER, N.E.PRATHER (1986) CELL 45,453-459 
2152 Nucleic Acids Research, Vol. 19, Supplement

DR1661 G.M.GARCIA, P.K.MA, D.A.MULLIN, J.R.WALKER, M.E.PRATHER (1986) CELL 45, $453-459$

DR1662

DR1663

Di21664

D21700

D21780

DR2480

DR2520

DR2540

DR2600

DR2601

DR2602

DR2680

DR2720

DR2920

DR2921

DR3040

DR3200

DR3201

DR3280

DR3320

DR3321

DR3880

DR3920

DR4000

DR4001

DR4080

DR4640

DR4680

DR4800

DR4880

DR5040

DR5080

DR5100

DR5120

DR5280

DR5320

DR5360

DR5880

DR6280

DR6281

DR6282

DR6320

DR6321

DR7740

D.A.MULLIN, G.M.GARCIA, J.R.WALKBR (1984) CELL 37, 669-674

Y. KOMINE, T. ADACHI, H.IMOKUGHI, H.OZEKI (1990) J. MOL. BIOL. 212, 579-598

Y.KOMINE, T.ADACHI, H.IHOKUCHI, H.OZERI (1990) J. MOL. BIOL. 212, 579-598

L.BOSSI (1983) BOL. GEN. GEIET. 192, 163-170

X.-R.GU, S.GIROUX, R.GEDERGRE (1988) NUCL. ACIDS RES. 16, 10936-10936

T. YAYADA (1989) NUCL ACIDS RES. 17, $4372-4372$

R.B.HALLICK ET AL. (1984) PLANT. MOL. BIOL. 3, 169-175

S.E.DOUGLAS, D.G.DURNFORD (1990) NUCL. ACIDS RES. 18, 1903-1903

K. OHYAYA ET AL. (1988), J. MOL. BIOL. 203, 281-298

K. OHYAYA ET AL. (1988) J. MOL. BIOL. 203, 281-298

K. OHYAYA ET AL. (1988) J. MOL. BIOL. 203, 281-298

C.J.HOWE (1985) CURR. GENET. 10, 139-145

D.DORYANN-PRZYBYL, G.STRITTMATTER, H.KOESSEL (1986) PLANT MOL. BIOL. 7, 419-431

A.KATO, F.TAKAIWA, K.SHINOZAKI, M.SUGIURA (1985) CURR. GENET. 9, 405-409

M.SUGIURA, K.SHINOZAKI, M.OHME IN:NATO ASI SER; SER. A 83 (1985) (MOL. FORM

FUNCT. PLANT GENONE) 325-334

D.HELIMUND, M.METZLAFF, E.SERFLING (1984) NUCL. ACIDS RES. 12, 8253-8268

D.R.SHAPIRO, K.K.TEWARI (1986) PLANT MOL. BIOL. 6, 1-12

D.R.SHAPIRO, K.K.TEWARI (1986) PLANT MOL. BIOL. 6, 1-12

W.GRUISSEM, G.ZURAWSKI (1985) IN:NATO ASI SER. SER. A 83 (MOL FORM FUNCT. PLANT GENOME) PP. $199-210$

R.J.A.KEUS ET AL. (1984) NUCL. ACIDS RES. 12, 5639-5646

R.J.A.KEUS ET AL. (1984) NUCL. ACIDS RES. 12, 5639-5646

R.NETZKER, H.G.KOECHEL, N.BAZAK, H.KUENTZEL (1982) NUCL. ACIDS RES . 10, 4783 -

4794 E.GRISI, T.A.BROWN, R.B.WARING, C.SCAZZOCCHIO, R.W.DAVIES (1982) NUCL.

ACIDS RES. 10, 3531-3539

G.BURGER, M.H.CITTERICH, M.A.NELSON, S.WERNER, G.MACINO (1985) EMBO J. 4, 197 204

S.G.BONITZ, A.TZAGOLOFF (1980) J. BIOL. CHEM. 255, 9075-9081 D.L.MILLER,

N.C.MARTIN (1981) CURR. GENET. 4, 135-143

N.C.MARTIN, D.MILLER, J.HARTLEY, P.MOYNIHAN, J.E.DONELSON (1980) CELL 19, 339 343 S.G.BONITZ, A.TZAGOLOFF (1980) J. BIOL. CHEM. 255, 9075-9081 D.L.MILLER, N.C.MARTIN (1981) CURR. GENET. 4, 135-143

G.D.CLARK-WALKER, C.R.MCARTHUR, K.S.SRIPRAKASH (1985) EMBO J. 4, 465-473

D.R. WOLSTENHOLME ET AL. (1987) PROC. NATL. ACAD. SCI. USA 84, 1324-1328

R.OKIMOTO, D.R.WOLSTENHOLME (1990) EMBO J. 9, 3405-3411

D.T.DUBIN, C-C.HSUCHEN, L.E.TILLOTSON (1986) CURR. GENET. 10, 701-707

D. O.CLARY, D.R. WOLSTENHOLME (1985) J. MOL. EVOL. 22, 252-271

P.CANTATORE ET AL. (1987) GENE 53, 41-54

H.T.JACOBS, D.J.ELLIOTT, V.B.MATH, A.FARQUHARSON (1988) J. MOL. BIOL. 202, 185 217

S.JOHANSEN, P.H.GUDDAL, T.JOHANSEN (1990) NUCL. ACIDS RES. 18, $411-419$

B.A.ROE, D.P.MA, R.K.WILSON, J.F.H.WONG (1985) J. BIOL. CHEM. 260, 9759-9774

P.CANTATORE ET AL. (1982) NUCL. ACIDS RES. 10, 3279-3289 R.GROSSKOPF, H. FELDMANN (1981) CURR. GENET. 4, 151-158 G.PEPE ET AL. (1983) BIOCHEM. INT. 6, 553-563

M.J.BIBB, R.A.VAN ETTEN, C.T.WRIGHT, M.W.WALBERG, D.A.CLAYTON (1982) CELL 26 , $167-180$

S.ANDERSON ET AL. (1982) J. MOL. BIOL. 156, 683-717

S.ANDERSON ET AL. (1981) NATURE 290, 457-465

R.E.BAKER, A.EIGEL, D.VOEGTEL, H.FELDMANN (1982) EMBO-J . 1, 291-295

O.SCHMIDT ET AL. (1980) NATURE 287, 750-752 J.VILLANUEVA, P. BULL, P.VALENZUELA, A.VENEGAS (1984) FEBS LETTERS 167, 165-169 G.THIREOS, M.D.PENN, H.GREER (1984)

PROC. NATL. ACAD. SCI. USA 81, 5096-5100

J.GAFNER, E.M.DE ROBERTIS, P.PHILIPPSEN (1983) EMBBO-J. 2, 583-591

V.GAMULIN ET AL. (1983) NUCL. ACIDS RES. 11, 8537-8546

V.GAMULIN ET AL. (1983) NUCL. ACIDS RES. 11, 8537-8546

P.H.YEN, N.DAVIDSON (1980) CELL 22, 137-148 S.SHARP ET AL. (1983) NUCL. ACIDS

RES. 11, 8677-8690 
DR7741 S.YUKI, S.INOUYE, S.ISHIMARU, K.SAIGO (1986) EUR. J. BIOCHEM. 158, 403-410

DS0220 J.BROIDA, J.ABELSON (1985) J. MOL. BIOL. 185, 545-563

DS0260 S.M.DESAI, J.VAUGHAN, S.B.WEISS (1986) NUCL. ACIDS RES. 14, 4197-4205

DS0261

DS0680

DS0860

DS1140

S.M.DESAI, J.VAUGHAN, S.B.WEISS (1986) NUCL. ACIDS RES. 14, 4197-4205

E.S.HAAS, J.W.BROWN, C.J.DANIELS, J.N.REEVE (1990) GENE 90, 51-59

B.P.KAINE, R.GUPTA, C.R.WOESE (1983) PROC. NATL. ACAD. SCI. USA 80, 3309-3312

A.MUTO, Y.ANDACHI, H.YUZAWA, H.YAMAO, S.OSAWA (1990) NUCL. ACIDS RES . 18, 5037 5043

DS1141 A.MUTO, Y.ANDACHI, H.YUZAWA, F.YAMAO, S.OSAWA (1990) NUCL. ACIDS RES. 18, $5037_{-}$ 5043

DS1180 T.SAMUELSSON, P.ELIAS, F.LUSTIG, Y.S.GUINDY (1985) BIOCHEM. J . 232, 223-228

DS1260

DS1500

M.J.ROGERS, A.A.STEINMETZ, R.T.WALKER (1986) NUCL. ACIDS RES . 14, 3145-3145

DS1520

H.HOTTINGER ET AL. (1987) GENE 60, 75-83

DS1540

M.C.ZWAHLEN, H.HOTTINGER (1989) NUCL. ACIDS RES. 17, 1772-1772

DS1541

E.F.WAWROUSEK, N.NARASIMHAN, J.N.HANSEN (1984) J. BIOL. CHEM.

C.J.GREEN, G.C.STEWART, M.A.HOLLIS, B.S.VOLD, K.F.BOTT (1985)

DS1542

C.J.GREEN, G.C.STEWART, M.A.HOLLIS, B.S.VOLD, K.F.BOTT (1985)

$259,3694-3702$

DS1660

D.A.STEEGE, J.I.HORABIN (1983) J. BACT. 155, 1417-1425

DS1661

F.TAMURA, S.NISHIMURA, M.OHKI (1984) EMBO J. 3, 1103-1107

DS1662

W.LEINFELDER, E.ZEHELEIN, M. -A. MANDRAND-BERTHELOT, A.BOECK (1988) NATURE 331, $723-725$

DS1663 Y.KOMINE, T.ADACHI, H.INOKUCHI, H.OZEKI (1990) J. MOL. BIOL. 212, 579-598

DS1664 Y.KOMINE, T.ADACHI, H.INOKUCHI, H.OZEKI (1990) J. MOL. BIOL. 212, 579-598

DS2180 M.KUNTZ, J.-L.EVRARD, J.-H.WEIL (1988) NUCL. ACIDS RES . 16, 8733-8733

DS2480

T.YAMADA (1989) NUCL. ACIDS RES. 17, 4372-4372

DS2520

R.B.HALLICK ET AL. (1984) PLANT. MOL. BIOL. 3, 169-175

DS2521

T.MANZARA, R.B.HALLICK (1988) NUCL. ACIDS RES. 16, 9866-9866

DS2600

DS2601

K.UMESONO, H.INOKUCHI, K.OHYAMA, H.OZEKI (1984) NUCL. ACIDS RES. 12, 9551-9565

DS2602

K. OHYAMA ET AL. (1988) J. MOL. BIOL. 203, 281-298

DS2640

K. OHYAMA ET AL. (1988) J. MOL. BIOL. 203, 281-298

R.P.OLIVER, C.POULSEN (1984) CARLSBERG RES. COMMUN. 49, 647-673

DS2680

C.J.HOWE, R.F.BARKER, C.M.BOWMAN, T.A.DYER (1988) CURR. GENET. 13, 343-349

DS2720

E.KREBBERS, A.STEINMETZ, L.BOGORAD (1984) PLANT. MOL. BIO. 3, 13-20

DS2721

A.A.STEINMETZ, E.T.KREBBERS, Z.SCHWARZ, E.J.GUBBINS, L.BOGORAD (1983) J. BIOL.

CHEM. 258, 5503-5511

DS2722

D.RUSSELL, K.M.T.MUSKAVITCH, L.BOGORAD (1987) NUCL.ACIDS RES. 15, 370-370

DS2920

M.SUGIURA, K.SHINOZAKI, M.OHME IN:NATO ASI SER; SER. A 83 (1985) (MOL. FORM FUNCT. PLANT GENOME) $325-334$

DS2921 K.YAMADA, K.SHINOZAKI, M.SUGIURA (1986) PLANT MOL. BIOL. 6, 193-199

DS2922 T.WAKASUGI, M.OHME, K.SHINOZAKI, M.SUGIURA (1986) PLANT MOL. BIOL. 7, 385-392

DS3200 G.BOOKJANS, B.M.STUMMANN, O.F.RASMUSSEN, K.W.HENNINGSEN (1986) PLANT MOL. BIOL. $6,359-366$

DS3240 H.NEUHAUS, T.PFANNSCHMIDT, G.LINK (1990) NUCL. ACIDS RES. 18, 368-368

DS3280 K.HOLSCHUH, W.BOTTOMLEY, P.R.WHITFELD (1984) NUCL. ACIDS RES 12, 8819-8834

DS3281 S.B.TAHAR, W.BOTTOMLEY, P.R.WHITFELD (1986) PLANT MOL. BIOL. 7, 63-70

DS3880 H.G.KOECHEL, C.M.LAZARUS, N.BASAK, H.KUENTZEL (1981) CELL 23, 625-633

DS3881 H.G.KOECHEL, C.M.LAZARUS, N.BASAK, H.KUENTZEL (1981) CELL 23, 625-633

DS3960 D.J.CUMMINGS, I.A.MACNEIL, J.DOMENICO, , E.T.MATSUURA (1985) J. MOL. BIOL. 185, $659-680$

DS4000 S.G.BONITZ, A.TZAGOLOFF (1980) J.BIOL.CHEM. 255, 9075-9081 D.L.MILLER, N.C.MARTIN (1981) CURR. GENET. 4, 135-143

DS4001 A.TZAGOLOFF, M.NOBREGA, A.AKAI, G.MACINO (1980) CURR. GENET. 2, 149-157

D.L.MILLER ET AL. (1979) J. BIOL. CHEM. 254, 11735-11740

DS4080 G.D.CLARK-WALKER, C.R.MCARTHUR, K.S.SRIPRAKASH (1985) EMBO J. 4, 465-473

DS4081 G.D.CLARK-WALKER, C.R.MCARTHUR, K.S.SRIPRAKASH (1985) EMBO J. 4, 465-473

DS4240 H.C.CHEN, H.WINTZ, J.H.WEIL, D.T.N.PILIAY (1989) NUCL. ACIDS RES. 17, 2613-2621

DS4360 W.SCHUSTER, A.BRENNICKE (1987) EMBO J. 6, 2857-2863

DS4400 J.M.GUALBERTO, H.WINTZ, J.-H.WEIL, J.-M.GRIENENBERGER (1988) MOL. GEN. GENET. $215,118-127$ 
DS4440 P.B.M.JOYCE, D.F.SPENGER, L.BONEN, M.W.GRAY (1988) PLANT KOL. BIOL. 10, 251-262 DS4441 P.B.M.JOYCE, D.F.SPERCER, L.BONEN, M.W.GRAY (1988) PLAIT MOL. BIOL. 10, 251-262 DS4442 P.B.M.JOYCE, M.W.GRAY (1989) NUCL. ACIDS RES. 17, 5461-5476

DS4480 H.WINTZ, J.-M.GRIENEMBERGER, J.-H.WEIL, D.M.LONSDALE (1988) CURR. GENET. 13, 247-254

DS4481 A.SANGARE, J.H.WEIL, J.M.GRIENENBERGER (1989) NUCL. ACIDS RES. 17, 7979-7979

DS4640 D.R.WOLSTENHOLME ET AL. (1987) PROC. NATL. AGAD. SCI. USA 84, 1324-1328

DS4641 D.R.WOLSTENHOUME ET AL. (1987) PROC. MATL. ACAD. SCI. USA 84, 1324-1328

DS4680 R.OKIMOTO, D.R.WOLSTEMHOUME (1990) BMBO J. 9, 3405-3411

DS4681 R.OKIMOTO, D.R.WOLSTENHOUE (1990) EMBO J. 9, 3405-3411

DS4760 I.UHLENBUSCH, R.M.RIPPE, G.GELLISSEN (1987) MATURWISSENSCHAFTEN 74, 142-143

DS4800 D.T.DUBIN, C-C.HSUCHEN, L.E.TILLOTSON (1986) CURR. GENET. 10, 701-707

DS4880 D.0.CLARY, D.R.WOLSTENHOLYE (1985) J. MOL. EVOL. 22, 252-271

DS4921 D.0.CLARY, D.R.WOLSTENHOLYE (1985) J. MOL. EVOL. 22, 252-271

DS5000 H.HIMENO ET AL. (1987) GENE 56, 219-230

DS5001 H.HIMENO ET AL. (1987) GENE 56, 219-230

DS5040 P.CANTATORE ET AL. (1988) CURR. GENET. 13, 91-96

DS5041 P.CANTATORE ET AL. (1988) CURR. GENET. 13, 91-96

DS5080 H.T.JACOBS, D.J.ELLIOTT, V.B.MATH, A.FARQUHARSON (1988) J. MOL. BIOL. 202, 185217

DS5081 H.T.JACOBS, D.J.ELLIOTT, V.B.MATH, A.FARQUHARSON (1988) J. MOL. BIOL. 202, 185217

DS5100 S.JOHANSEN, P.H.GUDDAL, T.JOHANSEN (1990) NUCL. ACIDS RES. 18, 411-419

DS5120 B.A.ROE, D.P.MA, R.K.WILSON, J.F.H.WONG (1985) J. BIOL. CHEM. 260, 9759-9774

DS5121 B.A.ROE, D.P.MA, R.K.WILSON, J.F.H.WONG (1985) J. BIOL. CHEM. 260, 9759-9774

DS5220 Y.H.W.LEE, L.L.LIAW, T.T.YUNG, S.J.LO (1989) NUCL. ACIDS RES. 17, 9477-9477

DS5280 R.GROSSKOPF, H.FELDMANN (1981) CURR. GENET. 4, 151-158

DS5281 R.GROSSKOPF, H.FELDMANN (1981) CURR. GENET. 4, 191-196

DS5282 P.CANTATORE ET AL. (1982) NUCL. ACIDS RES. 10, 3279-3289 G.PEPE ET AL. (1983) BIOCHEM. INT. $6,553-563$

DS5320 M.J.BIBB, R.A.VAN ETTEN, C.T.WRIGHT, M.W.WALBERG, D.A.CLAYTON (1981) CELL 26, $167-180$

DS5321 M.J.BIBB, R.A.VAN ETTEN, C.T.WRIGHT, M.W.WALBERG, D.A.CLAYTON (1981) CELL 26, $167-180$

DS5360 S.ANDERSON ET AL. (1982) J. MOL. BIOL. 156, 683-717

DS5361 S.ANDERSON ET AL. (1982) J. MOL. BIOL. 156, 683-717

DS5440 K.HAYASAKA, T.GOJOBORI, S.HORAI (1988) MOL. BIOL. EVOL. 5(6), 626-644

DS5480 K.HAYASAKA, T.GOJOBORI, S.HORAI (1988) MOL. BIOL. EVOL. 5(6), 626-644

DS5520 K.HAYASAKA, T.GOJOBORI, S.HORAI (1988) MOL. BIOL. EVOL. 5(6), 626-644

DS5560 K.HAYASAKA, T.GOJOBORI, S.HORAI (1988) MOL. BIOL. EVOL. 5(6), 626-644

DS5600 K.HAYASAKA, T.GOJOBORI, S.HORAI (1988) MOL. BIOL. EVOL. 5(6), 626-644

DS5640 K.HAYASAKA, T.GOJOBORI, S.HORAI (1988) MOL. BIOL. EVOL. 5(6), 626-644

DS5680 K.HAYASAKA, T.GOJOBORI, S.HORAI (1988) MOL. BIOL. EVOL. 5(6),626-644

DS5720 W.M.BROWN, E.M.PRAGER, A.WANG, A.C.WILSON (1982) J. MOL. EVOL. 18, 225-239

DS5760 W.M.BROWN, E.M.PRAGER, A.WANG, A.C.WILSON (1982) J. MOL. EVOL. 18, 225-239

DS5800 W.M.BROWN, E.M.PRAGER, A.WANG, A.C.WILSON (1982) J. MOL. EVOL. 18, 225-239

DS5840 W.M.BROWN, E.M.PRAGER, A.WANG, A.C.WILSON (1982) J. MOL. EVOL. 18, 225-239

DS5880 S.ANDERSON ET AL. (1981) NATURE 290, 457-465

DS5881 S.ANDERSON ET AL. (1981) NATURE 290, 457-465

A.C.WILSON (1982) J. MOL. EVOL. 18, 225-239 M.H.L.DE BRUIJN, A.KLUG (1983) EMBO J. 2, 1309-1321

DS6060 H.ENDOH, S.NAGAHASHI, N.OKADA (1989) NUCL. ACIDS RES. 17, 10122-10122

DS6240 R.DEBUCHY Y.BRYGOO (1985) EMBBO J. 4, 3553-3556

DS6241 R.DEBUCHY Y.BRYGOO (1985) EMBO J. 4, 3553-3556

DS6280 G.S.PAGE, B.D.HALL (1981) NUCL. ACIDS RES. 9, 921-934; R.E.BAKER, A.EIGEL, D.VOEGTEL, H.FELDMANN (1982) EMBO J. 1, 291-295

DS6281 R.STUCKA, H.FELDMANN (1988) NUCL. ACIDS RES. 16, 3583-3583

DS6320 H.AMSTUTZ, P.MUNZ, W.D.HEYER, U.LEUPOLD, J.KOHLI (1985) CELL 40, 879-886

DS6321 H.AMSTUTZ, P.MUNZ, W.D.HEYER, U.LEUPOLD, J.KOHLI (1985) CELL 40, 879-886 
Nucleic Acids Research, Vol. 19, Supplement 2155

DS6322 H.AMSTUTZ, P.MUNZ, W-D.HEYER, U.LEUPOLD, J.KOHLI (1985) CELL 40, 879-886

DS6400 M.V.OLSON ET AL. (1981) NATURE 291, 464-469

DS6401

M.V.OLSON ET AL. (1981) NATURE 291, 464-469 J.R.BROACH, L.FRIEDMAN, F.SHERMAN (1981) J. MOL. BIOL. 150, 375-387 S.B.SANDMEYER, M.V.OLSON (1982) PROC. NATL. ACAD. SCI. USA 79, 7674-7678

DS6402 R.C.OGDEN ET.AL. (1980) IN:TRANSFER RNA, D.SOELL, J.ABELSON, P. SCHIMGEL EDS. COLD SPRING HARB. 173-179

DS7240 Z.SZWEYKOWSKA-KULINSKA, A.JARMOLOWSKI, J.AUGUSTYNIAK (1989) GENE 77, 163-167

DS7560 B.J.LEE, M.RAJAGOPALAN, Y.S.KIM, K.H.YOU, K.B.JACOBSON, D.HATFIELD (1990) MOL. CELL. BIOL. 10, 1940-1949

DS7740 D.L.CRIBBS ET AL. (1987) J. MOL. BIOL. 197, 397-404

DS7741 D.L.CRIBBS ET AL. (1987) J. MOL. BIOL. 197, 397-404

DS7742 B.J.LEE, M.RAJAGOPALAN, Y.S.KIM, K.H.YOU, K.B.JACOBSON, D.HATFIELD (1990) MOL. CELL. BIOL. 10, 1940-1949

DS7800 D.L.CRIBBS ET AL. (1987) J. MOL. BIOL. 197, 397-404

DS7920 B.J.LEE, M.RAJAGOPALAN, Y.S.KIM, K.H.YOU, K.B.JACOBSON, D.HATFIELD (1990) MOL. CELL. BIOL. 10, 1940-1949

DS8040 D.L.HATFIELD, B.S.DUDOCK, F.C.EDEN (1983) PROC. NATL. ACAD. SCI. USA 80, 49404944

DS9280 H.RIZOS, G.H.LAWRENCE, T.S.STEWART (1989) NUCL. ACIDS RES. 17, 2139-2139

DS9281 A.M.DIAMOND, Y.MONTERO-PUERNER, B.J.LEE, D.HATFIELD (1990) NUCL. ACIDS RES. 18, 6727-6727

DS9990 H.J.HONG, S.H.YOO, O.J.YOO (1987) NUCL. ACIDS RES. 15, 4987-4987

DS9991 J.L.KRUPP, H.H.SHU, N.C.MARTIN (1988) NUCL. ACIDS RES. 16, 770-770

DS9992 K.L.HOE, H.J.HONG, S.H.YOO, 0.J.YOO (1987) NUCL. ACIDS RES. 15, 10045-10045

DT0220 J.BROIDA, J .ABELSON (1985) J. MOL. BIOL. 185, 545-563

DT0260 V.N.KSENZENKO ET AL. (1987) NUCL. ACIDS RES. 15, 5480-5481

DT0660 G.WICH, M.JARSCH, A.BOECK (1984) MOL. GEN. GENET. 196, 146-151

DT0661 G.WICH, L.SIBOLD, A.BOECK (1986) SYSTEM. APPL. MICROBIOL. 7, 18-25

DT0680 E.S.HAAS, C.J.DANIELS, J.N.REEVE (1989) GENE 77, 253-263

DT0740 G.WICH, L.SIBOLD, A.BOECK (1987) Z. NATURFORSCH. 42c, 373-380

DT1140 Y.ANDACHI ET AL. (1987) PROC. NATL. ACAD. SCI. USA 84, 7398-7402

DT1141 A.MUTO, Y.ANDACHI, H.YUZAWA, F.YAMAO, S.OSAWA (1990) NUCL. ACIDS RES. 18, 5037 5043

DT1180 T.SAMUELSSON ET AL. (1987) PROC. NATL. ACAD. SCI. USA 84, 3166-3170

DT1540 E.F.WAWROUSEK, J.N.HANSEN (1983) J. BIOL. CHEM. 258, 291-298

DT1541 E.F.WAWROUSEK, N.NARAS IMHAN, J.N.HANSEN (1984) J. BIOL. CHEM. 259, 3694-3702

DT1542 C.J.GREEN, G.C.STEWART, M.A.HOLLIS, B.S.VOLD, K.F.BOTT (1985) GENE 37,261-266

DT1580 M.WEISSHAAR, R.AHMADIAN, M.SPRINZL, M.SATOH, A.KUSHIRO, K.TOMITA(1990) NUCL. ACIDS RES. 18, 1902-1902

DT1581 M.WEISSHAAR, R.AHMADIAN, M.SPRINZL, M.SATOH, A.KUSHIRO, K.TOMITA (1990) NUCL. ACIDS RES. 18, 1902-1902

DT1660 G.L.DUESTER, W.M.HOLMES (1980) NUCL. ACIDS RES. 8, 3793-3807

DT1661 L.HUDSON, J.ROSSI, A. LANDY (1981) NATURE 294, 422-427 A.MIYAJIMA, T. YOKOTA, Y.TAKEBE, M.NAKAMURA, Y.KAZIRO (1983) J. BIOCHEM. 93, 1101-1108 G.AN, J.D.FRIESEN (1980) GENE 12, 33-39

DT1662 L.HUDSON, J.ROSSI, A.LANDY (1981) NATURE 294, $422-427$ G.AN, J.D.FRIESEN (1980) GENE 12, 33-39 A.MIYAJIMA, T.YOKOTA, Y.TAKEBE, M.NAKAMURA, Y.KAZIRD (1983) J. BIOCHEM. 93, 1101-1108

DT1663 B.DALRYUMPLE, J.S.MATTICK (1986) BIOCHEM. INT. 13,547-553

DT1820 B.DALRYUMPLE, J.S.MATTICK (1986) BIOCHEM. INT . 13,547-553

DT1821 M.A.HUGHES, D.S.JONES (1988) NUCL. ACIDS RES. 16, 7193-7193

DT2460 M.RICHARD, G.BELLEMARE (1990) NUCL. ACIDS RES. 18, 3061-3061

DT2520 R.D.HALLICK ET AL. (1984) PLANT. MOL. BIOL.3, 169-175

DT2600 K. OHYAMA ET AL. (1988) J. MOL. BIOL. 203, 281-298

DT2601 K. OHYAMA ET AL. (1988) J. MOL. BIOL. 203, 281-298

DT2640 R.P.OLIVER, C.POULSEN (1984) CARLSBERG RES . COMMUN. 49, 647-673

DT2680 F.QUIGLEY, J.H.WEIL (1985) CURR. GENET. 9, 495-503 
DT2720 A.A.STEIMAETZ, E.T.KREBBERS, Z.SCHWARZ, E.J.GUBBINS, L. BOGORAD (1983) J. BIOL. CHEY. 258, 5503-5511

DT2920 K. YAMADA, K.SHINOZAKI, M.SUGIURA (1986) PLANT MOL. BIOL. 6, 193-199

DT2921 T.WAKASUGI, M.OHAE, K.SHINOZAKI, M.SUGIURA (1986) PLANT MOL. BIOL. 7, 385-392

DT3200 O.RASYUSSEN, B.JEPSEN, B.STUMAAN, K.W.HENNINGSEN (1987) NUCL. ACIDS RES. 15, 854-854

DT3280 M.A.KASHDAN, B.S.DUDOCK (1982) J. BIOL. CHEM. 257, 1114-1116 K. HOLSCHUH, W.BOTTOMLEY, P.R.WITHFELD (1984) PLANT MOL. BIOL. 3, 313-317

DT3281 S.B.TAHAR, W.BOTTOMLEY, P.R.WHITFELD (1986) PLANT MOL. BIOL. 7, 63-70

DT3360 J.H.WEIL, G.BONNARD, M.KUNTZ, A.STEINMETZ IN:NATO ASI SER; SER. A 83 (1985) (MOL. FORM FUNCT. PLANT GENOME) 313-324

DT3880 H.G.KOECHEL, C.M. LAZARUS, N.BASAK, H.KUENTZEL (1981) CELL 23, 625-633

DT4000 M.LI, A.TZAGOLOFF (1979) CELL 18, 47-53

DT4001 R.E.BERLANI, C.PENTELLA, G.MACINO, A.TZAGOLOFF (1980) J. BACT. 141, 1086-1097

DT4080 G.D.CLARK-WALKER, C.R.MCARTHUR, K.S.SRIPRAKASH (1985) EMBO J . 4, 465-473

DT4081 G.D.CLARK-WALKER, C.R.MCARTHUR, K.S.SRIPRAKASH (1985) EMBO J . 4, 465-473

DT4640 D.R.WOLSTENHOLME ET AL. (1987) PROC. NATL. ACAD. SCI. USA 84, 1324-1328

DT4680 D.R.WOLSTENHOLME ET AL. (1987) PROC. NATL. ACAD. SCI. USA 84, 1324-1328

DT4880 D.0.CLARY, D.R. WOLSTENHOLME (1985) J. MOL. EVOL. 22, 252-271

DT4980 H.T.JACOBS, S.ASAKAWA, T.ARAKI, K.MIURA, M.J.SMITH, K.WATANABE (1989) CURR. GENET. 15, 193-206

DT5040 P.CANTATORE ET AL. (1988) CURR. GENET. 13, 91-96

DT5080 H.T.JACOBS, D.J.ELLIOTT, V.B.MATH, A.FARQUHARSON (1988) J. MOL. BIOL. 202, 185217

DT5090 T.L.GILBERT, J.R.BROWN, P.J.OHARA, N.E.BUROKER, A.T.BECKENBACH, M.J. SMITH (1988) NUCL. ACIDS RES. 16, 11825-11825

DT5120 B.A.ROE, D.P.MA, R.K.WILSON, J.F.H.WONG (1985) J. BIOL. CHEM. 260, 9759-9774 D.DUNON-BLUTEAU, M.VOLOVITCH, G.BRUN (1985) GENE 36, 65-78

DT5160 Y.YONEYAMA (1987) J. NIPPON MED. SCH. 54, 429-440

DT5200 S.O.SOUTHERN, P.J.SOUTHERN, A.E.DIZON (1988) J. MOL. EVOL. 28, 32-42

DT5280 K.KOIKE ET AL. (1982) GENE 20, 177-185

DT5281 G.GOERTZ, H.FELDMANN (1982) CURR. GENET. 5, 221-225

DT5320 M.J.BIBB, R.A.VAN ETTEN, C.T.WRIGHT, M.W.WALBERG, D.A.CLAYTON (1981) CELL 26, $167-180$

DT5360 S.ANDERSON ET AL. (1982) J. MOL. BIOL. 156, 683-717

DT5880 S.ANDERSON ET AL. (1981) NATURE 290, 457-465

DT7740 R.DELOTTO, P.SCHEDL (1984) J. MOL. BIOL. 179, 587-605

DT9990 Y. -N.CHANG, I.L.PIRTLE, R.M.PIRTLE (1986) GENE 48, 165-174

DT9991 R.D.SHORTRIDGE ET AL. (1989) GENE 79, 309-324

DV0260 S.M.DESAI, J.VAUGHAN, S.B.WEISS (1986) NUCL. ACIDS RES. 14, 4197-4205

DV0660 G.WICH, L.SIBOLD, A.BOECK (1986) SYSTEM. APPL. MICROBIOL. 7, 18-25

DV0860 B.P.KAINE (1987) J. MOL. EVOL. 25, 248-254

DV1140 A.MUTO, Y.ANDACHI, H.YUZAWA, F. YAMAO, S.OSAWA (1990) NUCL. ACIDS RES. 18, 5037 5043

DV1180 T.SAMUELSSON ET AL. (1987) PROC. NATL. ACAD. SCI. USA 84, 3166-3170

DV1350 R.SEDLMEIER, H.SCHMIEGER (1990) NUCL. ACIDS RES. 18, 4027-4027

DV1351 R.SEDLMEIER, H.SCHMIEGER (1990) NUCL. ACIDS RES . 18, 4027-4027

DV1500 A.C.PITTET, H.HOTTINGER (1989) NUCL. ACIDS RES. 17, 4873-4873

DV1540 C.J.GREEN, G.C.STEWART, M.A.HOLLIS, B.S.VOLD, K.F.BOTT (1985) GENE 37, 261-266

DV1660 M.YOSHIMURA, M.KIMURA, M.OHNO, H.INOKUCHI, H.OZEKI (1984) J. MOL. BIOL. 177 , $609-625$

DV1661 Y.KOMINE, T.ADACHI, H.INOKUCHI, H.OZEKI (1990) J. MOL. BIOL. 212, 579-598

DV1662 Y.KOMINE, T.ADACHI, H.INOKUCHI, H.OZEKI (1990) J. MOL. BIOL. 212, 579-598

DV2520 R.B.HALLICK ET AL. (1984) PLANT. MOL. BIOL. 3, 169-175

DV2600 K. OHYAMA ET AL. (1988) J. MOL. BIOL. 203, 281-298

DV2601 K. OHYAMA ET AL. (1988) J. MOL. BIOL. 203, 281-298

DV2640 G.ZURAWSKI, M.T.CLEGG (1984) NUCL. ACIDS RES. 12, 2549-2559

DV2720 E. KREBBERS, A.STEINMETZ, L. BOGORAD (1984) PLANT. MOL. BIOL. 3, 13-20

DV2721 G.STRITTMATTER, A.GOZDZICKA-JOZEFIAK, H.KOESSEL (1985) EMBO J. 4, 599-604 
DV2840 J.-M.VON ALIMEN, E.STUTZ (1988) NUCL. ACIDS RES. 16, 1200-1200

DV2920 M.SUGIURA, K.SHINOZAKI, M.OHME IN:MATO ASI SER; SER. A 83 (1985) (MOL. FORM FUNCT. PLANT GENOME) 325-334

DV2921 M.SUGIURA, K.SHINOZAKI, M.OHME IN:NATO ASI SER; SER. A 83 (1985) (MOL. FORM FUNCT. PLANT GENONE) 325-334

DV3200 D.R.SHAPIRO, K.K.TEWARI (1986) PLANT MOL. BIOL. 6, 1-12

DV3240 D.PRZYBYL ET AL. (1984) PLANT. MOL. BIOL. 3, 147-158

DV3280 J.-F.BRIAT, M.DRON, S.LOISEAUX, R.MACHE (1982) NUCL. ACIDS RES. 10, 6865-6878

DV3880 H.G.KOECHEL, C.M.LAZARUS, N.BASAK, H.KUENTZEL (1981) CELL 23, 625-633

DV3960 D.J.CUMMINGS, I.A.MACNEIL, J.DOMENICO, , E.T.MATSUURA (1985) J. MOL. BIOL. 185, $659-680$

DV4000 B.E.THALENFELD, A. TZAGOLOFF (1980) J. BIOL. CHEM. 255, 6173-6180

DV4001 D.MILLER, C.SIGURDSON, N.C.MARTIN, J.E.DONELSON (1980) NUCL. ACIDS RES . 8, 14351442 M.LI, A.TZAGOLOFF (1979) CELL 18, 47-53

DV4080 G.D.CLARK-WALKER, C.R.MCARTHUR, K.S.SRIPRAKASH (1985) EMBO J. 4, 465-473

DV4640 D.R.WOLSTENHOLME ET AL. (1987) PROC. NATL. ACAD. SCI. USA 84, 1324-1328

DV4800 D.T.DUBIN, C. -C.HSUCHEN, L.E.TILLOTSON (1986) CURR. GENET. 701-707

DV4880 D.0.CLARY, D.R.WOLSTENHOLME (1985) J. MOL. EVOL. 22, 252-271

DV4980 H.T.JACOBS, S.ASAKAWA, T.ARAKI, K.MIURA, M.J.SMITH, K.WATANABE (1989) CURR. GENET. $15,193-206$

DV5000 H.T.JACOBS, S.ASAKAWA, T.ARAKI, K.MIURA, M.J.SMITH, K.WATANABE (1989) CURR. GENET. 15, 193-206

DV5020 H.T.JACOBS, S.ASAKAWA, T.ARAKI, K.MIURA, M.J.SMITH, K.WATANABE (1989) CURR. GENET. 15, 193-206

DV5040 P.CANTATORE ET AL. (1988) CURR. GENET. 13, 91-96

DV5080 H.T.JACOBS, D.J.ELLIOTT, V.B.MATH, A.FARQUHARSON (1988) J. MOL. BIOL. 202, $185-$ 217

DV5120 B.A.ROE, D.P.MA, R.K.WILSON, J.F.H.WONG (1985) J. BIOL. CHEM. 260, 9759-9774

DV5280 M.KOBAYASHI, T.SEKI, K. YAGINUMA, K.KOIKE (1981) GENE 16, 297-307 C.SACCONE ET AL. (1981) NUCL. ACIDS RES. 9, 4139-4148

DV5320 M.J.BIBB, R.A.VAN ETTEN, C.T.WRIGHT, M.W.WALBERG, D.A.CLAYTON (1981) CELL 26, $167-180$

DV5360 S.ANDERSON ET AL. (1982) J. MOL. BIOL. 156, 683-717

DV5880 S.ANDERSON ET AL. (1981) NATURE 290, 457-465

DV6050 D.A.CAMPBELL (1989) NUCL. ACIDS RES. 17, 9479-9479

DV6160 T.DINGERMANN, W.BERTLING, F.PISTEL, E.AMON (1985) EUR. J. BIOCHEM. 146, 449-458

DV6161

T.DINGERMANN ET.AL. (1986) NUCL. ACIDS RES. 14, 1127-1127

DV6280 R.E.BAKER, A.EIGEL, D.VOEGTEL, H.FELDMANN (1982) EMBO J. 1, 291-295

DV6281 I.GOKHMAN, A.ZAMIR (1990) NUCL. ACIDS RES. 18, 6130-6130

DV6740 I.GOKHMAN, A.ZAMIR (1990) NUCL. ACIDS RES. 18, 6729-6729

DV7740 W.R.ADDISON ET AL. (1982) J. BIOL. CHEM. 257, 670-673

DV7741 R.DELOTTO, P.SCHEDL (1984) J. MOL. BIOL. 179, 587-605 J.LEUNG ET AL. (1984) GENE $34,207-217$

DV7920 R.C.PETERSON (1987) BIOCHIM. BIOPHYS. ACTA 908, 81-89

DV9990 G.J.ARNOLD ET AL. (1986) GENE 44, 287-297

DV9991 G.J.ARNOLD ET AL. (1986) GENE 44, 287-297

DV9992 R.D.SHORTRIDGE ET AL. (1989) GENE 79, 309-324

DV9993 H.U.THOMANN ET AL. (1989) J. MOL. BIOL. 209, 505-523

DV9994 H.U.THOMANN ET AL. (1989) J. MOL. BIOL. 209, 505-523

DV9995 H.U.THOMANN (1989) J. MOL. BIOL. 209, 505-523

DW0460 C.J.DANIELS, S.E.DOUGLAS, W.F.DOOLITTLE (1986) SYSTEM. APPL. MICROBIOL. 7, 26-29

DW0500 C.J.DANIELS, R.GUPTA, W.F.DOOLITTLE (1985) J. BIOL. CHEM. 260, 3132-3134

DW1140 F.YAMAO ET AL. (1985) PROC. NATL. ACAD. SCI. USA 82, 2306-2309

DW1141 F.YAMAO ET AL. (1985) PROC. NATL. ACAD. SCI. USA 82, 2306-2309

DW1230 R.TANAKA, A.MUTO, S.OSAWA (1989) NUCL. ACIDS RES. 17, 5842-5842

DW1540 E.F.WAWROUSEK, N.NARASIMHAN, J.N.HANSEN (1984) J. BIOL. CHEM. 259, 3694-3702

DW1660 R.A.YOUNG (1979) J. BIOL. CHEM. 254, 12725-12731

DW2440 D.ZHANG, R.J.SPREITZER (1989) NUCL. ACIDS RES. 17, 8873-8873

DW2520 R.B.HALLICK ET AL. (1984) PLANT. MOL. BIOL. 3, 169-175 
2158 Nucleic Acids Research, Vol. 19, Supplement

DW2600 K. OHYAMA ET AL. (1988) J. MOL. BIOL. 203, 281-298

DW2680 L.MARECHAL ET AL. (1987) CURR. GENET. 12, 91-98

DW2720 J.H.LUKENS, L.BOGORAD (1988) NUCL. ACIDS RES. 16, 5192-5192

DH2920 M.SUGIURA, K.SHIMOZAKI, M.OHME IN:NATO ASI SER; SER. A 83 FUNCT. PLANT GENOAE) 325-334

DW3000 W.SCHUSTER, J.M.GRIENENBERGER, J.-H.WEIL, A.BRENNICKE (1988) NUCL. ACIDS RES. $16,7737-7737$

DW3200 J.LEHMBECK, B.M.STUMAAN, K.W. HENNINGSEN (1987) NUCL. ACIDS RES. 15, 3630-3630

DW3640 D. -P.MA, Y.-W.YANG, S.E.HASNAIN (1988) NUCL. ACIDS RES. 16, 11373-11373

P.H.BOER, M.W.GRAY (1988) CURR. GENET. 14, 583-590

DW3760 J.J.SEILHAMER, D.J.CUMMINGS (1982) MOL. GEN. GENET. 187, 236-239

DW3770 A.E.PRITCHARD, J.J.SEILHAMER, R.MAHALINGAM, C.L.SABLE, S.E.VENUTI, D.J.CUMMINGS (1990) NUCL. ACIDS RES. 18, 173-180

DW3800 Y.SUYAMA (1985) NUCL. ACIDS RES. 13, 3273-3284

DW3880 H.G.KOECHEL, C.M.LAZARUS, N.BASAK, H.KUENTZEL (1981) CELL 23, 625-633

DW3960 D.J.CUMMINGS, I.A.MACNEIL, J.DOMENICO, , E.T.MATSUURA (1985) J. MOL. BIOL. 185, $659-680$

DW4080 G.D.CLARK-WALKER, C.R.MCARTHUR, K.S.SRIPRAKASH (1985) EMBO J. 4, 465-473

DW4120 N.C.MARTIN, H.D.PHAM, K.UNDERBRINK-LYON, D.L.MILLER, J.E.DONELSON (1980) NATURE $285,579-581$

DW4360 W.SCHUSTER, J.M.GRIENENBERGER, J.-H.WEIL, A.BRENNICKE (1988) NUCL. ACIDS RES. $16,7737-7737$

DW4440 L.MARECHAL ET AL. (1987) CURR. GENET. 12, 91-98

DW4480 L.MARECHAL ET AL. (1987) CURR. GENET. 12, 91-98 P.LEON, V.WALBOT, P.BEDINGER (1989) NUCL. ACIDS RES. 17, 4089-4099

DW4640 D.R.WOLSTENHOLME ET AL. (1987) PROC. NATL. ACAD. SCI. USA 84, 1324-1328

DW4680 R.OKIMOTO. D.R.WOLSTENHOLME (1990) EMBO J. 9, 3405-3411

DW4840 M.H.L.DE BRUIJN (1983) NATURE 304, 234-241

DW4880 D.0.CLARY, D.R. WOLSTENHOLME (1985) J. MOL. EVOL. 22, 252-271

DW4980 H.T.JACOBS, S.ASAKAWA, T.ARAKI, K.MIURA, M.J.SMITH, L.WATANABE (1989) CURR. GENET. 15, 193-206

DW5000 H.T.JACOBS, S.ASAKAWA, T.ARAKI, K.MIURA, M.J.SMITH, K.WATANABE (1989) CURR. GENET. 15, 193-206

DW5020 H.T.JACOBS, S.ASAKAWA, T.ARAKI, K.MIURA, M.J.SMITH, K. WATANABE (1989) CURR. GENET. 15, 193-206

DW5040 P.CANTATORE ET AL. (1988) CURR. GENET. 13, 91-96

DW5080 H.T.JACOBS, D.J.ELLIOTT, V.B.MATH, A.FARQUHARSON (1988) J. MOL. BIOL. 202, $185-$ 217

DW5100 S.JOHANSEN, P.H.GUDDAL, T.JOHANSEN (1990) NUCL. ACIDS RES. 18, $411-419$

DW5120 B.A.ROE, D.P.MA, R.K.WILSON, J.F.H.WONG (1985) J. BIOL. CHEM. 260, 9759-9774

DW5160 H.FUJII, T.SHIMADA, Y.GOTO, T.OKAZAKI (1988) J. BIOCHEM. 103, 474-481

DW5280 M.TAIRA ET AL. (1983) NUCL. ACIDS RES. 11, 1635-1643

DW5281 P.CANTATORE ET AL. (1982) NUCL. ACIDS RES. 10, 3279-3289; R.GROSSKOPF, H.FELDMANN (1981) CURR. GENET. 4, 191-196 G.PEPE ET AL. (1983) BIOCHEM. INT. 6, $553-563$

DW5320 M.J.BIBB, R.A.VAN ETTEN, C.T.WRIGHT, M.W.WALBERG, D.A.CLAYTON (1981) CELL 26, $167-180$

DW5360 S.ANDERSON ET AL. (1982) J. MOL. BIOL. 156, 683-717

DW5880 S.ANDERSON ET AL. (1981) NATURE 290, 457-465

DW6160 D.M.PEFFLEY, M.L. SOGIN (1981) BIOCHEMISTRY 20, 4015-4021

DW6280 H.S.KANG, J.ABELSON UNPUBLISHED RESULTS IN: R.C.ODGEN ET AL. (1979) CELL 17, 399-406 D.KIM, J.JOHNSON (1988) J. BIOL. CHEM. 263, 7316-7321

DW7560 K.KONDO, J.HODGKIN, R.H.WATERSTON (1988) MOL. CELL. BIOL. 8, 3627-3635

DW8040 R.AMMENDOLA, T.RUSSO, F.CIMINO (1988) NUCL. ACIDS RES. 16, $4728-4728$

DX0260 S.M.DESAI, J.VAUGHAN, S.B.WEISS (1986) NUCL. ACIDS RES. 14, 4197-4205

DX0860 B.P.KAINE (1987) J. MOL. EVOL. 25, 248-254

DX0980 G.WICH, W.LEINFELDER, A.BOECK (1987) EMBO J. 6, 523-528

DX1140 A.MUTO, Y.ANDACHI, H.YUZAWA, F.YAMAO, S.OSAWA (1990) NUCL. ACIDS RES. 18, $5037-$ 5043 
DX1180 T.SAMUELSSON, P.ELIAS, F.LUSTIG, Y.S.GUINDY (1985) BIOCHEM. J. 232, 223-228

DX1260

DX1340

DX1341

DX1540

DX1660

DX1661

DX2520

DX2600

DX2640

DX2680

DX2920

DX3200

DX3720

DX3800

DX3840

DX3880

DX4080

DX4120

DX4280

DX4320

DX4360

DX4440

DX4480

DX4640

DX4680

DX4880

DX4960

DX4980

DX5020

DX5040

DX5080

DX5120

DX5160

DX5280

DX5281

DX5320

DX5360

DX5880

DX6280

DX6281

DX6320

DX6321

DX6740

DX6900

DX7560

DX7740

DX7920

M.J.ROGERS, A.A.STEINMETZ, R.T.WALKER (1986) NUCL. ACIDS RES. 14, 3145-3145 V.GAMULIN, D.SOELL (1987) NUCL. ACIDS RES. 15, 6747-6747

V.GAMULIN, D.SOELL (1987) NUCL. ACIDS RES. 15, 6747-6747

C.J.GREEN, G.C.STEWART, M.A.HOLLIS, B.S.VOLD, K.F.BOTT (1985) GENE 37, 261-266

S.ISHII ET AL. (1984) NUCL. ACIDS RES. 12, 3333-3342

T.NAGASE, S.ISHII, F.IMAYOTO (1988) GENE 67, 49-57

R.B.HALLICK ET AL. (1984) PLANT. MOL. BIOL. 3, 169-175

K. UMESONO, H. INOKUCHI, K.OHYAMA, H.OZEKI (1984) NUCL. ACIDS RES. 12, 9551-9565 R.P.OLIVER, C.POULSEN (1984) GARLSBERG RES. COMMUN. 49, 647-673

F.QUIGLEY, J.H.WEIL (1985) CURR. GENET. 9, 495-503 C.J.HOWE (1985) CURR. GENET. $10,139-145$

M.SUGIURA, K.SHINOZAKI, M.OHME IN:NATO ASI SER; SER. A 83 (1985) (MOL. FORM FUNCT. PLANT GENOME) 325-334

J.LEHMBECK, B.M.STUMAANN, K.W.HENNINGSEN (1987) NUCL. ACIDS RES. 15, 3630-3630

T.Y.K.HEINONEN, M.N.SCHNARE, P.G.YOUNG, M.W.GRAY (1987) J. BIOL. CHEM. 262, $2879-2887$

T.Y.K.HEINONEN, M.N.SCHNARE, P.G.YOUNG, M.W.GRAY (1987) J. BIOL. CHEM. 262,

2879-2887 Y.SUYAMA, F.JENNEY, N.OKAWA (1987) CURR. GENET. 11, 327-330

G.B.MORIN, T.R.CECH (1988) NUCL. ACIDS RES. 16, 327-346

H.G.KOECHEL, C.M.LAZARUS, N.BASAK, H.KUENTZEL (1981) CELL 23, 625-633

G.D.CLARK-WALKER, C.R.MCARTHUR, K.S.SRIPRAKASH (1985) EMBO J. 4, 465-473

D.L.MILLER ET AL. (1983) IN: MITOCHONDRIA, R.J.SCHWEYEN ET AL. (ED.) PP. 151 -

164, DE GRUYTER BERLIN

E.A.GRABAU (1987) CURR. GENET. 11, 287-293

P.BORSUK, A.SIRKO, E.BARTNIK (1986) NUCL. ACIDS RES. 14, 7508-7508

M.GOTTSCHALK, A.BRENNICKE (1985) CURR. GENET. 9, 165-168

M.W.GRAY, D.F.SPENCER (1983) FEBS LETTERS 161, 323-327

T.D.PARKS, W.G.DOUGHERTY, C.S.LEVINGS III, D.H.TIMOTHY (1984) PLANT PHYSIOL. 76, 1079-1082

D.R.WOLSTENHOLME ET AL. (1987) PROC. NATL. ACAD. SCI. USA 84, 1324-1328

D.R.WOLSTENHOLME ET AL. (1987) PROC. NATL. ACAD. SCI. USA 84, 1324-1328

D. O.CLARY, D.R.WOLSTENHOLME (1985) J. MOL. EVOL. 22, 252-271

D.O.CLARY, D.R.WOLSTENHOLME (1987) J. MOL. EVOL. 25, 116-125

H.T.JACOBS, S.ASAKAWA, T.ARAKI, K.MIURA, M.J.SMITH, K.WATANABE (1989) CURR.

GENET. 15, 193-206

H.T.JACOBS, S.ASAKAWA, T.ARAKI, K.MIURA, M.J.SMITH, K.WATANABE (1989) CURR. GENET. 15, 193-206

P.CANTATORE ET AL. (1988) CURR. GENET. 13, 91-96

H.T.JACOBS, D.J.ELLIOTT, V.B.MATH, A.FARQUHARSON (1988) J. MOL. BIOL. 202, 185 217

B.A.ROE, D.P.MA, R.K.WILSON, J.F.H.WONG (1985) J. BIOL. CHEM. 260, 9759-9774

H.FUJII, T.SHIMADA, Y.GOTO, T.OKAZAKI (1988) J. BIOCHEM. 103, 474-481

D.R.WOLSTENHOLME, C.M. -R.FAURON, J.M.GODDARD (1982) GENE 20, 63-69

P.CANTATORE ET AL. (1982) NUCL. ACIDS RES. 10, 3279-3289

M.J.BIBB, R.A.VAN ETTEN, C.T.WRIGHT, M.W.WALBERG, D.A.CLAYTON (1981) CELL 26,

$167-180$

S.ANDERSON ET AL. (1982) J. MOL. BIOL. 156, 683-717

S.ANDERSON (1981) NATURE 290, 457-465

A.VENEGAS, E.GONZALEZ, P.BULL, P.VAlENZUELA (1982) NUCL. ACIDS RES. 10, 1093 1096

A.M.CIGAN, T.F.DONAHUE (1986) GENE 41, 343-348

H.AMSTUTZ, P.MUNZ, W.D.HEYER, U.LEUPOLD, J.KOHLI (1985) CELL 40, 879-886

H.AMSTUTZ, P.MUNZ, W-D.HEYER, U.LEUPOLD, J.KOHLI (1985) CELL 40, 879-886

K.AKAMA, S.TANIFUJI (1989) PLANT MOL. BIOL. 13, 599-600

J.M.PALMER, W.R. FOLK (1987) PLANT MOL. BIOL. 8, 47-51

M.KHOSLA, B.M.HONDA (1989) GENE 76, 321-330

S.SHARP ET AL. (1981) NUCL. ACIDS RES. 9, 5867-5882

R.A.HIPSKIND, S.G.CLARKSON (1983) CELL 34, 881-890 
DX7921 W.R.FOLK, H.HOFFSTETTER (1983) CELL 33, 585-593 R.A.KOSKI, S.G.CLARKSON (1982) J. BIOL. CHEY. 257, 4514-4521

DXE100 J.H.HAN, R.J.ROONEY, J.D.HARDING (1984) GENE 28, 249-255

DX9990 T.SANTOS, M.ZASLOFF (1981) CELL 23, 699-709

DK9991 H.J.DRABKIN, U.L.RAJBHANDARY (1985) J. BIOL. CHEM. 260, 5596-5602

DY0660 G.WICH, M.JARSCH, A.BOECK (1984) MOL. GEN. GENET. 196, 146-151

DY0740 G.WICH, L.SIBOLD, A.BOECK (1987) Z. NATURFORSCH. 42C, 373-380

DY1140 Y.ANDACHI ET AL. (1987) PROC. MATL. ACAD. SCI. USA 84, 7398-7402

DY1200 P.SIMONEAU, R.WENZEL, R. HERRMANN, P.C.HU (1990) NUCL. ACIDS RES. 18, 2814-2814

DY1540 E.F.WAWROUSEK, N.NARASIMHAN, J.N.HANSEN (1984) J. BIOL. CHEM. 259, 3694-3702

DY1580 M.WEISSHAR, R.AHMADIAN, M.SPRINZL, M.SATOH, A.KUSHIRO, K.TOMITA (1990) NUCL. ACIDS RES. 18, 1902-1902

DY1660 L.HUDSON, J.ROSSI, A.LANDY (1981) NATURE 294, $422-427$ G.AN, J.D.FRIESEN (1980) GENE 12, 33-39 A.MIYAJIMA, T.YOKOTA, Y.TAKEBE, M.NAKAMURA, Y.KAZIRO (1983) J. BIOCHEM. 93, 1101-1108 G.M.MCCORKLE, S.ALTMAN (1982) J. MOL. BIOL. 155, 83-103

DY1661 J.J,ROSSI, M.SCHOLD, G.P.LARSON, R.B.WALLACE (1982) GENE 20, 423-432

G.M.MCCORKLE, S.ALTMANN (1982) J.MOL.BIOL. 155, 83-103

DY1820 M.A.HUGHES, D.S.JONES (1988) NUCL. ACIDS RES. 16, 7193-7193

DY2520 R.B.HALLICK ET AL. (1984) PLANT. MOL. BIOL. 3, 169-175

DY2600 K. OHYAMA ET AL. (1988) J. MOL. BIOL. 203, 281-298

DY2680 F.QUIGLEY, J.H.WEIL (1985) CURR. GENET. 9, 495-503

DY2920 M.OHME, T.KAMOGASHIRA, K.SHINOZAKI, M.SUGIURA (1985) NUCL. ACIDS RES. 13, 10451056

DY3200 D.R.SHAPIRO, K.K.TEWARI (1986) PLANT MOL BIOL. 6, 1-12

DY3280 K.HOLSCHUH, W.BOTTOMLEY, P.R.WITHFELD (1984) PLANT MOL. BIOL. 3, 313-317

DY3360 J.H.WEIL, G.BONNARD, M.KUNTZ, A.STEINMETZ IN:NATO ASI SER; SER. A 83 (1985) (MOL. FORM FUNCT. PLANT GENOME) 313-324

DY3720 J.J.SEILHAMER, R.R.GUTELL, D.J.CUMMINGS (1984) J. BIOL. CHEM. 259, 5173-5181

DY3760 J.J.SEILHAMER, R.R.GUTELL, D.J.CUMMINGS (1984) J. BIOL. CHEM. 259, 5173-5181

DY3770 A.E.PRITCHARD, J.J.SEILHAMER, R.MAHALINGAM, C.L.SABLE, S.E.VENUTI, D.J.CUMMINGS (1990) NUCL. ACIDS RES. 18, 173-180

DY3840 G.B.MORIN, T.R.CECH (1988) NUCL. ACIDS RES. 16, 327-346

DY3880 R.NETZKER, H.G.KOECHEL, N.BAZAK, H.KUENTZEL (1982) NUCL. ACIDS RES. 10, 4783 4794

DY4000 M.P.NOBREGA, F.G.NOBREGA (1986) J. BIOL. CHEM. 261, 3054-3059

DY4001 M.P.NOBREGA, F.G.NOBREGA (1986) J. BIOL. CHEM. 261, 3054-3059

DY4080 G.D.CLARK-WALKER, C.R.MCARTHUR, K.S.SRIPRAKASH (1985) EMBO J. 4,465-473

DY4240 H.C.CHEN, H.WINTZ, J.H.WEIL, D.T.N.PILLAY (1989) NUCL. ACIDS RES. 17, 2613-2621

DY4400 S.BIRD, B.DUNCKER, P.GARBER, L.BONEN (1989) NUCL. ACIDS RES. 17 4379-4379

DY4440 P.B.M.JOYCE, D.F.SPENCER, L.BONEN, M.W.GRAY (1988) PLANT MOL. BIOL. 10, 251-262

DY4480 A.SANGARE, D.LONSDALE, J.H.WEIL, J.M.GRIENENBERGER (1989) CURR. GENET. 16, 195 201

DY4640 D.R.WOLSTENHOLME ET AL. (1987) PROC. NATL. ACAD. SCI. USA 84, 1324-1328

DY4840 M.H.L.DE BRUIJN (1983) NATURE 304, 234-241

DY4880 D.O.CLARY, D.R.WOLSTENHOLME (1985) J. MOL. EVOL. 22, 252-271

DY4980 H.T.JACOBS, S.ASAKAWA, T.ARAKI, K.MIURA, M.J.SMITH, K.WATANABE (1989) CURR. GENET. 15, 193-206

DY5000 H.T.JACOBS, S.ASAKAWA, T.ARAKI, K.MIURA, M.J.SMITH, K.WATANABE (1989) CURR. GENET. 15, 193-206

DY5020 H.T.JACOBS, S.ASAKAWA, T.ARAKI, K.MIURA, M.J.SMITH, K.WATANABE (1989) CURR. GENET. 15, 193-206

DY5040 P.CANTATORE ET AL. (1988) CURR. GENET. 13, 91-96

DY5080 H.T.JACOBS, D.J.ELLIOTT, V.B.MATH, A.FARQUHARSON (1988) J. MOL. BIOL. 202, 185 217

DY5100 S.JOHANSEN, P.H.GUDDAL, T.JOHANSEN (1990) NUCL. ACIDS RES. 18, $411-419$

DY5120 B.A.ROE, D.P.MA, R.K.WILSON, J.F.H.WONG (1985) J. BIOL. CHEM. 260, $9759-9774$

DY5160 Y.YONEYAMA (1987) J. NIPPON MED. SCH. 54, 429-440 
DY5280 P.CANTATORE ET AL. (1982) NUCL. ACIDS RES. 10, 3279-3289; R.GROSSKOPF, H.FELDMANN (1981) CURR. GENET. 4, 191-196 G.PEPE ET AL. (1983) BIOCHEM. INT. 6, 553-563 M.TAIRA ET AL. (1983) NUCL. ACIDS RES. 11, 1635- 1643

DY5320 M.J.BIBB, R.A.VAN ETTEN, C.T.WRIGHT, M.W.WALBERG, D.A.CLAYTON (1981) CELL 26, $167-180$

DY5360 S.ANDERSON ET AL. (1982) J. MOL. BIOL. 156, 683-717

DY5880 S.ANDERSON ET AL. (1981) NATURE 290, 457-465

DY6280 H.M.GOODMAN, M.V.OLSON, B.D.HALL (1977) PROC. NATL. ACAD. SCI. USA 74, 5453-5457

DY6740 N.STANGE, H.J.GROSS, H.BEIER (1988) EMBO J. 7, 3823-3828

DY7060 N.STANGE, H.BEIER (1986) NUCL. ACIDS RES. 14, 8691-8691

DY7200 Z.SZWEYKOWSKA-KULINSKA, H.BEIER (1990) NUCL. ACIDS RES. 18, 1894-1894

DY7740 B.SUTER, E.KUBLI (1988) MOL. CELL. BIOL. 8, 3322-3331

DY7920 F.MUELLER, S.G.CLARKSON (1980) CELL 19, 345-353

DY7921 E.GOUILLOUD, S.G.CLARKSON (1986) J. BIOL. CHEM. 261, 486-494

DY7922 F.STUTZ, E.GOUILLOUD, S.G.CLARKSON (1989) GEN. DEVELOP. 3, 1190-1198

DY9990 J.M.MACPHERSON, K.L.ROY (1986) GENE 42, 101-106

DY9991 J.M.MACPHERSON, K.L.ROY (1986) GENE 42, 101-106

\section{RNA SEQUENCES}

RA0380 X.-R.GU, K.NICOGHOSIAN, R.J.CEDERGREN, J.T.-F.WONG (1983) NUCL. ACIDS RES. 11, $5433-5442$

RA0500 R.GUPTA (1984) J. BIOL. CHEM. 259, 9461-9471

RA0501 R.GUPTA (1984) J. BIOL. CHEM. 259, 9461-9471

RA0502 R.GUPTA (1984) J. BIOL. CHEM. 259, 9461-9471

RA1140 Y.ANDACHI ET AL. (1989) J. MOL. BIOL. 209, 37-54

RA1180 T.SAMUELSSON ET AL. (1987) PROC. NATL. ACAD. SCI. USA 84, 3166-3170

RA1540 H.ISHIKURA, K.MURAO, Y.YAMADA, EMBO-FEBS MEETING, STRASBOURG, JULY 1980

RA1660 B.H.MIMS, N.E.PRATHER, E.J.MURGOLA (1985) J. BACT. 162, 837-839

RA1661 R.J.WILLIAMS, W.NAGEL, B.ROE, B.DUDOCK (1974) BIOCHEM. BIOPHYS . RES. COMM. 60, $1215-1221$

RA1662 E.LUND, J.E.DAHLBERG (1977) CELL 11, 247-262

RA3920 J.E.HECKMAN ET AL. (1980) PROC. NATL. ACAD. SCI. USA 77, 3159-3163

RA6360 S.TAKEMURA, K. OGAWA (1973) J. BIOCHEM. 74, 323-333

RA6400 J.R.PENSWICK, R.MARTIN, G.DIRHEIMER (1975) FEBS LETTERS 50, $28-31$

RA7680 K.U.SPRAGUE, O.HAGENBUECHLE, M.C.ZUNIGA (1977) CELL 11, 561-570

RA7681 K.U.SPRAGUE, O.HAGENBUECHLE, M.C.ZUNIGA (1977) CELL 11, 561-570

RA9990 C.C.BUNN, M.B.MATHEWS (1987) MOL. BIOL. MED. 4, 21-36

RA9991 C.C.BUNN, M.B.MATHEWS (1987) MOL. BIOL. MED. 4, 21-36

RC0500 R.GUPTA (1984) J. BIOL. CHEM. 259, $9461-9471$

RC1140 Y.ANDACHI ET AL. (1989) J. MOL. BIOL. 209, 37-54

RC1660 G.P.MAZZARA, W.H.MCCLAIN (1977) J. MOL. BIOL. 117, 1061-1079

RC6400 N.J.HOLNESS, G.ATFIELD (1976) BIOCHEM. J. 153, 447-454

RD0260 M.G.SHLYAPNIKOV, V.N.KSENZENKO, V.M.KRYUKOV, A.A.BAYEV (1986) EUR. J. BIOCHEM. $156,285-289$

RD0500 R.GUPTA (1984) J. BIOL. CHEM. 259, 9461-9471

RD1140 Y.ANDACHI ET AL. (1989) J. MOL. BIOL. 209, 37-54

RD1660 T.SEKIYA, M.MORI, N.TAKAHASHI, S.NISHIMURA (1980) NUCL. ACIDS RES. 8, 3809-3827

RD4800 C. -C.HSUCHEN, G.R.CLEAVES, D.T.DUBIN (1983) PLASMID 10, 55-65

RD5240 C. - C. HSUCHEN, G.R.CLEAVES, D.T.DUBIN (1983) PLASMID 10, 55-65

RD5280 K. RANDERATH, H.P.AGRAWAL, E.RANDERATH (1983) REC. RES. CAN. RES . 84, 103-120

RD5281 H.P.AGRAWAL, K.RANDERATH, E.RANDERATH (1981) NUCL. ACIDS RES. 9, 2535-2541

RD6040 W.G.FARMERIE, S.H.CHANG, W.E.BARNETT (1980) FED. PROC. 39, 2022 ABSTR. 2193

RD6400 J.GANGLOFF, G.KEITH, J.P.EBEL, G.DIRHEIMER (1972) BIOCHIM. BIOPHYS. ACTA 259 , 210-222

RD7920 E.HAUMONT, K.NICOGHOSIAN, H.GROSJEAN, R.J.CEDERGREN (1984) BIOCHIMIE 66, $579-582$

RD9160 Y.KUCHINO ET AL. (1981) J. BIOL. CHEM. 256, 9059-9062

RD9161 Y.KUCHINO ET AL. (1981) J. BIOL. CHEM. 256, 9059-9062

RD9220 V.N.VAKHARIA, R.P.SINGHAL (1982) BIOCHEM. BIOPHYS. RES. COMM. 105, 1072-1081 
RD9280 R20500 R=0501

R=1140 RS1660 RE1661

RE1662

RE2140

RE2440

RE2640

RP4800

RE5360

RE6320

RE6400

RE6780

RE6781

RE6940

RE7740

RE8100

RE9160

RE9990

RF0500

RF1140

RF1460

RF1540

RF1660

RF2020

RF2060

RF2520

RF3160

RF3280

RF3800

RF4000

RF4400

RF5280

RF6040

RF6120

RF6200

RF6320

RF6400

RF6401

RF6780

RF6820

RF6860

RF6940

RF7020

RF7680

RF7681

RF7740

RF7920

RF8100

RF8101

RF8102

RF9220
V.N.VAXHARIA (1981) FED. PROC. 40, 1753 ABSTR. 1234

R. CURTA (1984) J. BIOL. CHEM. 259, 9461-9471

R.GUPTA (1984) J. BIOL. CHEM. 259, $9461-9471$

Y.ANDACHI ET AL. (1989) J. MOL. BIOL. 209, 37-54

M.UZIEL, A.J.WEINBERGER (1975) NUCL. ACIDS RES. 2, 469-475

Z.OHASHI, F.HARADA, S.NISHIMURA (1972) FEBS LETTERS 20, 239-241 K.0.MUNNIGER,

S.H.CHANG (1972) BIOCHEM. BIOPHYS. RES. COMY . 46, 1837-1842

R. WATARABE, K. - I.MIURA (1985) BIOC. BIOP. RES. COM. 129, 679-685

G.P.O'NEILL ET AL. (1988) J. BACT. 170, 3810-3816

G.P.ONEILL, A.SCHOEN, H.CHOW, M.CHEN, Y.KIM, D.SOELL (1990) NUCL. ACIDS RES. 18 , $5893-5893$

A.SCHOEN ET AL. (1986) NATURE 322, 281-284

D.T.DUBIN, C. -C.HSUCHEN, L.E.TILLOTSON (1986) CURR. GEN. 10, 701-707

B.A.ROE, J.F.H.WONG, E.Y.CHEN (1982) PERSONAL COMMUNICATION

T. -W.WONG, T.MCCUTCHAN, J.KOHLI, D. SOELL (1979) NUCL. ACIDS RES . 6, 2057-2068

T.KOBAYASHI ET AL. (1974) BIOCHIM. BIOPHYS. ACTA 366, 168-181

D.PETERSON, A.SCHOEN, D.SOELL (1988) PLANT MOL. BIOL. 11, 293-299

D.PETERSON, A.SCHOEN, D.SOELL (1988) PLANT MOL. BIOL. 11, 293-299

M. BARCISZEWSKA, J.BARCISZEWSKI (1988) MOL. BIOL. REP. 13, 11-14

M.ALTWEGG, E.KUBLI (1980) NUCL. ACIDS RES. 8, 215-223

F.L.SMARDO JR., J.P.CALVET (1987) GENE 57, 213-220

J.C.CHAN ET AL. (1982) NUCL. ACIDS RES. 10, 3755-3758

F.L.SMARDO JR., J.P.CALVET (1987) NUCL. ACIDS RES. 2, 661-681

R.GUPTA (1984) J. BIOL. CHEM. 259, $9461-9471$

M.E.KIMBALL, K.S.SZETO, D.SOELL (1974) NUCL. ACIDS RES. 1, 1721-1732

G.KEITH, C.GUERRRIER-TAKADA, H.GROSJEAN, G.DIRHEIMER (1977) FEBS LETTERS 84 , 241-244

H. -H.ARNOLD, G.KEITH (1977) NUCL. ACIDS RES . 4, 2821-2829

B.G.BARRELL, F.SANGER (1969) FEBS LETTERS 3, 275-278

N.NEWHOUSE, K.NICOGHOSIAN, R.J.CEDERGREN (1981) CAN. J. BIOC. 59, 921-932

L.I.HECKER ET AL. (1982) NUCL. ACIDS RES. 10, 6433-6440

S.H.CHANG ET AL. (1976) CELL 9, 717-723

P.GUILLEMAUT, G.KEITH (1977) FEBS LETTERS 84, $351-356$

J.CANADAY, P.guilleMAUT, R.GLOECKLER, J.-H.WEIL (1980) PLANT SCI. LETTERS 20, $57-62$

M.N.SCHNARE, T.Y.K.HEINONEN, P.G.YOUNG, M.W.GRAY (1985) CURR. GEN. 9, 389-393

R.P.MARTIN ET AL. (1978) NUCL. ACIDS RES. 5, 4579-4592

L.MARECHAL ET AL. (1985) FEBS LETTERS 184, 289-293

K. RANDERATH, H.P.AGRAWAL, E.RANDERATH (1983) REC. RES . CAN. RES . 84, 103-120

S.H.CHANG ET AL. (1981) NUCL. ACIDS RES. 9, 3199-3204

G.A.GREEN, D.S.JONES (1986) BIOCHEM. J. 236, 601-603

B.ALZNER-DEWEERD, L.I.HECKER, W.E.BARNETT, U.L.RAJBHANDARY (1980) NUCL. ACIDS RES . 8, 1023-1032

T.MCCUTCHAN, S.SILVERMAN, J.KOHLI, D.SOELL (1978) BIOCHEMISTRY 17, 1622-1628

P.E.NIELSEN, V.LEICK (1982) BIOCHEM. BIOPHYS. RES. COMM. 106, 179-185

G.KEITH, G.DIRHEIMER (1987) BIOCHEM. BIOPHYS. RES. COMM. 142, 183-187

Z.JANOWICZ, J.M.WOWER, J.AUGUSTYNIAK (1979) PLANT SCI. LETTERS 14, 177-183

J.M.WOWER, Z.A.JANOWICZ, J.AUGUSTYNIAK (1979) PLANT SCI. LETTERS 14, 177-183

M.BARCISZEWSKA ET AL. (1984) BIOCHIMIE 66, 483-486

A.J.RAFALSKI ET AL. (1977) ACTA BIOC. POLONICA 24, 301-318

G.A.EVERETT, J.T.MADISON (1976) BIOCHEMISTRY 15, 1016-1021;

G.KEITH, G.DIRHEIMER (1980) BIOCHEM. BIOPHYS. RES. COMM. 92, 109-115

G.KEITH, G.DIRHEIMER (1980) BIOCHEM. BIOPHYS . RES . COMM. 92, 109-115

M.ALTWEGG, E.KUBLI (1979) NUCL. ACIDS RES. 7, 93-105

A.MAZABRAUD (1982) BIOCHIMIE 64, 955-960

Y.KUCHINO ET AL. (1982) NUCL. ACIDS RES. 10, 6421-6432

Y.KUCHINO ET AL. (1982) NUCL. ACIDS RES. 10,6421-6432

Y.KUCHINO ET AL. (1982) NUCL. ACIDS RES. 10, 6421-6432

G.KEITH ET AL. (1973) FEBS LETTERS 31, 345-347 
RF9280 F.-K.LIN ET AL. (1980) J. BIOL. CHEM. 255, 6020-6023

RF9281 F.-K.LIN ET AL. (1980) J. BIOL. CHEA. 255, 6020-6023

RF9340 G.KEITH, J.P.EBEL, G.DIRHEIMER (1974) FEBS LETTERS 48, 50-52

RF9990 B.A.ROE ET AL. (1975) BIOCHEM. BIOPHYS. RES. COYM. 66, 1097-1105

RG0220 S.STAHL, G.V.PADDOCK, J.ABELSON (1974) NUCL. ACIDS RES. 1, 1287-1304

RG0380 K.NICOGHOSIAN, X.-R.GU, R.CEDERGREN (1985) FEBS LETTERS 193, 255-260

RG0500 R.GUPTA (1984) J. BIOL. CHEM. 259, 9461-9471

RG0501 R.GUPTA (1984) J. BIOL. CHEM. 259, 9461-9471

RG0502 R.GUPTA (1984) J. BIOL. CHEM. 259, 9461-9471

RG0503 R.GUPTA (1984) J. BIOL. CHEM. 259, 9461-9471

RG0620 X. -R.GU, K.NICOGHOSIAN, R.J.CEDERGREN (1984)

RG1140 Y.ANDACHI ET AL. (1989) J. MOL. BIOL. 209, 37-54

RG1180 M.W.KILPATRICK, R.T.WALKER (1980) NUCL. ACIDS RES. 8, 2783-2786

RG1310

RG1380

RG1381

RG1540

RG1660

RG1661

RG1662

RG1700

RG1701

RG2530

J.S.ROKEM, A.SCHOEN, D.SOELL (1990) NUCL. ACIDS. RES. 18, 3988-3988

R.J.ROBERTS (1974) J. BIOL. CHEM. 249, 4787-4796

R.J.ROBERTS (1974) J. BIOL. CHEM. 249, 4787-4796

H.ISHIKURA, K.MURAO, Y.YAMADA, EMBO-FEBS MEETING, STRASBOURG, JULY 1980

C.W.HILL ET AL. (1973) J. BIOL. CHEM. 248, 4252-4262

C.SQUIRES, J.CARBON (1971) NATURE NEW BIOL. 233, 274-277

J.W.ROBERTS, J.CARBON (1975) J. BIOL. CHEM. 250, 5530-5541

C.W.HILL ET AL. (1973) J. BIOL. CHEM. 248, 4252-4262

RG4000

D.J.MAHONY ET AL. (1989) PROC. NATL. ACAD. SCI. USA 86, 7979-7983

RG4800

M.A.FRANCIS, E.R.SUH, B.S.DUDOCK (1989) J. BIOL. CHEM. 264, 17243-17249

RG5360

A.-P.SIBLER, G.DIRHEIMER, R.P.MARTIN (1986) FEBS LETTERS 194, 131-138

D.T.DUBIN, C. -C.HSUCHEN, L.E.TILLOTSON (1986) CURR. GEN. 10, 701-707

RG6280

B.A.ROE, J.F.H.WONG, E.Y.CHEN, P.A.ARMSTRONG (1981) PROC. THIRD CLEVELAND SYMP. A.G.WALTON (ED.) ELSEVIER AMSTERDAM

RG6281

M. YOSHIDA (1973) BIOCHEM. BIOPHYS. RES. COMM. 50, 779-784

RG6820

M.D.MENDENHALL ET AL. (1987) J. MOL. BIOL. 194, 41-58

RG6940

K.B.MARCU, R.E.MIGNERY, B.S.DUDOCK (1977) BIOCHEMISTRY 16, 797-806

M.BARCISZEWSKA, J.BARCISZEWSKI, Y.KUCHINO, S.NISHIMURA (1986) NUCL. ACIDS RES. $14,9525-9525$

RG7680 J.P.GAREL, G.KEITH (1977) NATURE 269, 350-352 M.C.ZUNIGA, J.A.STEITZ (1977) NUCL. ACIDS RES. 4, 4175-4196

RG7681 M.KAWAKAMI, K.NISHIO, S.TAKEMURA (1978) FEBS LETTERS 87, 288-290 M.KAWAKAMI ET AL. (1988) 104, 108-111

RG9990 R.C.GUPTA, B.A.ROE, K.RANDERATH (1980) BIOCHEMISTRY 19, 1699-1705

RG9991 R.C.GUPTA, B.A.ROE, K.RANDERATH (1979) NUCL. ACIDS RES . 7, 959-970

RH0260 V.M.KRYUKOV ET AL. EMBO-FEBS MEETING, STRASBOURG, JULY 1980

RH0380 K.NICOGHOSIAN, X.-R.GU, R.CEDERGREN (1985) FEBS LETTERS 193, 255-260

RH0500 R.GUPTA (1984) J. BIOL. CHEM. 259, 9461-9471

RH1140

RH1660

RH1700

RH4120

Y.ANDACHI ET AL. (1989) J. MOL. BIOL. 209, 37-54

RH6280

C.E.SINGER, G.R.SMITH (1972) J. BIOL. CHEM. 247, 2989-3000

C.E.SINGER, G.R.SMITH (1972) J. BIOL. CHEM. 247, 2989-3000

RH6281

A. - P.SIBLER, R.P.MARTIN, G.DIRHEIMER (1979) FEBS LETTERS 107, 182-186

RH6940

G.KEITH, G.PIXA, C.FIX, G.DIRHEIMER (1983) BIOCHIMIE 65, 661-672

G.KEITH, G.PIXA, C.FIX, G.DIRHEIMER (1983) BIOCHIMIE 65, 661-672

RH7740 103-107

RH9460

M.ALTWEGG, E.KUBLI (1980) NUCL. ACIDS RES. 8, 3259-3262

RH9990

RI0220 M.BOISNARD, G.PETRISSANT (1981) FEBS LETTERS 129, 180-184

M.D.ROSA, J.P.HENDRICK, M.R.LERNER, J.A.STEITZ (1983) NUCL. ACIDS RES. 11, 853870

RI0500

RI0501

C.GUTHRIE, W.H.MCCLAIN (1979) BIOCHEMISTRY 18, 3786-3795

RI1140 Y.ANDACHI ET AL. (1989) J. MOL. BIOL. 209, 37-54

RI1141 Y.ANDACHI ET AL. (1989) J. MOL. BIOL. 209, 37-54

RI1180 A. SCHOEN (1987) NUCL. ACIDS RES. 15, 5488-5488 
2164 Nucleic Acids Research, Vol. 19, Supplement

RI1580 N.HORIB ET AL. (1985) BIOCHEAISTRY 24, 5711-5715

RI1660 M.YALOS, B.G.BARELL (1971) BIOCHEY. BIOPHYS. RES. COMM. 43, 729-734

RI1661 M.YARUS, B.G. BARELL (1971) BIOCHEY. BIOPHYS. RES. COMM. 43, 729-734

RI1662 Y.KUGHINO, S.WATARABE, F.HARADA, S.NISHIMURA (1980) BIOCHEMISTRY 19, 2085-2089

MURAYATSU ET AL. (1988) J. BIOL. CHEM. 263, 9261-9267

RI2720 P.GUILLAYAUT, J.H.WEIL (1982) NUCL. ACIDS RES. 10, 1653-1659

RI3280 P.GUILL.PAUT, J.H.WEIL (1982) NUCL. ACIDS RES. 10, 1653-1659

RI3281 M.A.FRANCIS, B.S.DUDOCK (1982) J. BIOL. CHEM. 257, 11195-11198

RI4000 A.P.SIBLER, G.DIRHEIMER, R.P.MARTIN (1985) NUCL. ACIDS RES. 13, 1341-1345

RI4310 F.WEBER, A.DIETRICH, J.WEIL, L.MARECHAL-DROUARD (1990) NUCL. ACIDS RES. 18, $5027-5030$

RI4800 C. -C.HSUCHEN, G.R.CLEAVES, D.T.DUBIN (1983) PLASMID 10, 55-65

RI5360 B.A.ROE, J.F.H.WONG, E.Y.CHEN, P.A.ARMSTRONG (1981) PROC. THIRD CLEVELAND SYMP. A.G.WALTON (ED.) ELSEVIER AMSTERDAM

RI6280 G.PIXA, G.DIRHEIMER, G.KEITH (1984) BIOCHEM. BIOPHYS. RES . COMM. 119, 905-912

RI6360 S.TAKEMURA, M.MURAKAMI, M.MIYAZAKI (1969) J. BIOCHEM. 65, 553-566

RI6940 M.BARCISZEWSKA, G.KEITH, G.DIRHEIMER, J.BARCISZEWSKI (1988) NUCL. ACIDS RES. 16, 8175-8175

RI8100 N.SHINRIKI ET AL. (1981) NUCL. ACIDS SYMP. SER. 10, 211-214

RK0500 R.GUPTA (1984) J. BIOL. CHEM. 259, 9461-9471

RK0501 R.GUPTA (1984) J. BIOL. CHEM. 259, 9461-9471

RK1140 Y.ANDACHI ET AL. (1989) J. MOL. BIOL. 209, 37-54

RK1141 Y.ANDACHI ET AL. (1989) J. MOL. BIOL. 209, 37-54

RK1540 B.S.VOLD ET AL. (1982) NUCL. ACIDS RES. 10, 3125-3132

RK1541 B.S.VOLD ET AL. (1982) NUCL. ACIDS RES. 10, 3125-3132

RK1660 K.CHAKRABURTTY, A.STEINSCHNEIDER, R.V.CASE, A.H.MEHLER (1975) NUCL. ACIDS RES. 2, 2069-2075

RK2530 M.A.FRANCIS, E.R.SUH, B.S.DUDOCK (1989) J. BIOL. CHEM. 264, 17243-17249

RK4000 A.-P.SIBLER, G.DIRHEIMER, R.P.MARTIN (1986) FEBS LETTERS 194, 131-138

RK4800 C. -C.HSUCHEN, G.R.CLEAVES, D.T.DUBIN (1983) NUCL. ACIDS RES . 11, 8659-8662

RK5240 C. -C.HSUCHEN, G.R.CLEAVES, D.T.DUBIN (1983) NUCL. ACIDS RES . 11, 8659-8662

RK5280 E.RANDERATH, H.P.AGRAWAL, K.RANDERATH (1981) BIOCHEM. BIOPHYS . RES . COMM. 103, $739-744$

RK5360 B.A.ROE, J.F.H.WONG, E.Y.CHEN (1982) PERSONAL COMMUNICATION

RK6280 C.J.SMITH, H. -S.TEH, A.N.LEY, P.D'OBRENAN (1973) J. BIOL. CHEM. 248, 4475-4485

RK6400 J.T.MADISON, S.J.BOGUSLAWSKI (1974) BIOCHEMISTRY 13, 524-527

RK6820 G.QI-MIN, B.S.DUDOCK (1989) ACTA BIOCHIM. BIOPHYS. SINICA 21, 43-50

RK7740 S.SILVERMANN, I.C.GILLAM, G.M.TENER, D.SOELL (1979) NUCL. ACIDS RES. 6, 435-442

RK7741 D.L.CRIBBS, I.C.GILLAM, G.M.TENER (1982) NUCL. ACIDS RES. 10, 6393-639

RK8100 M.RABA ET AL. (1979) EUR. J. BIOCHEM. 97, 305-318

RK8101 K. HAYENGA ET AL. (1986) MOL. CELL. BIOCHEM. 71, 25-30

RK9160 C.HEDGCOTH, M.HARRISON, K.HAYENGA, B.J.ORTWERTH (1984) NUCL. ACIDS RES. 12 , $2535-2541$

RK9161 C.HEDGCOTH, M.HARRISON, K.HAYENGA, B.J.ORTWERTH (1984) NUCL. ACIDS RES. 12, $2535-2541$

RK9162 C.HEDGCOTH, M.HARRISON, K.HAYENGA, B.J.ORTWERTH (1984) NUCL. ACIDS RES. 12, $2535-2541$

RK9220 M.RABA ET AL. (1979) EUR. J. BIOCHEM. 97, 305-318

RK9221 M.RABA ET AL. (1979) EUR. J. BIOCHEM. 97, 305-318

RK9222 M.RABA ET AL. (1979) EUR. J. BIOCHEM. 97, 305-318

RLO220 W.H.MCCLAIN, K.FOSS (1984) CELL 38, 225-231

RL0260 M.G.SHLYAPNIKOV, S.I.KAZANTSEV, V.M.KRYUKOV, A.A.BAYEV 299-302

RL0500 R.GUPTA (1986) SYSTEM. APPL. MICROBIOL. 7, 102-105

RL0501 R.GUPTA (1986) SYSTEM. APPL. MICROBIOL. 7, 102-105

RL0502 R.GUPTA (1986) SYSTEM. APPL. MICROBIOL. 7, 102-105

RL0503 R.GUPTA (1986) SYSTEM. APPL. MICROBIOL. 7, 102-105

RL0504 R.GUPTA (1986) SYSTEM. APPL. MICROBIOL. 7, 102-105

RL1140 Y.ANDACHI ET AL. (1989) J. MOL. BIOL. 209, 37-54 
RL1141 Y.ANDACHI ET AL. (1989) J. MOL. BIOL. 209, 37-54

RL1142 Y.ANDACHI ET AL. (1989) J. MOL. BIOL. 209, 37-54

RL1460 G.DIRHEIMER, G.KEITH, G.PIXA (1983) BIOCHEM. BIOPHYS. RES. COM. 112, 578-585

RL1540 T.MATSUMOTO ET AL. (1987) J. BIOCHEM. 101, 1191-1198

RL1660 2. YAMAIZUMI ET AL. (1980) J. BIOL. CHEM. 255, 2220-2225

RL1661 H.-U.BLANK, D.SOELL (1971) BIOCHEM. BIOPHYS. RES. COMY. 43, 1192-1197

RL1662 H.-U.BLANK, D.SOELL (1971) BIOCHEM. BIOPHYS. RES. COMM. 43, 1192-1197

RL1700 H.S. ALIAUDEEN, S.K.YANG, D.SOELL (1972) FEBS LETTERS 28, 205-208

RL2020 N.NEWHOUSE, K.NICOGHOSIAN, R.J.CEDERGREN (1981) CAN. J. BIOC. 59, 921-932

RL2100 B.LARUE, N.NEWHOUSE, K.NICOGHOSIAN, R.J.CEDERGREN (1981) J. BIOL. CHEM. 256, $1539-1543$

RL2101 B.LARUE, N.NEWHOUSE, K.NICOGHOSIAN, R.J.CEDERGREN (1981) J. BIOL. CHEM. 256, $1539-1543$

RL2840 T.N.PILLAY, P.GUILLEMAUT, J.H.WEIL (1984) NUCL. ACIDS RES. 12, 2997-3001

RL2841 T.N.PILLAY, P.GUILLEMAUT, J.H.WEIL (1984) NUCL. ACIDS RES. 12, 2997-3001

RL2842 T.N.PILIAY, G.GUILLEMAUT, J.H.WEIL (1984) NUCL. ACIDS RES . 12, 2997-3001

RL3160 M.L.OSORIO-ALMEIDA ET AL. (1980) BIOCHEM. BIOPHYS. RES . COMM. 92, 102-108

RL3161 M.L.OSORIO-ALMEIDA ET AL. (1980) BIOCHEM. BIOPHYS. RES. COMM. 92, 102-108

RL3162 M.L.OSORIO-ALMEIDA ET AL. (1980) BIOCHEM. BIOPHYS. RES. COMM. 92, 102-108

RL3280 J.CANADAY, P.GUILLEMAUT, R.GLOECKLER, J.H.WEIL (1980) PLANT SCI. LETTERS 20, 57 62

RL3920 J.E.HECKMAN ET AL. (1980) PROC. NATL. ACAD. SCI. USA 77, 3159-3163

RL3921 J.E.HECKMAN ET AL. (1980) PROC. NATL. ACAD. SCI. USA 77, 3159-3163

RL4000 A.-P.SIBLER, G.DIRHEIMER, R.P.MARTIN (1986) FEBS LETTERS 194, 131-138

R.P.MARTIN ET AL. (1990) BIOCHEMISTRY 29, 956-959

RL4310 L.MARECHAL-DROUARD, M.NEUBURGER, P.GUILLEMAUT, R.DOUCE, J.H.WEIL, A.DIETRICH (1990) FEBS 262, 170-172

RL4400 G.A.GREEN, L.MARECHAL, J.-H.WEIL, P.GUILLEMAUT (1987) PLANT MOL. BIOL. 10, $13-19$ L.MARECHAL-DROUARD, J.-H.WEIL, P.GUILLEMAUT (1988) NUCL. ACIDS RES . 16, 4777 -

4788 L.MARECHAL-DROUARD, P.GUILLEMAUT (1988) NUCL. ACIDS RES. 16, 11812-11812

RL4401 G.A.GREEN, L.MARECHAL, J.-H.WEIL, P.GUILLEMAUT (1987) PLANT MOL. BIOL. 10, 13-19 L.MARECHAL-DROUARD, J.-H.WEIL, P.GUILLEMAUT (1988) NUCL. ACIDS RES. 16, 4777 4788 L.MARECHAL-DROUARD, P.GUILLEMAUT (1988) NUCL. ACIDS RES. 16, 11812-11812

RL4402 L.MARECHAL-DROUARD, J.-H.WEIL, P.GUILLEMAUT (1988) NUCL. ACIDS RES . 16, 4777 4788

RL4403 L.MARECHAL-DROUARD, P.GUILLEMAUT (1988) NUCL. ACIDS RES. 17, 11812-11812

RL5280 K.RANDERATH, H.P.AGRAWAL, E.RANDERATH (1983) REC. RES. CAN. RES . 84, $103-120$

RL5281 K.RANDERATH, H.P.AGRAWAL, E.RANDERATH (1981) BIOCHEM. BIOPHYS. RES . COMM. 100, $732-737$

RL5282 K.RANDERATH, H.P.AGRAWAL, E.RANDERATH (1981) BIOCHEM. BIOPHYS . RES . COMM. 100, $732-737$

RL5360 B.A.ROE, J.F.H.WONG, E.Y.CHEN (1982) PERSONAL COMMUNICATION

RL5361 B.A.ROE, J.F.H.WONG, E.Y.CHEN (1982) PERSONAL COMMUNICATION

RL6280 S.H.CHANG, S.KUO, E.HAWKINS, N.R.MILLER (1973) BIOCHEM. BIOPHYS . RES . COMM. 51, 951-955

RL6281 E.RANDERATH ET AL. (1979) EUR. J. BIOCHEM. 93, 79-94

RL6360 A.MURASUGI, S. TAKEMURA (1978) J. BIOCHEM. 83, 1029-1038

RL6980 G.A.GREEN, L.MARECHAL, J.-H.WEIL, P.GUILLEMAUT (1988) PLANT MOL. BIOL. 10, 13-19 L.MARECHAL-DROUARD, P.GUILLEMAUT (1988) NUCL. ACIDS RES. 16, 11812-11812

RL6981 G.A.GREEN, L.MARECHAL, J.-H.WEIL, P.GUILLEMAUT (1988) PLANT MOL. BIOL. 10, 13-19 L.MARECHAL-DROUARD, P.GUILLEMAUT (1988) NUCL. ACIDS RES. 16, 11812-1812

RL6982 L.MARECHAL-DROUARD, J.-H.WEIL, P.GUILLEMAUT (1988) NUCL. ACIDS RES. 16, 4777 4788

RL6983 L.MARECHAL-DROUARD, P.GUILLEMAUT (1988) NUCL. ACIDS RES. 16, $11812-11812$

RL7070 L.MARECHAL-DROUARD, M.NEUBURGER, P.GUILLEMAUT, R.DOUCE, J.H.WEIL, A.DIETRICH (1990) FEBS LETTERS 262, 170-172

RL7560 T.A.TRANQUILLA, R.CORTESE, D.MELTON, J.D.SMITH (1982) NUCL. ACIDS RES. 10, 7919 7934 
2166 Nucleic Acids Research, Vol. 19, Supplement

RL9160 E.RANDERATH, R.C.GUPTA, H.P.MORRIS, K.RANDERATH (1980) BIOCHEMISTRY 19, 3476 3483

RL9161 E.RANDERATH, R.C.GUPTA, H.P.MORRIS, K.RANDERATH (1980) BIOCHEMISTRY 19, 34763483

RL9280 R.PIRTLE, M.KASHDAN, I.PIRTLE, B.DUDOCK (1980) NUCL. ACIDS RES. 8, 805-815

RL9400 I.G.VASIL'EVA, M.A.TUKALO, I.A.KRIKLI'YI, G.K.MATSUKA (1985) MOLECULAR BIOLOGY (USSR) 18, 1073-1076

RL9401 M.A.TUKALO ET AL. (1980) DOKL. AKAD. NAUK SSSR 253, 253-256 (ENGL. TRANSL. 222225)

RL9990 F.HARADA, M.MATSUBARA, N.KATO (1984) NUCL. ACIDS RES. 12, 9263-9269

RHO100 P.W.PIPER, K.T.ELDER (1978) NUCL. ACIDS RES. 5, 4761-4779

RH0500 R.GUPTA (1984) J. BIOL. CHEM. 259, 9461-9471

RM0900 M.W.KILPATRICK, R.T.WALKER (1981) NUCL. ACIDS RES. 9, 4387-4390

RM1140 Y.ANDACHI ET AL. (1989) J. MOL. BIOL. 209, 37-54

RH1540 Y. YAMADA, H.ISHIKURA (1980) NUCL. ACIDS RES. 8, 4517-4520

RM1660 S.CORY, K.A.MARCKER (1970) EUR. J. BIOCHEM. 12, 177-194

RH2530 M.A.FRANCIS, E.R.SUH, B.S.DUDOCK (1989) J. BIOL. CHEM. 264, 17243-17249

RM2560 J.M.MCCOY, N.M.KEENE, D.S.JONES (1986) BIOCHEM. J. 238, 297-300

RM3280 R.PIRTLE ET AL. (1981) NUCL. ACIDS RES. 9, 183-188

RM4000 A.P.SIBLER, G.DIRHEIMER, R.P.MARTIN (1985) NUCL. ACIDS RES . 13, 1341-1345

RM4001 R.P.MARTIN, A. -P.SIBLER, R.BORDONNE, G.DIRHEIMER (1983) MOLECULAR BIOLOGY (USSR) $17,915-936$

RM4400 L.MARECHAL ET AL. (1986) PLANT MOL. BIOL. 7, 245-253

RM6280 H.GRUHL, H.FELDMANN (1976) EUR. J. BIOCHEM. 68, 209-217 0.KOIWAI, M.MIYAZAKI (1976) J. BIOCHEM. 80, 951-959

RM6820 M.BARCISZEWSKA, G.DIRHEIMER, G.KEITH (1983) BIOCHEM. BIOPHYS. RES . COMM. 114, $1161-1168$

RM6940 T.ZWIERZYNSKI, A.J.RAFALSKI, K.GULEWICZ, W.KRZYZOSIAK (1983) PERSONAL COMMUNICATION

RM8100 P.W.PIPER (1975) EUR. J. BIOCHEM. 51, 283-293

RM9220 G.PETRISSANT, M.BOISNARD (1974) BIOCHIMIE 56, 787-789

RM9990 F.HARADA, M.MATSUBARA, N.KATO (1984) NUCL. ACIDS RES. 12, 9263-9269

RNO260 V.M.KRYUKOV ET AL. EMBO-FEBS MEETING, STRASBOURG, JULY 1980

RNO380 K.NICOGHOSIAN, X.-R.GU, R.CEDERGREN (1985) FEBS LETTERS 193, 255-260

RN0500 R.GUPTA (1984) J. BIOL. CHEM. 259, 9461-9471

RN0620 X. -R.GU, K.NICOGHOSIAN, R.J.CEDERGREN (1984) FEBS-LETTERS 176, $462-466$

RN1140 Y.ANDACHI ET AL. (1989) J. MOL. BIOL. 209, 37-54

RN1660 K. OHASHI ET AL. (1976) NUCL. ACIDS RES. 3, 3369-3376

RN6400 G.KEITH, G.PIXA (1984) BIOCHIMIE 66, 639-643

RN6940 M.Z.BARCISZEWSKA, D.S.JONES (1988) NUCL.ACIDS RES. 16, 9349-9349

RN9160 E.Y.CHEN, B.A.ROE (1978) BIOCHEM. BIOPHYS. RES. COMM. 82, 235-246

RN9161 B.A.ROE ET AL. (1979) NUCL. ACIDS RES. 6, 673-688

RN9280 E.Y.CHEN, B.A.ROE (1980) BIOCHIM. BIOPHYS. ACTA 610, 272-284

RN9990 E.Y.CHEN, B.A.ROE (1980) BIOCHIM. BIOPHYS. ACTA 610, 272-284

RN9991 F.HARADA, M.MATSUBARA, N.KATO (1989) NUCL. ACIDS RES. 17, 8371-8371

RP0180 F.HARADA, G.G.PETERS, J.E.DAHLBERG (1979) J. BIOL. CHEM. 254, 10979-10985

RP0181 F.HARADA, G.G.PETERS, J.E.DAHLBERG (1979) J. BIOL. CHEM. 254, 10979-10985

RP0220 J.G.SEIDMAN, B.G.BARELL, W.H.MCCLAIN (1975) J. MOL. BIOL. 99, 733-760

RP0260 V.M.KRYUKOV ET AL. EMBO-FEBS MEETING, STRASBOURG, JULY 1980

RP0500 R.GUPTA (1984) J. BIOL. CHEM. 259, 9461-9471

RP0501 R.GUPTA (1984) J. BIOL. CHEM. 259, 9461-9471

RP0502 R.GUPTA (1984) J. BIOL. CHEM. 259, 9461-9471

RP1140 Y.ANDACHI ET AL. (1989) J. MOL. BIOL. 209. 37-54

RP1180 T.SAMUELSSON ET AL. (1987) PROC. NATL. ACAD. SCI. USA 84, 3166-3170

RP1540 T.HASEGAWA, K.MURAO, H.ISHIKURA (1985) BIOCHEM. INT. 10, 663-671

RP1700 Y.KUCHINO, Y.YABUSAKI, F.MORI, S.NISHIMURA (1984) NUCL. ACIDS RES. 12, 1559-1562

RP1701 Y.KUCHINO, Y.YABUSAKI, F.MORI, S.NISHIMURA (1984) NUCL. ACIDS RES. 12, 1559-1562

RP1702 Y.KUCHINO, Y.YABUSAKI, F.MORI, S.NISHIMURA (1984) NUCL. ACIDS RES. 12, 1559-1562

RP3280 M. FRANCIS ET AL. (1982) NUCL. ACIDS RES 10, 2755-2758 
RP4000

RP4400

RP6280

RP6281

RP6360

RP6940

RQ0220

$\mathrm{RQ0260}$

RQ0380

RQ0500

RQ1140

RQ1660

RQ1661

RQ2640

RQ4800

$\mathrm{RQ6080}$

RQ6081

$\mathrm{RQ6082}$

RQ8100

RQ8101

RQ9160

RQ9280

RQ9990

RQ9991

RR0220

RR0380

RR0500

RR0501

RR0502

RR1140

RR1141

RR1540

RR1660

RR1661

RR1662

RR1663

RR1664

RR2530

RR4000

RR4001

RR4800

RR5240

RR5280

RR5360

RR6400

RR6401

RR6402

RR6820

RR8100

RR8101

RR9280

A. -P.SIBLER, G.DIRHEIMER, R.P.MARTIN (1986) FEBS LETTERS 194, 131-138

P. RUNEBERG-ROOS ET AL. (1987) PLANT MOL. BIOL. 9, 237-246

G.KEITH, G.PIXA, C.FIX, G.DIRHEIMER (1983) BIOCHIMIE 65, 661-672

M.WINEY ET AL. (1986) J. MOL. BIOL. 192, 49-63

K. OGAWA, M.KAWAKAMI, Y.SHIMIZU, S.TAKEMURA (1982) J. BIOCHEM. 91, 1241-1248

M.Z. BARCISZEWSKA (1986) BULL. POL. ACAD. SCI. CHEM. 34, 375-379

J.G.SEIDMAN, M.M.COMER, W.H.MCCLAIN (1974) J. MOL. BIOL. 90, 677-689

M.G.SHLIAPNIKOV ET AL. (1984) BIOCHIM. BIOPHYS. ACTA 782, 313-319

K.NICOGHOSIAN, X.-R.GU, R.CEDERGREN (1985) FEBS LETTERS 193, 255-260

R.GUPTA (1984) J. BIOL. CHEM. 259, 9461-9471

Y.ANDACHI ET AL. (1989) J. MOL. BIOL. 209, 37-54

M. YANIV, W.R.FOLK (1975) J. BIOL. CHEM. 250, 3243-3253

M. YANIV, W.R. FOLK (1975) J. BIOL. CHEM. 250, 3243-3253

A.SCHOEN, C.G.KANNANGARA, S.GOUGH, D.SOELL (1988) NATURE 331, 187-189

D.T.DUBIN, C. - C. HSUCHEN (1984) PERSONAL COMMUNICATION

N.HANYU, Y.KUCHINO, S.NISHIMURA, H.BEIER (1986) EMBO J. 5, 1307-1311

N.HANYU, Y.KUCHINO, S.NISHIMURA, H.BEIER (1986) EMBO J. 5, 1307-1311

N.HANYU, Y.KUCHINO, S.NISHIMURA, H.BEIER (1986) EMBO J. 5, 1307-1311

Y.KUCHINO, H.BEIER, N.AKITA, S.NISHIMURA (1987) PROC. NATL. ACAD. SCI. USA 84, $2668-2672$

Y.KUCHINO, H.BEIER, N.AKITA, S.NISHIMURA (1987) PROC. NATL. ACAD. SCI. USA 84, $2668-2672$

J.A.YANG ET AL. (1983) NUCL. ACIDS RES. 11, 1991-1996

G.KEITH (1984) NUCL. ACIDS RES. 12, 2543-2547

F. HARADA, M.MATSUBARA, N.KATO (1989) NUCL. ACIDS RES. 17, 8371-8371

F. HARADA, M.MATSUBARA, N.KATO (1989) NUCL. ACIDS RES. 17, 8371-8371

G.P.MAZZARA ET AL. (1977) J. BIOL. CHEM. 252, 8245-8253

K.NICOGHOSIAN, X.-R.GU, R.CEDERGREN (1985) FEBS LETTERS 193, 255-260

R.GUPTA (1984) J. BIOL. CHEM. 259, 9461-9471

R.GUPTA (1984) J. BIOL. CHEM. 259, 9461-9471

R.GUPTA (1984) J. BIOL. CHEM. 259, 9461-9471

Y.ANDACHI ET AL. (1989) J. MOL. BIOL. 209, 37-54

Y.ANDACHI ET AL. (1989) J. MOL. BIOL. 209, 37-54

H.ISHIKURA, K.MURAO, Y.YAMADA, EMBO-FEBS MEETING, STRASBOURG, JULY 1980

K.MURAO ET AL. (1972) BIOCHEM. BIOPHYS. RES. COMM. 47, 1322-1337

K. CHAKRABURTTY (1980) NUCL.ACIDS RES. 8, 4459-4472

S.KIESEWETTER, W.FISCHER, M.SPRINZL (1987) NUCL. ACIDS RES. 15, 3184-3184

S.YOKOYAMA ET AL. (1988) NUCL. ACIDS RES. SYMP. SERIES, 49-50

S.KIESEWETTER, W.FISCHER, M.SPRINZL (1987) NUCL. ACIDS RES. 15, 3184-3184

S.YOKOYAMA ET AL. (1988) NUCL. ACIDS RES. SYMP. SERIES, 49-50

S.KIESEWETTER, W.FISCHER, M.SPRINZL (1987) NUCL. ACIDS RES. 15, 3184-3184

M.A.FRANCIS, E.R.SUH, B.S.DUDOCK (1989) J. BIOL. CHEM. 264, 17243-17249

A. -P.SIBLER, G.DIRHEIMER, R.P.MARTIN (1986) FEBS LETTERS 194, 131-138

A.-P.SIBLER, G.DIRHEIMER, R.P.MARTIN (1986) FEBS LETTERS 194, 131-138

C. - C.HSUCHEN, G.R.CLEAVES, D.T.DUBIN (1983) PLASMID 10, 55-65

C. - C.HSUCHEN, G.R.CLEAVES, D.T.DUBIN (1983) PLASMID 10, 55-65

H.P.AGRAWAL, R.C.GUPTA, K.RANDERATH, E.RANDERATH (1981) FEBS LETTERS 130, 287 290

B.A.ROE, J.F.H.WONG, E.Y.CHEN, P.A.ARMSTRONG (1981) PROC. THIRD CLEVELAND SYMP.

A.G.WALTON (ED.) ELSEVIER AMSTERDAM

J.WEISSENBACH, R.MARTIN, G.DIRHEIMER (1975) EUR. J . BIOCHEM. 56, 527-532

G.KEITH, G.DIRHEIMER (1980) BIOCHEM. BIOPHYS. RES. COMM. 92, 116-119

G.KEITH, G.DIRHEIMER (1980) BIOCHEM. BIOPHYS . RES. COMM. 92, 116-119

M.Z.BARCISZEWSKA, G.KEITH, E.KUBLI, J.BARCISZEWSKI (1986) BIOCHIMIE 68, 319-323

F.HARADA, S.NISHIMURA (1980) BIOCHEM. INT . 1, 539-546

F.HARADA, S.NISHIMURA (1980) BIOCHEM. INT. 1, 539-546

E.K.MILLER, I.L.PIRTLE, B.S.DUDOCK, R.M.PIRTLE (1983)

NUCL. ACIDS RES. 11, 2013-

2016

RR9281 G.KEITH (1984) NUCL. ACIDS RES. 12, 2543-2547 
R29282

RSO220

RS0380

RSO500

RS0501

RS0502

RS1140

RS1141

RS1180

RS1660

RS1661

RS1662

RS1663

RS1664

RS1665

RS4000

RS4001

RS4002

RS4800

RS5240

RS5 560

RS5361

RS5880

RS6280

RS6400

RS6401

RS6940

RS7040

RS7740

RS7741

RS7742

RS8100

RS9160

RS9161

RS9162

RS9280

RS9281

RS9990

RS9991

RT0220

RT0380

RT0500

RT0501

RT1140

RT1141

RT1180

RT1540

RT1660

RT3280

RT3920

RT4000

G.KEITH (1984) NUCL. ACIDS RES. 12, 2543-2547

W.H.MCCLAIN, B.G.BARRELL, J.G.SEIDMAN (1975) J. KOL. BIOL. 99, 717-732

K.NICOGHOSIAN, X.-R.GU, R.CEDERGREN (1985) FEBS LETTERS 193, 255-260

R.GUPTA (1986) SYSTEY. APPL. MICROBIOL. 7, 102-105

R.GUTTA (1986) SYSTEA. APPL. MICROBIOL. 7, 102-105

R.GUPTA (1986) SYSTEY. APPL. MICROBIOL. 7, 102-105

Y.ANDACHI ET AL. (1989) J. MOL. BIOL. 209, 37-54

Y. ANDACHI ET AL. (1989) J. MOL. BIOL. 209, 37-54

T.SAYUELSSON ET AL. (1987) PROC. NATL. ACAD. SCI. USA 84, 3166-3170

D.A.STEEGE (1983) NUCL. ACIDS RES. 11, 3823-3832

Y.YAYADA, H.ISHIKURA (1973) FEBS LETTERS 29, 231-234 D.ISH-HOROWICZ, B.F.C.CLARK (1973) J. BIOL. CHEY. 248, 6663-6673

W.FISCHER, M.SPRINZL (1985) BIOCHEM. INT. 11, 661-668 H.GROSJEAN ET AL. (1985)

NUCL. ACIDS. RES. 13, 5697-5706

H.GROSJEAN ET AL. (1985) NUCL. ACIDS. RES. 13, 5697-5706

H. ISHIKURA, Y.YAMADA, S.NISHIMURA (1971) FEBS LETTERS 16, 68-70

A.SCHOEN, A.BOECK, G.OTT, M.SPRINZL, D.SOELL (1989) NUCL. ACIDS RES. 18, 7159 -

7165

R.MARTIN, A.-P.SIBLER, G.DIRHEIMER (1982) BIOCHIMIE 64, 1073-1079

R.MARTIN, A.-P.SIBLER, G.DIRHEIMER (1982) BIOCHIMIE 64, 1073-1079

R.MARTIN, A.-P.SIBLER, G.DIRHEIMER (1982) BIOCHIMIE 64, 1073-1079

D.T.DUBIN, C.-C.HSUCHEN, G.R.CLEAVES, K.D.TIMKO (1984) J. MOL. BIOL. 176, 251 260

D.T.DUBIN, C. -C.HSUCHEN, G.R.CLEAVES, K.D.TIMKO (1984) J. MOL. BIOL. 176, 251 260

P.ARCARI, G.G.BROWNLEE (1980) NUCL. ACIDS RES . 8, 5207-5212

M.H.L.DEBRUIJN, A.KLUG (1983) EMBO J. 2, 1309-1321

M.H.L.DEBRUIJN ET AL. (1980) NUCL. ACIDS RES. 8, 5213-5222

M.V.OLSON ET AL. (1981) NATURE 291, 464-469

H.G.ZACHAU, D.DUETTING, H.FELDMANN (1966) HOPPE-SEYLER'S Z. PHYSIOL. CHEM. 347 , $212-235$

H.G.ZACHAU, D.DUETTING, H.FELDMANN (1966) HOPPE-SEYLER'S Z. PHYSIOL. CHEM. 347 , $212-235$

M.BARCISZEWSKA, G.KEITH, G,DIRHEIMER, J.BARCISZEWSKI (1988) NUCL. ACIDS RES. 16, $8175-8175$

M.A.FRANCIS, B.S.DUDOCK (1989) NUCL. ACIDS RES. 17, 7996-7996

D.L.CRIBBS, I.C.GILLAM, G.M.TENER (1987) J. MOL. BIOL. 197, 389-395

D.L.CRIBBS, I.C.GILLAM, G.M.TENER (1987) J. MOL. BIOL. 197, 389-395

D.L.CRIBBS, I.C.GILLAM, G.M.TENER (1987) J. MOL. BIOL. 197, 389-395

N.KATO, H.HOSHINO, F.HARADA (1983) BIOCHEM. INT. 7, 635-645

K.RANDERATH, H.P.AGRAWAL, E.RANDERATH (1983) REC. RES. CAN. RES . 84, 103-120

H.ROGG, P.MUELLER, M.STAEHELIN (1975) EUR. J. BIOCHEM. 53, 115-127

K.RANDERATH, H.P.AGRAWAL, E.RANDERATH (1983) REC. RES . CAN. RES . 84, 103-120

D. HATFIELD, A.DIAMOND, B.DUDOCK (1982) PROC. NATL. ACAD. SCI. USA 79, 6215-6219

D. HATFIELD, A.DIAMOND, B.DUDOCK (1982) PROC. NATL. ACAD. SCI. USA 79, 6215-6219

N.KATO, H.HOSHINO, F.HARADA (1983) BIOCHEM. INT. 7, 635-645

J.P.CAPONE, P.A.SHARP, U.L.RAJBHANDARY (1985) EMBO J. 4, 213-221

C.GUTHRIE, C.A.SCHOLLA, H.YESIAN, J.ABELSON (1978) NUCL. ACIDS RES. 5, 1833-1844

K.NICOGHOSIAN, X.-R.GU, R.CEDERGREN (1985) FEBS LETTERS 193, 255-260

R.GUPTA (1984) J. BIOL. CHEM. 259, 9461-9471

R.GUPTA (1984) J. BIOL. CHEM. 259, 9461-9471

Y.ANDACHI ET AL. (1987) PROC. NATL. ACAD. SCI. USA 84, 7398-7402

Y.ANDACHI ET AL. (1987) PROC. NATL. ACAD. SCI. USA 84, 7398-7402

T.SAMUELSSON ET AL. (1987) PROC. NATL. ACAD. SCI. USA 84, 3166-3170

T.HASEGAWA, H.ISHIKURA (1978) NUCL. ACIDS RES. 5, 537-548

L. CLARKE, J.CARBON (1974) J. BIOL. CHEM. 249, 6874-6885

M.A.KASHDAN ET AL. (1980) J. BIOL. CHEM. 255, 8831-8835

J.E. HECKMAN ET AL. (1980) PROC. NATL. ACAD. SCI. USA 77, 3159-3163

A. -P.SIBLER, G.DIRHEIMER, R.P.MARTIN (1981) FEBS LETTERS 132, 344-348 
RT5360 B.A.ROE, J.F.H.WONG, E.Y.CHEN (1982) PERSONAL COMMUNICATION

RT6400 J.WEISSENBACH, I.KIRALY, G.DIRHEIMER (1977) BIOCHIMIE 59, 381-391

RT6401 J.WEISSENBACH, I.KIRALY, G.DIRHEIMER (1977) BIOCHIMIE 59, 381-391

RT9280 G.KEITH (1986) BIOCHIMIE 68, 325-327

RV0380 K.NICOGHOSIAN, X.-R.GU, R.CEDERGREN (1985) FEBS LETTERS 193, 255-260

RV0381 X.-R.GU, K.NICOGHOSIAN, R.J.CEDERGREN, J.T.-F.WONG (1983) NUCL. ACIDS RES. 11, $5433-5442$

RV0382 X.-R.GU, K.NICOGHOSIAN, R.J.CEDERGREN, J.T.-F.WONG (1983) NUCL. ACIDS RES. 11, $5433-5442$

RV0500 R.GUPTA (1984) J. BIOL. CHEM. 259, 9461-9471

RV0501 R.GUPTA (1984) J. BIOL. CHEM. 259, 9461-9471

RV1140 Y.ANDACHI ET AL. (1989) J. MOL. BIOL. 209, 37-54

RV1180 T.SAMUELSSON ET AL. (1987) PROC. NATL. ACAD. SCI. USA 84, 3166-3170

RV1460 C.TAKADA-GUERRIER, H.GROSJEAN, G.DIRHEIMER, G.KEITH (1976) FEBS LETTERS 62, 1-3

RV1540 K.MURAO, T.HASEGAWA, H.ISHIKURA (1982) NUCL. ACIDS RES. 10, 715-718

RV1660 M. YANIV, B.G.BARELL (1971) NATURE 233, 113-114

RV1661 M.YANIV, B.G.BARREL (1971) NATURE 233, 113-114

RV1662 F.KIMURA, F.HARADA, S.NISHIMURA (1971) BIOCHEMISTRY 10, 3277-3283

RV3280 H.M.SPROUSE, M.KASHDAN, L.OTIS, B.DUDOCK (1981) NUCL. ACIDS RES. 9, 2543-2547

RV3920 J.E.HECKMAN ET AL. (1980) PROC. NATL. ACAD. SCI. USA 77, 3159-3163

RV4800 D.T.DUBIN, C. - C.HSUCHEN, L.E.TILLOTSON (1986) CURR. GEN. 10, 701-707

RV5280 K.RANDERATH, H.P.AGRAWAL, E.RANDERATH (1983) REC. RES. CAN. RES. 84, $103-120$

RV5281 K.RANDERATH, H.P.AGRAWAL, E.RANDERATH (1983) REC. RES. CAN. RES . 84, 103-120

RV5360 B.A.ROE, J.F.H.WONG, E.Y.CHEN, P.A.ARMSTRONG (1981) PROC. THIRD CLEVELAND SYMP.

A.G.WALTON (ED.) ELSEVIER AMSTERDAM

RV6360 K.OGAWA, K.NISHIKAWA, S.TAKEMURA (1988) NUCL. ACIDS RES. 19, 125-128

RV6400 J.BONNET ET AL. (1974) BIOCHIMIE 56, 1211-1213

RV6401 V.G.GORBULEV, V.D.AXEL'ROD, A.A.BAYEV (1977) NUCL. ACIDS RES. 4, 3239-3258

RV6402 V.D.AXEL'ROD, V.M.KRYUKOV, S.N.ISAENKO, A.A.BAYEV (1974) FEBS LETTERS 45, 333 336

RV6940 M.BARCISZEWSKA, D.S.JONES (1987) NUCL. ACIDS RES. 15, 1333-1333

RV7740 W.R.ADDISON, I.C.GILLAM, G.M.TENER (1982) J. BIOL. CHEM. 257, 674-677

RV7741 W.R.ADDISON, I.C.GILLAM, S.HAYASHI, G.M.TENER (1985) CAN. J. BIOCHEM. 63, 176 182

RV7742 W.R.ADDISON, I.C.GILLAM, S.HAYASHI, G.M.TENER (1985) CAN. J. BIOCHEM. 63, 176 182

RV8100 P.W.PIPER (1975) EUR. J. BIOCHEM. 51, 295-304

RV9160 N.SHINDO-OKADA ET AL. (1981) J. BIOCHEM. 90, 535-544

RV9161 N.SHINDO-OKADA ET AL. (1981) J. BIOCHEM. 90, 535-544

RV9220 P.JANK, D.RIESNER, H.J.GROSS (1977) NUCL. ACIDS RES . 4, 2009-2020

RV9990 E.Y.CHEN, B.A.ROE (1977) BIOCHEM. BIOPHYS. RES. COM. 78, 631-640

RW0140 J.C.HU, J.E.DAHLBERG (1983) NUCL. ACIDS RES. 11, 4823-4833

RW0500 R.GUPTA (1984) J. BIOL. CHEM. 259, 9461-9471

RW1140 Y.ANDACHI ET AL. (1989) J. MOL. BIOL. 209, 37-54

RW1141 Y.ANDACHI ET AL. (1989) J. MOL. BIOL. 209, 37-54

RW1660 D.HIRSH (1971) J. MOL. BIOL. 58, 439-458

RW3160 L.MARECHAL ET AL. (1985) NUCL. ACIDS. RES. 13, 4411-4416

RW3280 J.CANADAY, P.GUILLEMAUT, R.GLOECKLER, J.-H.WEIL (1981) NUCL. ACIDS RES . 9, 47-53

RW3920 J.E.HECKMAN ET AL. (1980) PROC. NATL. ACAD. SCI. USA 77, 3159-3163

RW4000 A. - P.SIBLER, R. BORDONNE, G.DIRHEIMER, R.MARTIN (1980) COMP. REND. ACAD. SCI.

PARIS D 290, 695-698 R.P.MARTIN ET AL. (1990) BIOCHEMISTRY 29, 956-959

RW4400

L.MARECHAL ET AL. (1985) NUCL. ACIDS. RES. 13, 4411-4416

RW5280 K. RANDERATH, H.P.AGRAWAL, E. RANDERATH (1983) REC. RES. CAN. RES. 84, 103-120

RW5360 B.A.ROE, J.F.H.WONG, E.Y.CHEN, P.A.ARMSTRONG (1981) PROC. THIRD CLEVELAND SYMP.

A.G.WALTON (ED.) ELSEVIER AMSTERDAM

RW6280 G.KEITH, A.ROY, J.P.EBEL, G.DIRHEIMER (1972) BIOCHIMIE 54, 1417-1426

RW6820 K.GOSH, H.P.GOSH (1984) NUCL. ACIDS RES. 12, 4997-5003

RW8040 F.HARADA, R.C.SAWYER, J.E.DAHLBERG (1975) J. BIOL. CHEM. 250, 3487-3497

L.C.WATERS, W. -K. YANG (1975) J. BIOL. CHEM. 250, 6627-6629 
2170 Nucleic Acids Research, Vol. 19, Supplement

RW9280 M.FOURNIER ET AL. (1978) BIOCHIM. BIOPHYS. ACTA 521, 198-208

RX0380 K.NICOGHOSIAN, X.-R.GU, R.CEDERGREN (1985) FEBS LETTERS 193, 255-260

RX0500 R.GUPTA (1984) J. BIOL. CHEM. 259, 9461-9471

RX0540 Y.KUCHINO, M. IHARA, Y.YABUSAKI, S.NISHIMURA (1982) NATURE 298, 684-685

RX0820 Y.KUCHINO, M.IHARA, Y.YABUSAKI, S.NISHIMURA (1982) NATURE 298, 684-685

RX0900 Y.KUCHINO, M. IHARA, Y.YABUSAKI, S.NISHIMURA (1982) NATURE 298, 684-685

RX1140 Y.ANDACHI ET AL. (1989) J. MOL. BIOL. 209, 37-54

RX1180 R.T.WALKER, U.L.RAJBHANDARY (1978) NUCL. ACIDS RES. 5, 57-70

RX1300 Y.KUCHINO, I. YAMAMOTO, S.NISHIMURA (1982) NUCL. ACIDS RES. 10, 6671-6674

RX1420 B.R.VANI, T.RAMAKRISHNAN, Y.KUCHINO, S.NISHIMURA (1984) NUCL. ACIDS RES . 12, 3933-3936

RX1540 Y.YAMADA, Y.KUCHINO, H.ISHIKURA (1980) J. BIOCHEM. 87, 1261-1269

RX1580 K. WATANABE ET AL. (1979) J. BIOCHEM. 86, 893-905

RX1581 K.WATANABE ET AL. (1979) J. BIOCHEM. 86, 893-905

RX1660 B.Z.EGAN, J.F.WEISS, A.D.KELMERS (1973) BIOCHEM. BIOPHYS . RES . COMM. 55, 320-327

RX1661 S.K.DUBE, K.A.MARCKER (1969) EUR. J. BIOCHEM. 8, $256-262$

RX2100 B.ECAROT - CHARRIER, R.J.CEDERGREN (1976) FEBS LETTERS 63, 287-290

RX2560 J.M.MCCOY, D.S.JONES (1980) NUCL. ACIDS RES. 8, 5089-5093

RX3160 J.CANADAY, P.GUILLEMAUT, J.-H.WEIL (1980) NUCL. ACIDS RES . 8, 999-1008

RX3280 J.L.CALAGAN ET AL. (1980) J. BIOL. CHEM. 255, 9981-9984

RX3920 J.E.HECKMAN ET AL. (1978) CELL 13, 83-95

RX4120 J.CANADAY, G.DIRHEIMER, R.P.MARTIN (1980) NUCL. ACIDS RES . 8, 1445-1457

RX4400 L.MARECHAL ET AL. (1986) PLANT MOL. BIOL. 7, 245-253

RX4800 D.T.DUBIN, C. - C.HSUCHEN (1984) NUCL. ACIDS RES. 12, 4185-4189

RX5360 D.T.DUBIN, C. - C.HSUCHEN (1984) NUCL. ACIDS RES. 12, 4185-4189

RX6080 Y.KUCHINO, T.MITA, S.NISHIMURA (1981) NUCL. ACIDS RES. 9, 4557-4562

RX6120 P.O.OLINS, D.S.JONES (1980) NUCL. ACIDS RES. 8, 715-729

RX6200 A.M.GILLUM ET AL. (1977) NUCL. ACIDS RES. 4, 4109-4131

RX6280 M.SIMSEK, U.L.RAJBHANDARY (1972) BIOCHEM. BIOPHYS . RES . COMM. 49, 508-515

N.BEAUCHEMIN, J.PAQUETTE, R.CEDERGREN (1987) BIOCHEM. CELL BIOL. 65, 43-49

J.DESGRES, G.KEITH, K.C.KUO, C.W.GEHRKE (1989) NUCL. ACIDS RES. 17, 865-882

RX6360 S.YAMASHIRO-MATSUMURA, S.TAKEMURA (1979) J. BIOCHEM. 86, 335-346

RX6820 H.P.GHOSH, K.GHOSH, M. SIMSEK, U.L.RAJBHANDARY (1982) NUCL. ACIDS RES. 10, 3241 3247

RX6940 T.ZWIERZYNSKI, A.J.RAFALSKI, K.GULEWICZ, W.KRZYZOSIAK (1983) PERSONAL COMMUNICATION

RX6980 J.CANADAY, P.GUILLEMAUT, J.-H.WEIL (1980) NUCL. ACIDS RES . 8, 999-1008

RX7620 Y.KUCHINO, M.KATO, H.SUGISAKI, S.NISHIMURA (1979) NUCL. ACIDS RES. 6, 3459-3469

RX7740 S.SILVERMAN ET AL. (1979) NUCL. ACIDS RES. $6,421-433$

RX7860 K.WATANABE, K.ASAI, T.OSHIMA, Y.KUCHINO (1981) J. BIOCHEM. 90, 1259-1266

RX7920 M.WEGENEZ ET AL. (1975) EUR. J. BIOCHEM. 60, 295-302

RX7980 A.M.GILLUM, N.URQUHART, M.SMITH, U.L.RAJBHANDARY (1975) CELL 6, 395-405

RX8100 P.W.PIPER, B.F.C.CLARK (1974) EUR. J. BIOCHEM. 45, 589-600

RX9160 M.SIMSEK, U.L.RAJBHANDARY, M.BOISNARD, G.PETRISSANT (1974) NATURE 247, 518-520

RX9460 M.SIMSEK, U.L.RAJBHANDARY, M.BOISNARD, G.PETRISSANT (1974) NATURE 247, 518-520

RX9990 A.M.GILLUM, B.A.ROE, M.P.J.S.ANANDARAJ, U.L.RAJBHANDARY (1975) CELL 6, 407-413

RY0500 R.GUPTA (1984) J. BIOL. CHEM. 259, 9461-9471

RY1140 Y.ANDACHI ET AL. (1989) J. MOL. BIOL. 209, 37-54

RY1460 R.S.BROWN ET AL. (1978) NUCL. ACIDS RES. 5, 23-36

RY1540 B.MENICHI ET AL. (1980) BIOCHEM. BIOPHYS. RES . COMM. 95, 461-467

RY1541 B.MENICHI ET AL. (1980) BIOCHEM. BIOPHYS. RES . COMM. 95, 461-467

RY1660 H.M.GOODMAN ET AL. (1970) EUR. J. BIOCHEM. 13, 461-483

RY1661 H.M.GOODMAN ET AL. (1970) EUR. J. BIOCHEM. 13, 461-483

RY2560 G.A.GREEN, D.S.JONES (1985) NUCL. ACIDS RES. 13, 1659-1663

RY3800 M.N.SCHNARE, T.Y.K.HEINONEN, P.G.YOUNG, M.W.GRAY (1985) CURR. GEN. 9, 389-393

RY3920 J.E. HECKMAN, B.ALZNER-DEWEERD, U.L.RAJBHANDARY (1979) PROC. NATL. ACAD. SCI. USA

$76,717-721$

RY4000 A.-P.SIBLER, G.DIRHEIMER, R.P.MARTIN (1983) FEBS LETTERS 152, 153-156

RY4400 L.MARECHAL, P.GUILLEMAUT, J.-H.WEIL (1985) PLANT MOL. BIOL. 5, 347-351 
RY6120 G.A.GREEN, D.S.JONES (1985) NUCL. ACIDS RES. 13, 1659-1663

RY6320 G.VOEGELI (1979), NUCL. ACIDS RES. 7, 1059-1065

RY6360 S.HASHIMOTO, S.TAKEMURA, M.MIYAZAKI (1972) J. BIOCHEM. 72, 123-134

RY6400 J.T.MADISON, H. -K.KUNG (1967) J. BIOL. CHEM. 242, 1324-1330

RY6820 H.BEIER, M.BARCISZEWSKA, H.-D.SICKINGER (1984) EMBO J. 3, 1091-1096

RY6821 H.BEIER, M.BARCISZEWSKA, H. -D.SICKINGER (1984) EMBO J. 3, 1091-1096

RY6940 J.BARCISZEWSKI, M.BARCISZEWSKA, B.SUTER, E.KUBLI (1985) PLANT SCIENCE 40, 193 196

RY7060 H.BEIER ET AL. (1984) EMBO J. 3, 351-356

RY7061 H.BEIER ET AL. (1984) EMBO J. 3, 351-356

RY7740 B.SUTER, M.ALTWEGG, Y.CHOFFAT, E.KUBLI (1986) ARCH. BIOCH. BIOPH. 247, 233-237

RY9280 G.D.JOHNSON, I.L.PIRTLE, R.M.PIRTLE (1985) ARCH. BIOCH. BIOPH. 236, 448-453

RY9990 H.v.TOL, N.STANGE, H.J.GROSS, H.BEIER (1987) EMBO J. 6, 35-41

RY9991 H.v.TOL, N.STANGE, H.J.GROSS, H.BEIER (1987) EMBO J. 6, 35-42 